\section{A repertoire of biomedical applications of noble metal} nanoparticles

\author{
Azharuddin M, Zhu GH, Das D, Ozgur E, Uzun L, \\ Turner APF \& Patra HK (2019)
}

Chemical Communications, 55 (49) 6964-6996.

Noble metals comprise any of several metallic chemical elements that are outstandingly resistant to corrosion and oxidation, even at elevated temperatures. This group is not strictly defined, but the tentative list includes ruthenium, rhodium, palladium, silver, osmium, iridium, platinum and gold, in order of atomic number. The emergence of noble metal nanotechnology is attracting huge interest from the scientific community and has led to an unprecendented expansion of research and exploration of applications in electrochemistry, catalysis and biomedicine. Noble metal nanocomposites can be synthesised both by topdown and bottom up approaches, as well as via organism-assisted routes, and subsequently modified appropriately for the field of use. Nanoscale analogues of gold, silver, platinum, and palladium in particular, have gained primary importance owing to their excellent intrinsic properties and diversity of applications; they offer unique functional attributes, which are quite unlike the bulk material. Modulation of noble metal nanoparticles in terms of size, shape and surface functionalisation has endowed them with unusual capabilities and manupulation at the chemical level, which can lead to changes in their electrical, chemical, optical, spectral and other intrinsic properties. In this comprehensive review, we highlight recent advances in the adaptation of noble metal nanomaterials and their applications in therapeutics, diagnostics, sensing, and environmental monitoring.

\section{Introduction}

In chemistry, noble metals are defined as metals that are outstanding resistant to corrosion and oxidation even at elevated temperatures and these include the metals of groups VIIb, VIII and $1 \mathrm{~b}$ of the second and third transition series of the periodic table i.e. rhodium (Rh), ruthenium $(\mathrm{Ru})$, palladium $(\mathrm{Pd})$, silver $(\mathrm{Ag})$, osmium $(\mathrm{Os})$, iridium (Ir), platinum (Pt), and gold (Au). ${ }^{1}$ Noble metals have a long and rich history, which probably dates back to as early as the Egyptian First
Dynasty. They belong to a class of elements that has found a wide range of applications encompassing aerospace, electronic industries and most importantly, the health sector ${ }^{2-5}$. The amalgamation of nanoscience and biotechnology has spawned a growing field of research in the form of nanobiotechnology. In this new arena, the technological leap of synthesising and controlling materials at nanoscale level has provided an immense opportunity to progress medical and healthcare treatment, diagnostics and therapies. ${ }^{6}$ Noble metals are eclectic non-toxic agents in the sense that they have a wide diversity of biomedical applications, which include use in highly sensitive diagnostic assays, ${ }^{7}$ thermal ablation as radiotherapy enhancers, ${ }^{8-11}$ and drug and gene delivery vehicles. ${ }^{12-18}$ Among all noble metals, $\mathrm{Au}$ and $\mathrm{Ag}$ nanoparticles are most extensively studied due to the well-established synthesis routes, their relatively higher content in the earth crust, and better safety profile. Nanoparticlebased systems are now becoming an effective tool in "Theranostics" (i.e. simultaneous diagnosis and therapy) because of their unique properties of excellent penetration and traceability within the body, which allows for a more efficient therapy with a reduced risk of any toxic side effects in comparison to conventional therapies. ${ }^{19,16,20,21}$ The unique characteristics of noble metal nanostructures, in terms of high surface-to-volume ratio, broad optical properties, ease of synthesis, and tunability of surface functionalisation and modification, provide an important added dimensions in biodiagnostics, biophysical studies, biosensing and medical therapy. ${ }^{16,20,21}$ Noble metal nanoparticles (NMN) have played an equally important role in the development of novel biosensors, to add to or enhance the accuracy and specificity of already existing biomolecular diagnostics. The physicochemical attributes of noble metals at the nanoscale level have led to the development of a wide variety of biosensors such as: (i) nanobiosensors for point care disease detection, (ii) nanoprobes for in vivo cell imaging, tracking and pathogenesis of disease progression and (iii) other nanobiotechnology-based tools that enhance basic biological research. ${ }^{22-25}$

The colloidal state of noble metals has been the subject of intensive investigations because of their effectiveness, and various questions have been raised regarding their safety profile in human body. Colloidal gold, silver, platinum, palladium, iridium, ruthenium and rhodium are easily and widely available on the market for use in combating many diseases, free radicals and bacteria. In this review, we provide an extensive literature survey covering recent developments in this field.

\section{Synthetic Routes for NMN}

The preparation of nanoparticles fundamentally follows two distinctly different approaches, top-down and bottom-up (Scheme 1). ${ }^{26}$ The top-down processes involve bulk materials which are reduced to particles with nano-dimension using various physical and chemical methodologies. On the other hand, in a bottom-up approach, nanoparticles are constructed through the assembly of the atoms, the molecules, or the clusters and thus this is generically termed self-assembly.

Externally controlled tools are utilised in a top-down approach for cutting, milling and shaping the materials into the desired order and shape. Several physical methods, such as pyrolysis, ${ }^{27}$ lithography, ${ }^{28-}$ 30 thermolysis, ${ }^{31,32}$ and radiation-induced methods ${ }^{33}$ belong in this category. A major limitation of the top-down approach is the 
imperfect surface structure of metallic nanoparticles, which substantially affects their physical and chemical properties. ${ }^{34}$ Moreover, enormous energy is required to maintain the high pressure and high-temperature conditions during these synthetic procedures and this makes these processes expensive.

In a bottom-up methodology, the originally formed nanoparticles are subsequently assembled into the final material, using chemical as well as biological procedures. The bottom-up approach is advantageous as it provides a far better control over the final product formation with less surface deformation and more homogeneous chemical composition. Moreover, the processes are in general less expensive as well. The bottom-up approach is commonly used for wet-chemical synthesis procedures, such as chemical, ${ }^{35-37}$ electrochemical, ${ }^{38,39}$ polyol reduction ${ }^{40}$ and sonochemical. ${ }^{41,42}$ However, one major challenge associated to these processes is the purification of the nanoparticles from toxic chemicals, organic solvents and reagents for further biomedical applications.

\section{Top-down approaches}

One of the commonly used protocols is micropatterning. ${ }^{43}$ Apart from the most common approach of photolithography, various other techniques have evolved in the recent past. ${ }^{44}$ Scanning, soft, nanoimprint, colloidal, nanosphere and E-beam lithography are among some of these new methods. In principle, all these techniques use either light, electrons, a focused beam of electrons or electrostatic forces to selectively remove nano-structures from a precursor to develop ordered arrays of nano-materials.

In a milling process, macro-scale materials are ground in a ball mill to generate particles of nano dimensions. ${ }^{45}$ The kinetic energy transfer from balls to powder is behind the reduction in grain size. Various parameters like, type of mill, milling atmosphere, milling media, intensity, time, temperature, etc. play a crucial role in controlling the shape and size of the nanoparticles. ${ }^{46}$ Different devices designed for various purposes have been developed in order to overcome these constrains including shaker mills, tumbler mills, vibratory mills, attrition mills, planetary mills, etc. For bulk production of nanomaterials, the attrition process is highly advantageous. However, one major limitation of this process is the imperfect surface and significant crystallographic damage of the processed materials. Pyrolysis is another important technique commonly used. ${ }^{47} \mathrm{~A}$ precursor in its vapour state is forced through an orifice with high pressure and burning. Through further processing of the obtained solid ash, nanoparticles are recovered. Pyrolysis is frequently used for the preparation of noble metal nanoparticles. ${ }^{27,48}$ One important drawback of the method is the requirement for large amounts of energy.

\section{Bottom-Up approaches}

The most commonly utilised and easiest bottom-up approach is the chemical reduction of metal ions in solutions. In principle, an ionic salt is reduced using various reducing agents under appropriate reaction conditions and in presence of a stabilising agent. ${ }^{35-37} \mathrm{~A}$ plethora of reducing agents, such as Na-citrate, hydrazine, hydrogen, $\mathrm{LiAlH}_{4}, \mathrm{NaBH}_{4}$, and alcohols can be used. According to Lee-Meisel method, ${ }^{49}$ nitrate and sulphate salts are reduced using $\mathrm{NaBH}_{4}$, sodium citrate, and hydrogen. The $\mathrm{pH}$ of the medium plays a crucial role in modulating the size and shape of the particles. ${ }^{50}$ At high $\mathrm{pH}$, owing to faster reduction, both rod and spherical nanoparticles were found, while at relatively lower $\mathrm{pH}(5-6)$, triangular and other polyhedral structures were obtained because of the slower reaction. Similarly, Au nanoparticles can be prepared from an aqueous solution of $\mathrm{HAuCl}_{4}$ using citrate as the reducing agent. ${ }^{51,52}$ The average particle size can be controlled by varying the ratio of reducing/stabilising agents as well as the $\mathrm{pH}$ of the system. ${ }^{53,54} \mathrm{On}$ the other hand, platinum, another important class of noble metal nanoparticles is relatively under explored. Sodium polyacrylate stabilised cubic and tetrahedral platinum nanoparticle synthesis in solution phase has been reported by El-Sayed et al. ${ }^{55} \mathrm{~A}$ general strategy based on a chemical reduction method involving different metal combinations (cobalt, iron, and nickel) with platinum has been reported by Zhang. ${ }^{56}$ Another popular nanoparticle fabrication process involves microemulsions. The first microemulsion-based synthesis was reported for palladium, rhodium, and platinum nanoparticles synthesis. ${ }^{57}$ Since then, the process gained popularity owing to its ease of operation and control over the size and shape of the products. ${ }^{58-60}$ Herein, two separate microemulsions containing salts and reducing agents are mixed together in presence of amphiphile. Inter microemulsion collision leads to the mixing of the reactants and consequently nanoparticles are formed. This strategy helps in growing nanoparticles with uniform shape and size as the microemulsions are used as a template while the nanoparticles are growing during the process. This method offers benefits to prepare thermodynamically stable and monodispersed nanoparticles. ${ }^{61}$

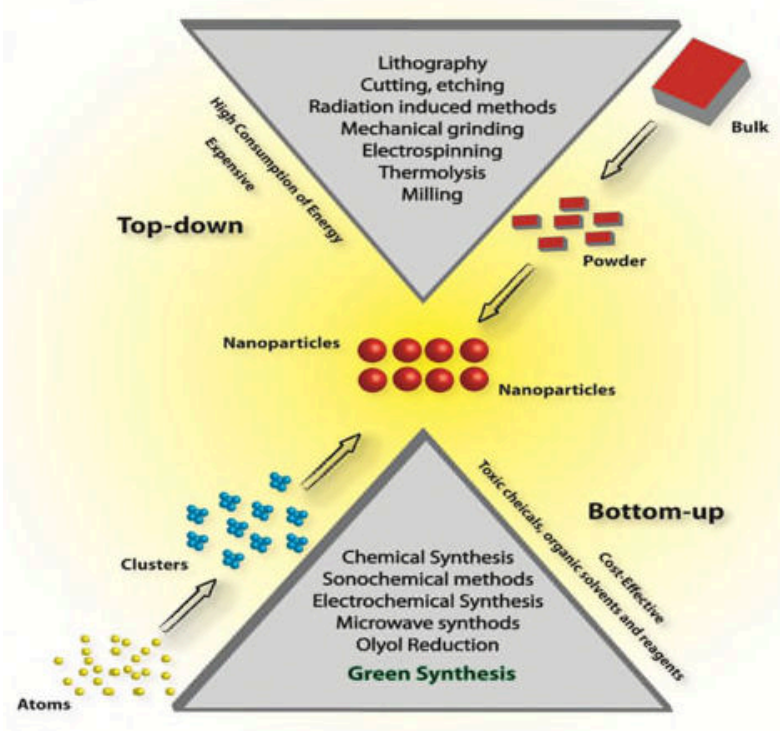

Scheme 1 Schematic presentation of the top-down and bottom-up approaches for nanoparticle synthesis.

In a laser ablation process, a solid surface is irradiated with a laser beam and the materials become heated at low laser flux and are finally evaporated or sublimated. ${ }^{62}$ At a higher flux, the materials are converted to form plasma. The lack of any requirement to remove excess reagents as well as the possibility of metal nanoparticle synthesis in both aqueous and organic solvents has allowed the laser ablation method to emerge as a potential alternative for chemical reduction methods. There have been several reports where this process was used to prepare a variety of noble metal nanoparticles including silver, gold, and platinum. ${ }^{63-65}$ Fast processing times, 
control over the size and shape of the particles and high yields are among the major advantages of this process.

Microwave-based synthesis and electrochemical methods are the other two important approaches to be mentioned. Microwave irradiation is used for the "one-pot" preparation of metal nanoparticles from their salts and polymeric surfactant solutions. ${ }^{66}$ It is a relatively fast and easy method with high selectivity and control over size and morphology of the end products. ${ }^{67}$ The electrochemical method was first introduced by Reetz. ${ }^{68} \mathrm{~A}$ metal sheet was dissolved from the anode and the metal salt thus produced was reduced on the cathode of an electrochemical cell producing the desired metal nanoparticles. ${ }^{69,70}$ Importantly, control over the particle size can easily be achieved without any template. Considering the excess use of chemicals and solvents in the chemical synthesis of nanoparticles, greener approaches with minimal use of such hazardous chemicals have been developed. One major driving force for these greener approaches is nature's efficiency in making these nano-materials. Mimicking nature, may not be not easy, but it has allowed chemists to develop several green synthetic protocols for nanoparticle synthesis using water as the medium and proteins or carbohydrates as capping agents. ${ }^{71,72}$ Starch has been used as both a reducing as well as a stabilising agent for the synthesis of stable silver nanoparticles. ${ }^{73,74}$ Similarly, gold nanoparticles have been prepared utilising different biomolecules as capping agents and lactic acid as the reducing agent. ${ }^{74}$ Chitosan, a natural biopolymer, has also been used as a reducing and stabilising agent. ${ }^{75}$ In another "greener" approach, hydrogels of synthesised peptides and other small molecules were successfully used to create nanoparticles where the hydrogel nano-structures act as the template and help in creating the shape and size of the nanoparticles. ${ }^{76,77}$ Das et al. prepared a tryptophan-appended peptide amphiphile able to form hydrogel where gold nanoparticles with defined shape and size could be prepared using the indole residue as the reducing agent, without the need for any external agent. ${ }^{78,79}$

\section{Organism-based synthesis of NMN}

The quest for the development of economically as well as environmentally benign methods led to exploration of the potential of micro-organisms in this respect. ${ }^{80}$ Biological systems are excellent examples of hierarchical organisations of atoms or molecules and this attracted researchers to use micro-organisms as potential cell factories for nano-material preparation. Both prokaryotic (bacteria) and eukaryotic (algae, fungi, plants) species are used for this purpose.

Bacteria are often exposed to metal rich environments and have the ability to develop resistance to these extreme conditions. Thus, prokaryotes like bacteria are an automatic choice for the production of nanomaterials. Pseudomonas stutzeri AG259, a metal accumulating bacterium, was utilised by Klaus et al. to create intracellular nanocrystals of metallic silver and monoclinic silver sulphide. ${ }^{81}$ Extracellular synthesis of nanoparticles was first reported by Shahverdi and co-workers. ${ }^{82}$ Nanocrystals of silver were prepared by incubating the biomass of Bacillus licheniformis in presence of silver nitrate, where $\mathrm{NADH}$ acted as the reducing agent in presence of nitrate reductase. ${ }^{83}$ Gold nanoparticles are also prepared by accumulation and reduction of gold salts by bacteria. Bacillus licheniformis, Shewanella algae, Stenotrophomonas maltophilia,
Lactobacillus strains, present in the whey of butter milk are some of the examples of bacteria which have been used to produce gold nanomaterials. ${ }^{84-87}$ In addition to these, bacteria like Schewanella and Acinetobactor calcoaceticus PUCM 1011 were utilised for the preparation of platinum nanoparticles. ${ }^{88,89}$ Though promising in terms of its green nature and control over the shape and size of the particles, bacterial-mediated synthesis suffers from disadvantages such as difficulty in handling and low yield. In recent years, eukaryotic organisms have emerged as a better alternative for the synthesis of noble metal nanoparticles, owing to easier protocols as well as costeffectiveness. Fungi were first tested by Sastry et al. for the preparation of metal and metal oxide nanoparticles. ${ }^{90}$ Gold nanoparticles were prepared using Verticillium $s p$. when $\mathrm{AuCl}_{4}$ was reduced within the fungal cells. Fusarium oxysporum was used to prepare gold and silver nanoparticles with uniform dimensions. ${ }^{91} \mathrm{An}$ environmentally friendly and cost-effective method for the synthesis of silver nanoparticles using cell-free filtrate of Aspergillus flavus was reported by Panwar and coworkers. ${ }^{80}$ Another important biological media are the algae. Algae, like Chlorella vulgaris and Pithophora oedogonia, have been used successfully to construct silver nanoparticles.92,93 Gold nanoparticles have been prepared involving various seaweeds like Sargassum wightii by Singaravelu et al. ${ }^{94}$ Plant extracts are also attractive media for the synthesis of nanoparticles and the process has been referred to as Phytosynthesis. Live alfalfa plant can take gold ions from solid media and the secretome from live alfalfa plant can reduce gold ions to $\mathrm{Au}^{0}$, which can be taken up by the plant and consequently used to produce gold nanoparticles. ${ }^{95}$ Neem (Azadirachta indica) leaf extract was successfully used by Shankar et al. to prepare silver, gold, and bimetallic Au/Ag core-shell nanoparticles. ${ }^{96}$ Similar plant extracts (bark, leaf, fruit, and gum) have been used by several researchers to produce a variety of noble metal nanoparticles. ${ }^{97-100}$

As discussed, several physical, chemical as well as biological methods have been developed for the synthesis of nanoparticles. All these processes are widely used based on the utility and applicability of the nano-products. However, the existing protocols all suffer from certain drawbacks. Thus, the development of alternative processes to fabricate nanoparticles with controlled and tuneable properties is still an open challenge.

\section{Surface Modification and Functionalisation of NMN}

NMN have attracted significant attention in various applications ranging from electronics to sensing, biolabeling, photonics, nanomedicine and catalysis, due to their electrical, chemical, optical, spectral and other intrinsic properties. ${ }^{101,102,103}$ To increase the biocompatibility, sensing, and specific targeting of NPs, it is necessary to stabilise NPs against agglomeration and to functionalise them. ${ }^{104-106}$ Attaching appropriate organic groups to the metal surfaces is the most common way to achieve this (Fig. 1). Through metal-thiolate (M-S) linkages, ${ }^{107}$ organosulphur groups coordinate to various metals such as $\mathrm{Ag}, \mathrm{Cu}, \mathrm{Fe}, \mathrm{Au} .{ }^{108}$ Metal-carbon (M-C=) covalent bonds using aryl diazonium as the precursors ${ }^{109}$ have been used to stabilise metal NPs. Metal-carbene $(M=C)$ or metal-nitrene $(M=N) \pi$ bonds formed with diazo derivatives, have been utilised to functionalise various metal NPs such as $\mathrm{Au}, \mathrm{Pt}, \mathrm{Ti}, \mathrm{Ru}$, and Pd. ${ }^{110,111}$ Metal-acetylide/-vinylidene bonds are formed via acetylene derivatives onto metal surfaces. ${ }^{112}$ Surface modification or functionalisation of metal NPs can be accomplished with amines or 
ammonium ions, negatively charged carboxylate groups, and phosphines. ${ }^{113}$

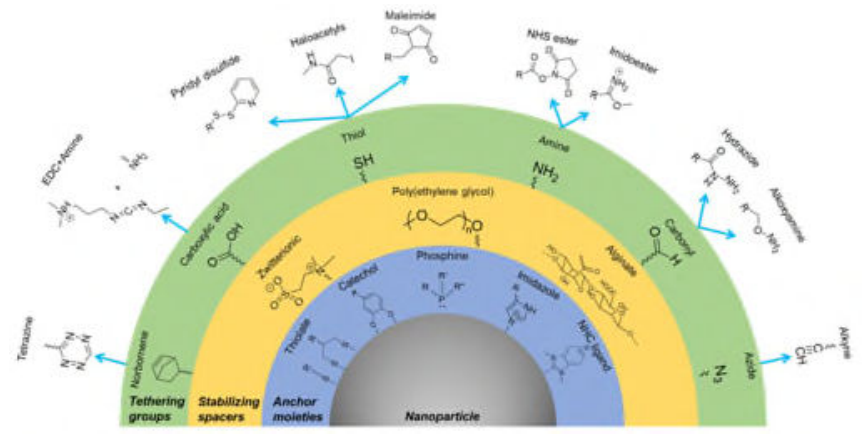

Fig. 1 Schematic illustration of representative anchor moieties, stabilizing spacers, tethering groups, and conjugation groups for functionalising noble nanoparticles. NHC = $\mathrm{N}$-heterocyclic carbenes, $\mathrm{NHS}=\mathrm{N}$-Hydroxysuccinimide, $\mathrm{EDC}=1$-ethyl-3-(3dimethylaminopropyl)carbodiimide hydrochloride.

\section{Analytical techniques for NMN characterisation}

The unique properties of noble metal NPs such as thermal, electrical, chemical, and optical rely on the size, morphology and surface charge. Various techniques have been developed to characterise the metal NPs. ${ }^{114}$ Size distribution, average particle diameter, surface charge, and shape govern the physical stability of metal NPs. ${ }^{115}$ Scanning electron microscopy (SEM), ${ }^{116}$ dark-field and field-emission scanning electron microscopy (FE-SEM), ${ }^{117,118}$ transmission electron microscopy (TEM), ${ }^{119}$ high-resolution TEM (HRTEM), ${ }^{120-122}$ and atomic force microscopy (AFM) ${ }^{123,124}$ are commonly utilised to estimate the size, shape, and surface morphology. Dynamic light scattering (DLS) observations enable the determination of particle sizes and their size distributions in situ. ${ }^{125,126}$ Small-angle $X$-ray scattering (SAXS), extended X-ray absorption fine structure (EXAFS), $X$-ray absorption near-edge structure analysis (XANES), and electron spin resonance (ESR) provide information about the local structure and electronic properties of metal NPs with different surface chemistry and morphology. ${ }^{127,128} \mathrm{X}$-ray photoelectron spectroscopy (XPS), ${ }^{129}$ Fourier transform infrared (FTIR) spectroscopy and solidstate nuclear magnetic resonance spectroscopy (SSNMR) can be used to obtain information about surface chemistry of metal NPs. ${ }^{130}$ Matrix-assisted laser-desorption ionisation time-of-flight (MALDITOF) mass spectrometry (MS), inductively coupled plasma mass spectrometry (ICP-MS), UV-vis spectroscopy and exclusion chromatography with UV-vis detection (SEC-UV-vis) have also all been utilised to characterise various properties of nanomaterials (Fig. 2). ${ }^{114,131,132}$ Energy-Dispersive X-ray spectroscopy (EDX) analysis can be used to confirm the chemical composition of the metal NPs. ${ }^{119}$

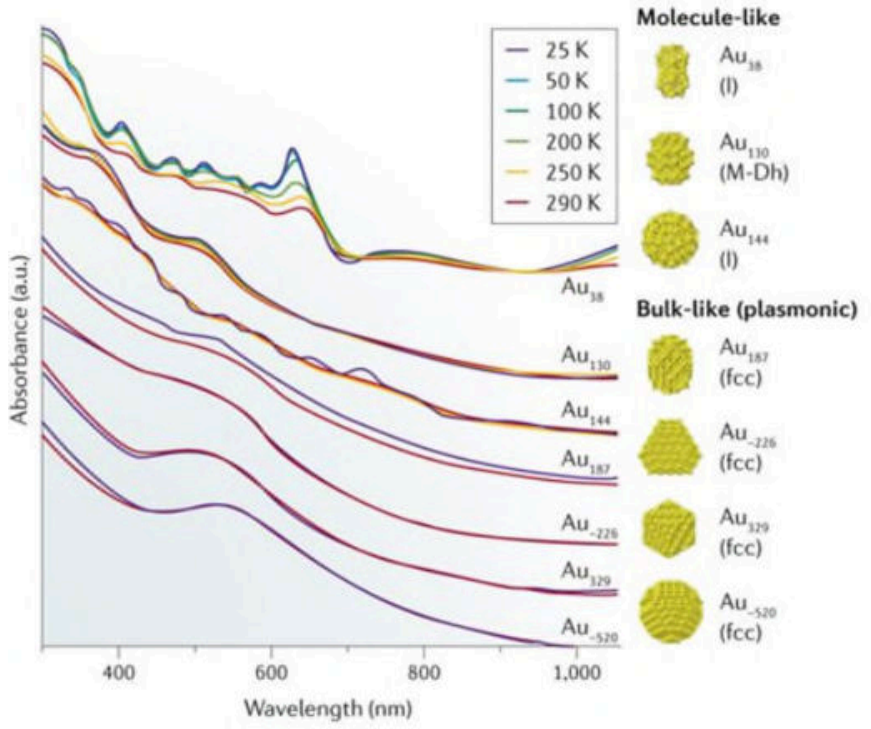

Fig. 2 Evolution of optical absorption spectra of gold clusters with various sizes, measured at different temperatures, as indicated. $A u_{n}$ clusters with $n=38,130$ and 144 show discrete energy states in the spectra and have icosahedral (I) or Marks decahedral (M-Dh) structures, whereas the clusters with $\mathrm{n}=187, \sim 226,329$ and $\sim 520$ have plasmonic resonances originating from their metallic band structure and a face-centered cubic (fcc) structure. Reprinted with permission from Reference ${ }^{133}$

\section{Biomedical applications of NMN}

Complexes of noble metals have been used as therapeutic agents since ancient times. With the advent of nanobiotechnology, there has been a surge towards the development of different kinds of nanostructures with a diverse range of biomedical applications (Fig. 3). In this regard, NMN have gained primary importance; there are several reasons for this including: (i) ease of size and shape modulation; (ii) unique optical and photothermal properties; and (iii) surface functionalisation. Since these nanomaterials can interact with biomolecules both at the surface and inside the cell, they represent an excellent repertoire of biocompatible nanoscale drugs. These NMN can be synthesised both chemically and biogenically with high efficiency, ${ }^{134,135}$ and these engineered nanoscale versions of noble metals have inspired researchers to develop innumerable therapeutic agents for the treatment of a wide range of diseases, ${ }^{136,137}$ where nanotechnology-based approaches have been shown that play a significant role in treatment and early diagnosis of these diseases. NMN are the most common nanobiotechnological materials used for developing biosensors for clinical diagnostics, due to their ease in fabrication, physiochemical malleability, and high surface areas, ${ }^{138}$ allied with their unique spectral and optical properties. NMN have had a promising impact on the development of new biosensors and on enhancing the specificity and sensitivity of already existing biosensing techniques for biomolecular diagnostics (Table 4). Noble metal nanostructures can be engineered to specifically recognise biomolecules and provide a rapid and accurate estimation of the concentration of an analyte. This can be achieved by exploiting changes in the optical properties of noble metal colloids as a result of affinity interactions modulating their size and electronic configuration (Fig. 8). ${ }^{139}$ The unique optical properties of different surface modified noble metal nano formulations have been used for targeting biological components such as DNA, RNA, cells, proteins, small organic molecules, and other biological components. This section will point out some of the unique therapeutic and diagnostic abilities of NMN. 


\section{Therapeutic efficacy of NMN}

The uptake of inorganic or NMN has been studied extensively in recent years. The mechanism of cellular internalisation of noble metal nanoparticles such as gold, silver and platinum are not necessarily similar and are, at the same time, ambiguous. Size, shape, surface charge, and surface chemistry play extremely important roles in cellular uptake both in vitro and in vivo. Spherical gold nanoparticles (GNPs) exhibit greater cellular uptake than their corresponding rod structures. ${ }^{140}$ It has been reported that $40-50 \mathrm{~nm}$ particles have the most effective cellular internalisation. ${ }^{141,142}$ In a separate study, it was shown that $50 \mathrm{~nm}$ GNPs can enter into cells at a relatively faster rate and at a higher concentration than other sizes. ${ }^{140}$ This observation was further validated by both in vitro and in vivo studies. ${ }^{143}$ AsPC-1, PANC-1, and MiaPaca-2 (pancreatic cell lines) upon incubation with GNPs of varying hydrodynamic radii, exhibited the greatest uptake for $20 \mathrm{~nm}$ particles, as shown by TEM analysis. Another important factor which modulates cellular internalisation of noble metal nanoparticles is surface charge. ${ }^{144,145}$ The exterior of the cell is mostly anionic; hence positively charged noble metal nanoparticles can easily traverse through the cell membrane via electrostatic interaction. ${ }^{144}$ However, negatively charged noble metal nanoparticles have also been observed in the cell interior as a result of them passively targeting lipophilic domains. ${ }^{146}$ One report suggests that zwitterionic noble metal nanoparticles can be a potent and highly efficient drug delivery system. ${ }^{147,148}$

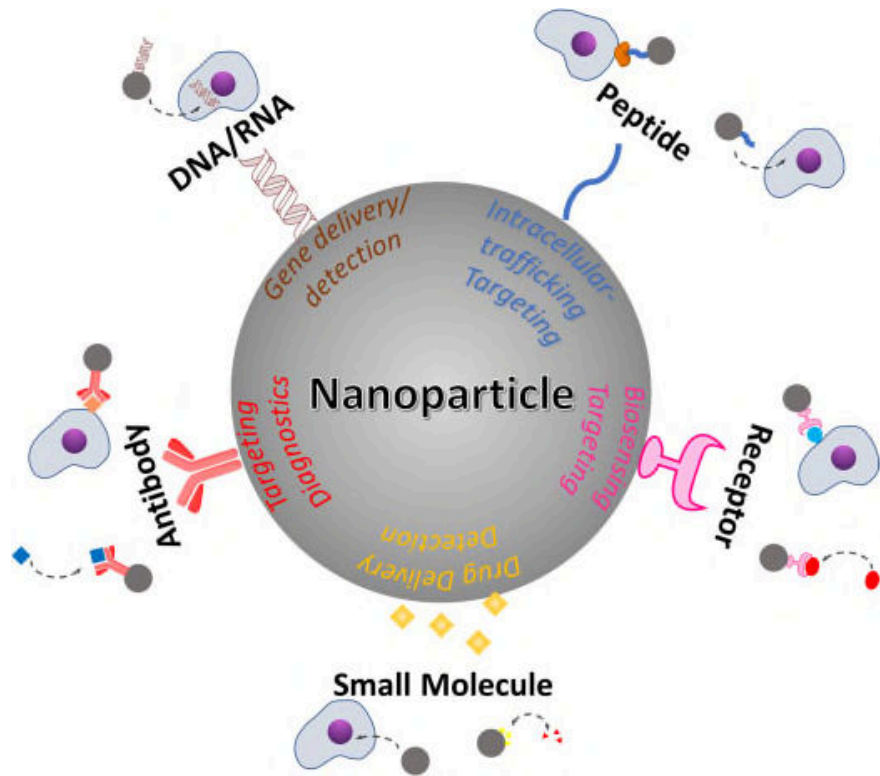

Fig. 3 Biomedical applications of nanoparticles through conjugation with various active moieties including nucleic acids, peptides, receptors, antibodies, and small molecules.

Angiogenesis has been shown to be critically involved in a number of diseases such as cancer, rheumatoid arthritis, and macular degeneration. ${ }^{149,150}$ Under normal conditions, angiogenesis is tightly regulated by various anti-angiogenic factors such as thrombospondins (TSP-1), platelet factor 4, vascular endothelial growth factor (VEGF), platelet-derived growth factor (PDGF), and transforming growth factor beta (TGF- $\beta$ ). ${ }^{151}$ Under pathological condition, this balance is disrupted that leads to angiogenesis. ${ }^{151}$ In such cases, there is generation of highly abnormal blood vessels, which become hyperpermeable to plasma proteins.

A number of anti-angiogenic agents have been clinically tested but they seem to target only the VEGF ${ }^{152}$ mediated signalling. ${ }^{153}$ Also, these agents possess serious toxicities which result in hypertension, thrombosis, and fatal hemorrhage. ${ }^{149,150}$ Here, noble metal nanoparticles can be used as an effective anti-angiogenic agent, since they have the ability to target multiple pathways involved in angiogenesis. ${ }^{154}$ Uncapped GNPs exhibit anti-angiogenic properties by inhibiting the activity of heparin-binding proteins such as VEGF ${ }^{152}$ and basic fibroblast growth factor (bFGF) in vitro and VEGF induced angiogenesis in vivo. ${ }^{155} \mathrm{It}$ was observed that heparin-binding proteins are absorbed on the surface of the GNPs and lose their functional attributes. ${ }^{156}$ The size of GNPs also dictates their anti-angiogenic activity; in one study it was shown that VEGF ${ }^{152}$ preincubated with GNPs of varying size $(5-20 \mathrm{~nm})$ had a dramatic effect on VEGF signalling events. ${ }^{157}$ The suppression of heparin-binding growth factors by nanoparticles has further explained their effectiveness against multiple myeloma via inhibiting VEGF- and bFGF- dependent proliferation as tested in cell lines OPM-1, RPMI-8266, and U-266. This study revealed that cells are arrested in the $\mathrm{G} 1$ phase of the cell cycle with an up-regulation of p21 and p27. ${ }^{158}$ The anti-angiogenic properties of GNPs could also modulate the status of B-chronic lymphocytic leukemia (B-CLL) cells. ${ }^{155}$ Exposure of GNPs to B-CLL cells resulted in an increase in apoptosis in a dose-dependent manner. ${ }^{159}$ Angiogenesis also plays a crucial role in the promotion and maintenance of inflammatory diseases such as rheumatoid arthritis (RA). It has been observed that $13 \mathrm{~nm}$ GNPs exhibit anti-rheumatoid activity in collagen-induced arthritis in rats. ${ }^{160}$ GNPs bind to VEGF in the synovial fluid of patients suffering from RA and affect their cellular proliferation and migration. Further, histological studies showed that there is reduction in tumour necrosis factor alpha (TNF$\alpha$ ) and interleukin beta (IL- $\beta$ ) after intra-articular administration of GNPs. Silver nanoparticles (AgNPs) have also been shown to act as an anti-angiogenic agent. AgNPs with size of $40 \mathrm{~nm}$ were used to study their anti-angiogenic properties in bovine retinal epithelial cells (BREC). AgNPs successfully inhibited cell proliferation and migration in VEGF induced angiogenesis in BRECs and prevented the formation of new blood vessels. ${ }^{159}$ Furthermore, tumour bearing mice demonstrated a reduction of ascite production and suppression of tumour progression upon treatment with AgNPs. ${ }^{161,162}$

Cancer is one of the largest life-threatening diseases worldwide and has led to millions of deaths, most of them in developing countries. A combination of surgery, chemotherapy and radiation therapy constitutes the major treatment procedures for almost all cancer therapy. Since these conventional therapeutic regimens are whole body approach, there is significant systemic damage to healthy tissues and subsequently health-related issues. ${ }^{154}$ In order to minimise the damage to non-cancerous tissue, noble metal nanoparticles have been utilised as a potential cancer therapeutic agent for non-invasive tumour treatment. ${ }^{163}$ In this regard, application of a magnetic field selectively heats the nanomaterials, which allows for selective and effective destruction of tumour cells. ${ }^{163}$ Currently, photodynamic therapy (PDT), regional hyperthermia, and radiotherapy are actively being exploited for localised cancer treatment. ${ }^{101,164,165}$ PDT treatment is mainly achieved by focusing the light source on the affected area of the body. The spectrum of light used here is in the range of 630-900 nm, that is the near infrared region (NIR), which is readily absorbed by the tissue. ${ }^{164}$ This range of wavelength minimises the light extinction by intrinsic chromophores in the normal or healthy tissue. ${ }^{166}$ In regional hyperthermic tumour therapy, the cancerous cells are damaged upon exposure to elevated temperatures. ${ }^{167}$ There is loss of membrane integrity, DNA damage, and induction of apoptosis as well as necrosis within a few hours. ${ }^{168}$ In radiation therapy, cancer patients are treated with ionising radiations, which is effective but at the same time it is invasive with numerous side effects on healthy 
tissues. Noble metal nanoparticles hold great promise as PDT, hyperthermia, and radiotherapy agents. Surface plasmon resonance (SPR) of noble metal nanoparticles has been effectively exploited for PDT anticancer treatment. ${ }^{169}$ In one study, it has been shown that GNPs can act as PDT agents and selectively destroy cancerous cells at very low laser frequency. ${ }^{170}$ Citrate capped GNPs $(15 \mathrm{~nm})$ have also been deployed as photothermal therapy (PTT) agents against A431 cells. This study showed that upon exposure to low levels of laser light, GNPs induce the destruction of the malignant cells through reactive oxygen species (ROS) mediated apoptosis (Fig. 4a). ${ }^{171}$ Further, the shape of the GNPs plays an extremely important role in PDT therapy, GNPs with different geometry were tested against HUVEC cells and it was noted that gold nanorods were 100 times more potent than the other shapes tested. ${ }^{172}$ Similarly, mice injected with GNPs had a significant reduction of deep tissue tumours after a brief exposure to NIR. ${ }^{173}$ GNPs have been used for treatment of skin cancer; GNPs were administered into the tail vein of mice and local laser induced hyperthermia was employed for reduction and complete inhibition of skin tumours. ${ }^{174}$ Radio frequency ablation (RFA) in conjunction with GNPs has proved to be an effective treatment strategy for liver cancer cell (HepG2) lines; here citrate coated GNPs demonstrated a time-dependent cytotoxic effect upon exposure to the RF field. ${ }^{175}$ Noble metal nanoparticles offer an attractive advantage in radiotherapy owing to their excellent optical properties, surface plasmon resonance, and surface modalities. For example, upon X-ray irradiation, GNPs have been shown to induce cellular apoptosis by the generation of ROS. ${ }^{176}$ This therapeutic treatment strategy has effectively increased the percentage of cancer cells killed without harming the nearby surrounding healthy tissue. ${ }^{177,178}$ Mice injected with GNPs upon X-ray exposure exhibit a fourfold reduction in tumour size and also an extended lifetime of the animal. ${ }^{179}$

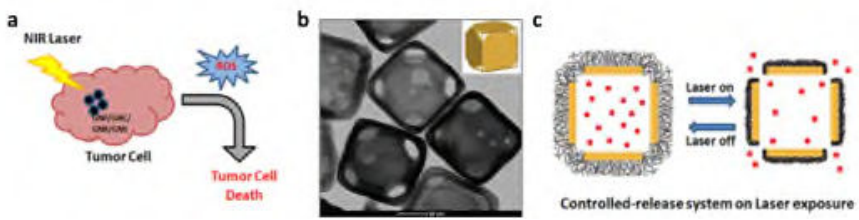

Fig. 4 (a) Schematic representation of ROS generated tumour cell death using NIR induced metal nanoparticles (b) TEM images of Au nanocages for which the surface was covered by a pNIPAAm-co-pAAm copolymer with an LSCT at $39^{\circ} \mathrm{C}$. The inset shows a magnified TEM image of the corner of such a nanocage. (c) Schematic illustration of the controlled-release system (cross-sectional view): upon exposure to a near-infrared laser, the light is absorbed by the nanocage and converted into heat, leading to the collapse of smart polymeric brushes and release off loaded drugs.

Transport of drugs or therapeutic agents into the cells by GNPs have been the subject of intensive studies in biomedical treatment. Surface functionalised gold colloids have been extensively studied for interaction with the cell membrane for efficient and improved drug delivery. ${ }^{145,180,181}$ In one report, it was observed that surface ligand rearrangement on GNPs can regulate cell membrane permeability. ${ }^{146}$ Gold nanoparticles functionalised with an ordered arrangement of amphiphilic molecules were able to penetrate the cell membrane more efficiently than particles with a disordered arrangement of the same molecules that were entrapped in vesicular bodies. The therapeutic activity of GNPs on cells can be regulated through passive and active targeting mechanisms. Passive targeting is based on the concept of an enhanced permeability and retention (EPR) effect; here gold colloids can extravasate into the tumour stroma because of the defective vasculature and increased lymphatic drainage leading to its accumulation at the target site (Fig. 5). ${ }^{154,182}$ Active targeting relies on surface tuneability of GNPs specifically designed for the target molecules to provide high specificity and selectivity. ${ }^{183-185}$ These attributes of gold nanostructures have been developed for applications in photothermal therapy, ${ }^{186-188}$ genetic regulation, ${ }^{189-191}$ and drug treatment. ${ }^{192,193}$ GNPs are considered a potential and powerful therapeutic probe for specific and selective killing of cancer cells. ${ }^{194}$ GNPs scaffolds have been synthesised for use as transfection agents in gene therapy for curing cancer and genetic disorders. GNPs coated with oligonucleotides are being applied as intracellular gene alteration agents for controlling protein expression in cells. ${ }^{195}$ Ribonucleic acid (RNA) modulated colloidal gold nanoparticles have been successfully tested for knockdown of luciferase activity, ${ }^{196}$ because the conjugated nanomaterials possess an extended half-life as compared to double-stranded(ds)-RNA, demonstrating a high gene knockdown capability in cell models. Positively charged amino acid (first generation lysine dendrons) coated GNPs have proved to be effective and non-toxic transfection vectors for DNA delivery, providing up to 28 times greater effectiveness than the conventional negatively charged polylysine version. ${ }^{197}$

\section{EPR debate}

It is worth mentioning, however, the debate within the nanotechnology community on EPR effect. The general belief is that PEGylated nanoparticles have elongated blood circulation time and could result in enhanced EPR effect. This concept seems problematic when considering the astonishingly small number of translational products as compared to the large number of research articles produced based on this assumption. ${ }^{9}$ It is yet to be determined that whether the intercellular or intracellular extravasation is the predominant mechanism for macromolecules accumulation within tumors, as intercellular gaps are very rare. ${ }^{10}$ Therefore, further investigation on the extravasation mechanism of nanoparticles to tumours is required to provide useful insight and guidelines for designing nanoparticle formulations.

Targeted delivery of drugs has been carried out efficiently using gold colloids by loading drugs onto GNPs through non-covalent or covalent interactions. Drug entrapment with GNPs is achieved through the use of hydrophobic or hydrophilic pockets ${ }^{198}$ presented by the monolayer. Polymer encapsulated GNPs provide an amphiphilic surrounding for the entrapment of hydrophobic silicon phthalocyanine 4 (Pc 4), a photodynamic therapy (PDT) agent. ${ }^{199}$ This conjugation releases the drug efficiently and quickly and deep into tumour tissues within hours of incubation. Covalently conjugated GNPs drugs are released through glutathione (GSH) displacement ${ }^{200}$ or through linker cleavage. ${ }^{201} \mathrm{~A}$ GSH-mediated release strategy using 6-mercaptopurine-9-b-D-ribofuranoside functionalised GNPs, has been used to enhance anti-proliferative activity against K-562 cell lines compared to the free drug. ${ }^{202}$ The GSH-mediated pathway has also been investigated to track the movement of GNPs carrying either fluorescein or doxorubicin molecules into a tumour model. ${ }^{203}$ 
a

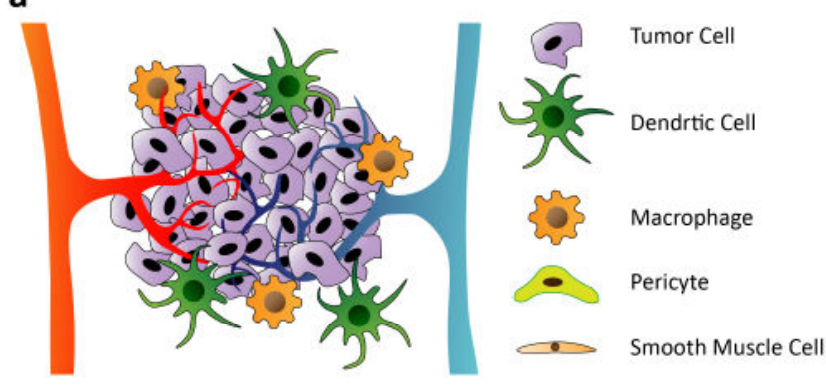

b

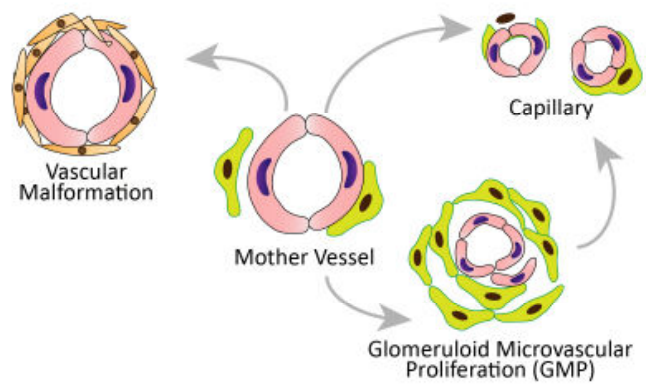

C

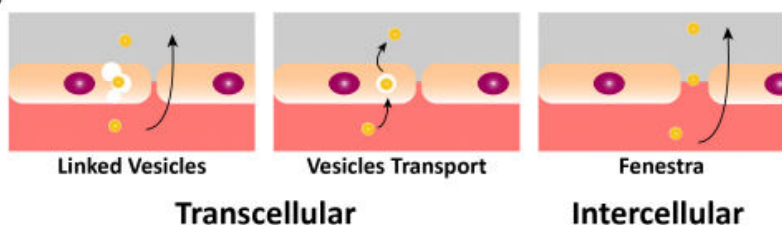

Fig. 5 (a) Schematic illustration of tumour microenvironment. (b) Mother vessels with thinned or compressed endothelial cells, degraded basement membranes, and pericyte detachment are highly permeable to both small molecules and proteins. Mother vessels can further differentiate into glomeruloid microvascular proliferations, vascular malformations, and capillaries. (c) Schematic representation of transcellular and intercellular transport of nanoparticles from across vessel wall.

Although, no GNPs have been approved clinically, a few of them have been going through clinical trials. These nanodrugs harness the lightabsorbing ability of GNPs and are being currently explored for treating solid tumours and acne. One such gold colloid nanodrug approved for clinical trials is AuroLase, developed by Nanospectra, this comprises silica-gold nanoshells coated with polyethylene glycol (PEG) designed for the treatment of solid tumours by thermal ablation using a NIR source. ${ }^{204}$ Here, silica provides a dielectric core, gold nanoshells confer thermal ablation ability, while the PEG induces an overall stability to the nanocomposite. ${ }^{11}$ In another example, Sebashells developed by Sebacia Inc., which are similar to AuroLase, have been applied to treat acne by disrupting overactive sebaceous glands in the skin. ${ }^{205}$ These Sebashells are topically administered to the site of acne, delivered deep into the sebaceous glands by low frequency ultrasound and ultimately stimulated via a NIR laser, utilising the heating capacity of the gold nanoshells for effective acne treatment (Fig. $\mathbf{4} \mathbf{b}$ and $\mathbf{c}$ ). These studies have been done in vivo showing the potential efficacy of Sebashells in preventing inflammatory acne lesions. ${ }^{204}$

Silver nanoparticles (AgNPs) possess anticancer and antitumour properties by inhibiting angiogenesis around tumour tissues. This has led to an extensive research regarding the potential application of AgNPs in cancer treatment both in vitro and in vivo. These studies have been conducted on different cancerous cell line models such as MCF-7, B10F17, A549, SiHa, and HeLa cell lines. Monomeric polymer encapsulated AgNPs have shown antileukemic properties against
AML human cell lines. ${ }^{206}$ This study provides a dose and size dependent response of AgNPs against these cell lines in vitro. AgNPs proved to be a potent antileukemic agent by providing high specificity against AML cell lines as opposed to normal hematopoietic cells. The mechanism behind this activity is that AgNPs increase the production of ROS and release of silver ions ( $\mathrm{Ag}$ ) from nanomaterials, this results in the induction of apoptosis and DNA damage. The release of $\mathrm{Ag}$ ions from $\mathrm{AgNPs}$ has also been proposed to induce tumour cell sensitisation, ${ }^{207}$ these $\mathrm{Ag}$ ions are captured by free electrons, generating an oxidising agent which reduces the production of ATP in tumour cells and subsequently enhances intracellular ROS concentration. It has also been reported that release of $\mathrm{Ag}$ ions from AgNPs is greater as compared to bulk or powder silver. ${ }^{208}$ Silver ions do not produce hydroxyl radicals $(\bullet \mathrm{OH})$ in the presence of $\mathrm{H}_{2} \mathrm{O}_{2}$, which is a mild reducing agent. In contrast, AgNPs produce $\bullet \mathrm{OH}$ in the presence of $\mathrm{H}_{2} \mathrm{O}_{2}$ only at acidic $\mathrm{pHs}$. This $\mathrm{pH}$ dependent $\bullet \mathrm{OH}$ production by AgNPs confers their anticancer and antitumour activity. Biogenically synthesised AgNPS have also shown anticancer properties, ${ }^{209}$ like AgNPs synthesised from mushroom which were tested against MDA-MB-231 human breast cancer cell lines. AgNPs disrupt the cell membrane integrity and increase production of lactate dehydrogenase (LDH), a biomarker for cell death. AgNPs synthesised using Bacillus funiculus and leaf extract from Podophyllum hexandrum, causes caspase mediated apoptotic cell death. ${ }^{210,211}$ The antitumour activity of AgNPs was studied in multiple drug resistant (MDR) malignant melanoma cell tumours in vivo. ${ }^{212}$ Here, transactivator of transcription (TAT) was anchored onto AgNPs surface; this conjugation increases the antitumour activity by several fold.

Cisplatin, a platinum complex, has been used for several decades for treating a number of abnormalities. In contrast, the application of platinum nanoparticles (PtNPs) as therapeutic agents is still in its infancy. ${ }^{213}$ PtNPs possess the penetration capacity of entering cells ${ }^{214}$ and the uptake and bioactivity of PtNPs have been investigated thoroughly which includes their cytotoxicity, genotoxicity, and effects on protein expression in human cells. ${ }^{214}$ PtNPs penetrate into the cells through diffusion and are localised inside the cytoplasm. Upon exposure to PtNPs several events take place inside the cells such as, DNA damage at the S-phase of the cell cycle ultimately leading to apoptosis, up regulation of p53 and p21, and down regulation of proliferating cell nuclear antigens. These intracellular effects of PtNPs make it a potent anticancer therapeutic candidate for future use. In vitro PtNP treatment elicits DNA damage and antioxidant response. ${ }^{142}$ The anti-cancer activity of platinum nanomaterials ${ }^{215}$ has been shown in a recent study where synchronous application of PtNPs in conjunction with hadron therapy resulted in enhanced DNA strand disruption. Irradiation of platinum by carbon ion leads to the generation of $\bullet \mathrm{OH}$ radicals which in turn amplifies the extent of damage to DNA. ${ }^{216}$ An investigation with human colon carcinoma cells (HT29) exhibited a size-, dose-, and time-dependent response upon incubation with PtNPs. ${ }^{142}$ The mechanistic reason behind the DNA damage was due to the release of $\mathrm{Pt}^{2+}$ ions from PtNPs causing a significant DNA damage and cellular apoptosis. ${ }^{214,217}$ Hence, it was predicted that the nanoparticle itself does not interact directly with DNA, instead the soluble $\mathrm{Pt}^{2+}$ ions form a complex with DNA similar to cisplatin. ${ }^{214}$ Culturing cells with PtNPs leads to the subsequent activation of p53 and p21, which causes genotoxic stress. ${ }^{217}$ Thus, PtNPs can be potentially used in radiosensitisation as well. ${ }^{215}$ Apart from being effective in cancer therapy, PtNPs have been applied for the treatment of Parkinson's disease by functioning as a mitochondrial complex I, by lowering ROS generation, and by scavenging free radicals such as superoxide and $\mathrm{H}_{2} \mathrm{O}_{2}{ }^{218}$ PtNPs synthesised using leaf extract have also been used to 
treat Parkinson's disease. ${ }^{219}$ The neuroprotective activity of the phytochemical conjugated PtNPs was studied in experimentally induced Parkinsonism in the zebra fish model. The results verified that upon pre-treatment with PtNPs, experimentally induced Parkinsonism could be reversed. PtNPs have been revealed to provide protection against oxidation-induced inflammation, this action of PtNPs decreases the osteoblastogenesis which causes bone loss. ${ }^{220}$ PtNPs play an important role in reducing cellular oxidative stress by acting as a quencher for ROS such as $\mathrm{H}_{2} \mathrm{O}_{2}$ and superoxide, thus resembling two biological enzymes, catalase and superoxide dismutases (SOD). Apoferritin surface functionalised PtNPs (AFPtNPs) have been applied for studying the scavenging capability of $\mathrm{H}_{2} \mathrm{O}_{2}$ and superoxide on mammalian cell line Caco-2. It was observed that AF-PtNPs successfully compensated $\mathrm{H}_{2} \mathrm{O}_{2}$ and superoxide. Owing to the receptor mediated internalisation of ferritinfunctionalised nanoparticles into the cells, the membrane integrity was preserved and other adverse interactions with cellular proteins were avoided. After incorporation into Caco-2 cells, PtNPs decrease the oxidative stress within the cell and increase cell viability. ${ }^{221}$ ROS scavenging and apoptotic properties of PtNPs have also shown promising potential in treating ultraviolet (UV) induced inflammatory responses in the skin. ${ }^{222} \mathrm{An}$ in vitro study in cell lines revealed a marked increase in ROS generation in UV-treated $\mathrm{HaCaT}$ keratinocytes cell lines, while a decrease in ROS production was observed in PtNPs treated cell lines. It was shown that mice treated with PtNPs gel prior to UV irradiation demonstrated a significant inhibition of UVB-induced inflammation and UVA-induced photo allergy compared to untreated controls.

Well documented studies on metal nanodrugs such as gold, silver and platinum have been thoroughly carried out for an extended period of time and some of them have even found their way into clinical trials (Table 1\&2). ${ }^{223}$ Technologies based on alternative noble metal nanocomposites are being intensively studied for probable applications in the medical sector. Palladium is one such noble metal and its nanostructure has drawn tremendous interest in the last decade for a variety of applications. ${ }^{224-229}$ Despite the remarkable property of palladium as a metal and its diversified exploitation in several biomedical applications, ${ }^{230,231}$ palladium nanocomposites have made a late entry into the nanobiotechnology field. Here, we discuss the therapeutic property of palladium nanomedicines routed in their catalytic, photothermal and biological activity. Firstly, polymer functionalised palladium resin has been used as a prodrug. This palladium nanocomposite resin complex has been shown to activate a number of biologically inert drugs such as 5-fluoro-1propargyluracil ${ }^{232}$ and $\mathrm{N}^{4}$-propargyloxycarbonyl gemcitabine. ${ }^{233}$ These two drugs are otherwise biologically inactive, but combined treatment with palladium nanocomposite resin restores the antiproliferative and cytotoxic activity of these drugs in colorectal and pancreatic cancer cells. Toxicity of these resin palladium conjugates has been performed in the yolk sac of zebra fish and the results indicate no apparent toxicity while the chemical activity of the prodrug remains intact. ${ }^{232}$ Photothermal efficiency of palladium nanostructures such as palladium nanosheets, has opened the door for their incorporation in cancer therapeutics. Hexagonal palladium nanosheets displayed efficient photothermal conversion efficiency due to their strong adsorption in the NIR region. ${ }^{234}$ This photothermal efficiency depends on size and surface coating, which in turn affects the cellular uptake of these nanosheets. ${ }^{235,236} \mathrm{An}$ interesting finding is that palladium nanosheets tend to show better photostability than even gold and silver nanostructures. When palladium nanosheets are coated with GSH, they demonstrate better renal clearance. ${ }^{237}$ In vivo studies have shown that in the absence of any irradiation, these GSH-palladium nanosheets exhibited longer retention time in the circulating blood, accumulate near the tumour site, and showed no toxicity, whereas upon irradiation with NIR laser, tumour ablation occurs. ${ }^{237}$ The attractive properties of these nanostructured materials have further extended their application in more complex assemblies for combined photothermalchemo/photothermal-photodynamic therapy treatment. Anticancer drug loaded silica nanoparticles entrapped within palladium nanosheets have proved to be an effective treatment strategy for combined photothermal and chemo-therapy; heat resulting from the NIR light conversion leads to $\mathrm{pH}$ dependent release of anti-cancer drugs and the cellular uptake of palladium nanosheets was significantly enhanced by the mesoporous coating of the silica nanoparticles. ${ }^{238}$ Other lesser known nanomaterials of Rh, Ir, and Os have still not been put to wide use in biomedical research, although there have been a few examples. The UV plasmonic properties of Rh nanocomposites have been extensively studied to show their potential uses in UV plasmonic and photocatalytic applications. ${ }^{239} \mathrm{Ir}$ and Os nanoparticles remain less explored and need a thorough investigation regarding their future efficacy in clinical and human health research.

Table 1 Noble metal nanoparticles in clinical trials

\begin{tabular}{llllll}
\hline $\begin{array}{l}\text { Type of noble } \\
\text { metal } \\
\text { nanoparticles }\end{array}$ & Condition or disease & $\begin{array}{l}\text { Properties of noble metal } \\
\text { nanoparticles }\end{array}$ & NCT number & Phase & Recruitment Status \\
\hline GNPs & $\begin{array}{l}\text { Coronary Artery Disease } \\
\text { Atherosclerosis }\end{array}$ & $\begin{array}{l}\text { GNPs with silica-iron oxide shells } \\
\text { with photothermic burning or } \\
\text { melting effect onto the lesion }\end{array}$ & NCT01436123 & Phase I & $\begin{array}{l}\text { Terminated (under } \\
\text { political pressure) }\end{array}$ \\
GNPs & Type 1 Diabetes & $\begin{array}{l}\text { GNPs with attached peptide } \\
\text { fragment related to insulin }\end{array}$ & NCT02837094 & Phase I & Recruiting \\
GNPs & $\begin{array}{l}\text { Gliosarcoma } \\
\text { Recurrent Glioblastoma }\end{array}$ & $\begin{array}{l}\text { Small GNPs with nucleic acid } \\
\text { arranged on the surface (NU- } \\
\text { 0129) }\end{array}$ & NCT03020017 & Phase I & Active, not recruiting \\
GNPs & $\begin{array}{l}\text { Stable Angina } \\
\text { Heart Failure }\end{array}$ & $\begin{array}{l}\text { with photothermic burning or } \\
\text { melting effect onto the lesion }\end{array}$ & NCT01270139 & N/A & Completed \\
& $\begin{array}{l}\text { Atherosclerosis } \\
\text { Multivessel Coronary } \\
\text { Artery Disease }\end{array}$ & $\begin{array}{l}\text { AgNPs \& GNPs suspended in } 70 \% \\
\text { isopropyl alcohol used for cavity } \\
\text { pre-treatment }\end{array}$ & NCT03669224 & N/A & Not yet recruiting \\
Caries Class li & & & &
\end{tabular}




\begin{tabular}{|c|c|c|c|c|c|}
\hline GNPs & Stomach Diseases & $\begin{array}{l}\text { Functionalised GNPs \& carbon } \\
\text { nanotubes nanosensors array } \\
\text { identifying gastric diseases }\end{array}$ & NCT01420588 & N/A & Unknown \\
\hline GNPs & Parkinson's Disease & $\begin{array}{l}\text { Functionalised GNPs \& carbon } \\
\text { nanotubes nanosensors array } \\
\text { identifying Parkinson's diseases }\end{array}$ & NCT01246336 & N/A & Completed \\
\hline AgNPs & $\begin{array}{l}\text { Foot Infection Fungal } \\
\text { Infection, Bacterial }\end{array}$ & AgNPs containing cream & NCT03752424 & Phase I & Recruiting \\
\hline AgNPs & $\begin{array}{l}\text { Oral microbial colony } \\
\text { formation }\end{array}$ & AgNPs containing gel & NCT02761525 & N/A & Completed \\
\hline AgNPs & Dental Caries & Nanosilver fluoride (5\%) solution & NCT01950546 & Phase I & Completed \\
\hline AgNPs & Tooth Demineralization & $\begin{array}{l}\text { AgNPs incorporated into the } \\
\text { primer orthodontic Transbond XT }\end{array}$ & NCT02400957 & Phase III & Unknown \\
\hline AgNPs & Chronic Rhinosinusitis & Colloidal AgNPs & NCT03243201 & Phase I & $\begin{array}{l}\text { Withdrawn (IND not } \\
\text { approved) }\end{array}$ \\
\hline AgNPs & Down Syndrome & AgNPs containing fluor varnish & NCT01975545 & Phase II & Unknown \\
\hline AgNPs & $\begin{array}{l}\text { Partial Dentin Caries } \\
\text { Removal }\end{array}$ & Nanosilver fluoride solution & NCT03193606 & N/A & Active, not recruiting \\
\hline AgNPs & $\begin{array}{l}\text { Central Venous Catheter } \\
\text { Related Infections }\end{array}$ & $\begin{array}{l}\text { Central venous catheter } \\
\text { impregnated with AgNPs } \\
\left(\text { AgTive }^{\circledR}\right)\end{array}$ & NCT00337714 & Phase IV & Completed \\
\hline AgNPs & $\begin{array}{l}\text { Antimicrobial efficacy } \\
\text { In healthy subjects }\end{array}$ & Nanosilver gel & NCT00659204 & Phase III & Unknown \\
\hline AgNPs & Rhinosinusitis & Topical silver colloid & NCT02403479 & Phase I/II & Unknown \\
\hline AgNPs & Postoperative Pain & AgNPs gel & NCT03692286 & Phase IV & Not yet recruiting \\
\hline AgNPs & Dental Caries & Nanosilver fluoride solution & NCT03186261 & Phase III & Not yet recruiting \\
\hline AgNPs & Plantar Warts & $\begin{array}{l}\text { Colloid silver and fig extract } \\
\text { mixture }\end{array}$ & NCT02338336 & Phase I/II & Completed \\
\hline AgNPs & Surgical Site Infection & $\begin{array}{l}\text { Colloid silver containing bath } \\
\text { wipes }\end{array}$ & NCT03401749 & Phase IV & Recruiting \\
\hline
\end{tabular}

Exploring the anti-viral potential of NMN: Concern regarding growing microbial resistance to all types of antimicrobial agents used against different infectious diseases has led to a fusion between nanotechnology and microbiology. Broad-spectrum activities of noble metal nanostructures and their application to resolve microbial resistance issues have initiated a positive development in this field. The antibacterial, antifungal, antiviral, and antiprotozoal property of noble metal nanoparticles have attracted huge interest from the scientific community throughout the world (Fig. 6). This section will elucidate some of these diversified and multifunctional facets of noble metal nanoparticles with regards to their antimicrobial potentials (Table 3). Apart from their roles as antitumour agents, GNPs have been employed to deliver antibiotics and antibacterial agents as well. A variety of antibiotic conjugated gold colloids have shown promising activity against various bacterial strains. ${ }^{240}$ The exact mechanism behind this antibacterial activity of GNPs has evaded researchers, but one of the primary reasons could be stable antibiotic-GNP conjugate formation. In one report it has been suggested that the direct use of antibiotic in the synthesis of GNPs offers a much-improved antibacterial activity. ${ }^{241}$ GNPs are also investigated for their antiviral activity against human immunodeficiency virus (HIV), the cause of acquired immunodeficiency syndrome (AIDS). Functionalisation of GNPs with HIV-1 integral protein transduction domain (PTD) was tested in vitro in a human fibroblast cell line. It was observed that surface modified GNPs $(\sim 5 \mathrm{~nm})$ can traverse across the plasma membrane, whereas larger particles $(\sim 30 \mathrm{~nm})$ are unable to do so. This study provides clear evidence that smaller sized GNPs can be used as a drug delivery vehicle for AIDS. ${ }^{242}$ Free SDC-1721, a derivative of TAK-779 and a known $\mathrm{CC} 5$ antagonist, which is the primary entry co-receptor for transmitted strains of HIV-1, has no inhibitory effect on HIV infection. However, when conjugated with GNPs, the resulting SDC-1721-GNPs conjugates showed enhanced inhibitory activity against HIV infection. ${ }^{243}$ Another anti-HIV activity was studied with bare and PEG coated GNPs, in which it was demonstrated that bare GNPs exhibit significant anti-HIV properties as compared to PEG-GNPs; this may be due to the fact that nanoparticles coated with charge stabilisers (PEG) are larger in size and hence cannot enter into the cells and inhibit viral growth. ${ }^{244}$ Receptor binding inhibitory activity of GNPs against HIV was studied using sugar coated nanoparticles. This study showed that sugar coated GNPs block the function of dendritic cellspecific ICAM-3 grabbing non-integrin (DC-SIGN), which constitutes a major receptor for HIV-1. ${ }^{245}$ GNPs have also been applied for treatment of Tuberculosis (TB) by utilising multi-block copolymer conjugated GNPs as a successful delivery vehicle for TB drugs such as Rifampicin. ${ }^{246}$ Application of GNPs as a drug delivery machinery has led to their incorporation in immunisation therapy due to their small size and ability to enter cells. For example, GNP-conjugated chitosan exhibits an enhanced serum antibody response which is several folds more powerful than the naked DNA vaccine. ${ }^{247}$ GNPs are potential carriers for the development of synthetic peptide vaccine against foot-and-mouth disease virus (FMDV). A synthetic peptide resembling FMDV proteins was conjugated with GNPs, and after immunisation it was observed that there was production of specific antibodies against the peptide. ${ }^{248}$ The role of GNPs in cancer immunotherapy has also been studied extensively. ${ }^{249}$ There are 
several reviews regarding the advancements of conjugated GNPs in vaccine delivery. ${ }^{250}$ One group of researchers illustrated the adjuvant properties of GNPs in facilitating the delivery of both the ovalbumin (OVA) peptide antigen and CpG adjuvant, resulting in an enhanced therapeutic effect in a B16-OVA tumour model. ${ }^{251}$ Silver nanoparticles (AgNPs) represent one of the most common nanocomposites used in consumer goods and in medical products, including wound healing bandages and a variety of antiseptic sprays. ${ }^{252}$ AgNPs have been shown to provide protection against various infectious diseases, since they act as antifungal, antiarthropod, antiviral and antiprotozoal agents. ${ }^{253}$ Additionally, the powerful antimicrobial as well as highly toxic activity of silver nanocomposites have been extensively studied and reported. ${ }^{252,254-}$ ${ }^{257}$ AgNPs have been shown to possess higher cytotoxicity compared to the well documented GNPs. ${ }^{258-260}$ Three probable explanations are given in order to describe the antibacterial activity of AgNPs: (i) direct interaction of AgNPs with the bacterial cell membrane results in membrane disruption and complex formation with substances located intracellularly; ${ }^{261}$ (ii) AgNPs interact with the thiol groups ($\mathrm{SH}$ ) and produce ROS; 262 and (iii) subsequently, there is release of $\mathrm{Ag}^{+}$ ions which inhibit respiratory enzymes and also increase ROS generation (Fig. 7). ${ }^{263}$

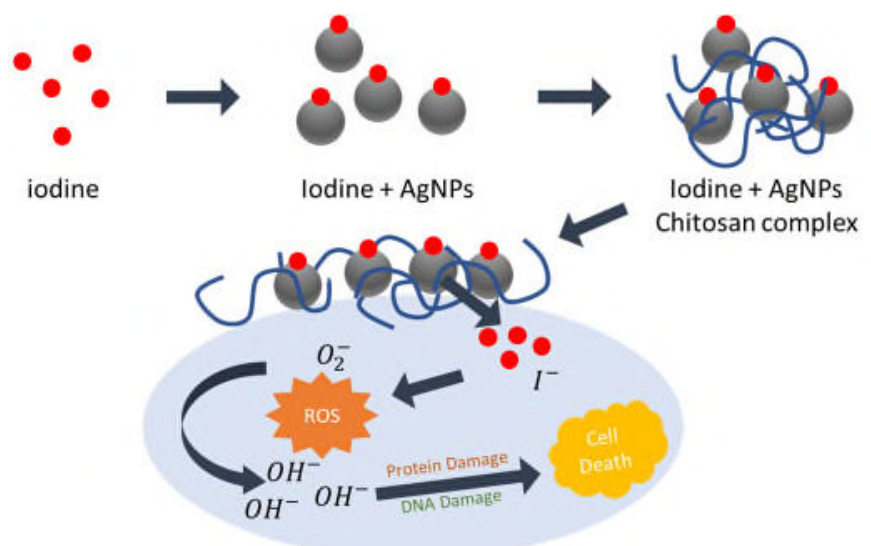

Fig. 6 Schematic representation of the proposed mechanism of antibacterial activity of the iodinated chitosan-Ag NP composite. Modified from Ref ${ }^{262}$.

Table 2 Therapeutic applications of noble metal nanoparticles.

\begin{tabular}{llll}
\hline $\begin{array}{l}\text { Type of noble metal } \\
\text { nanoparticles }\end{array}$ & Application & $\begin{array}{l}\text { Properties of noble metal } \\
\text { nanoparticles }\end{array}$ & References \\
\hline GNPs & Inhibition of VEGF 165 and bFGF & Anti-angiogenic & $155-157$ \\
GNPs & $\begin{array}{l}\text { Prevention of multiple myeloma } \\
\text { Inhibition of B-chronic lymphocytic } \\
\text { leukemia }\end{array}$ & Anti-angiogenic & 160 \\
GNPs & Anti-angiogenic & 264 \\
GNPs & As PDT agents for cancer treatment & Anti-angiogenic & 265 \\
GNPs & LSPR & $199,204,266$ \\
GNPs & As PTT agents for cancer treatment & LSPR & $171,186-188$ \\
Gold nanorods & As PDT therapy for cancer treatment & LSPR & $172-174$ \\
GNPs & For skin cancer treatment & LSPR/hyperthermia & $174,204,205$ \\
GNPs & Treatment for liver cancer & LSPR/Radio frequency ablation & 175 \\
AgNPs & Inhibition of VEGF & Anti-angiogenic & 161,162 \\
AgNPs & Cancer treatment & Anti-angiogenic & 206,207 \\
AgNPs & Breast cancer treatment & Anti-angiogenic & $209-211$ \\
AgNPs & Prevention against MDR malignant & Anti-angiogenic & 212 \\
& melanoma cell tumours & & 215 \\
PtNPs & Cancer treatment & LSPR/radiation therapy & 214,217 \\
PtNPs & Cancer treatment & Anti-angiogenic & 232,233 \\
\hline PdNPs & Cancer treatment & Anti-angiogenic & $234-236$ \\
PdNPs & As PTT agents for cancer treatment & LSPR/Hyperthermia & 237 \\
\hline PdNPs & Tumour treatment & LSPR/Photothermal ablation & \\
\hline
\end{tabular}

Table 3 Antimicrobial properties of noble metal nanoparticles.

\begin{tabular}{llll}
\hline $\begin{array}{l}\text { Type of noble metal } \\
\text { nanoparticles }\end{array}$ & Application & Antimicrobial properties & References \\
\hline GNPs & $\begin{array}{l}\text { Inhibition of vancomycin-resistant } \\
\text { enterococci }\end{array}$ & Antibacterial & 240 \\
Cefaclor capped GNPs & Inhibition of E. coli and S. aureus & Antibacterial & 241 \\
$\begin{array}{l}\text { GNPs functionalised with } \\
\text { PTD }\end{array}$ & Prevention of HIV-1 & Antiviral & 242 \\
GNPs-SDC 1721 conjugate & Inhibition of HIV-1 & Antiviral & 243 \\
PEG-GNPs & Prevention of HIV & Antiviral & 244 \\
Sugar coated GNPs & Inhibition of receptor binding in HIV-1 & Antiviral & 245 \\
Copolymer conjugated GNPs & $\begin{array}{l}\text { As drug delivery vehicle for Rifampicin for } \\
\text { treatment of Tuberculosis }\end{array}$ & Antibacterial & 246 \\
AgNPs & $\begin{array}{l}\text { Inhibition of S. aureus, Streptococcus } \\
\text { pyrogenes, S. enteric and Enterococcus } \\
\text { faecalis }\end{array}$ & Antibacterial & 267 \\
\end{tabular}




\begin{tabular}{|c|c|c|c|}
\hline PEG-AgNPs & $\begin{array}{l}\text { Inhibitory action against S. aureus, } \\
\text { Salmonella typhimurium }\end{array}$ & Antibacterial & 268 \\
\hline AgNPs & Prevention of Tuberculosis & Antibacterial & 269 \\
\hline AgNPs & $\begin{array}{l}\text { Inhibitory action against Candida albicans, } \\
\text { C. Tropicalis, Trichophyton } \\
\text { mentaprophytes, C. glabrata and C. krusei }\end{array}$ & Antifungal & 253,270 \\
\hline AgNPs & Prevention of severe keratitis & Antifungal & 271 \\
\hline AgNPs & Inhibition of plaque formation in MPV & Antiviral & 272 \\
\hline AgNPs & Prevention of HIV & Antiviral & 273-277 \\
\hline AgNPs & Inhibition of virus binding in HIV-1 & Antiviral & 275 \\
\hline AgNPs & Prevention of $\mathrm{H} 1 \mathrm{~N} 1$ & Antiviral & 278 \\
\hline AgNPs & $\begin{array}{l}\text { Inhibitory action against HSV }-1, \text { HSV-2 and } \\
\text { HPIV-3 }\end{array}$ & Antiviral & 279,280 \\
\hline AgNPs & $\begin{array}{l}\text { Cytotoxic effect against AD3 virus } \\
\text { particles }\end{array}$ & Antiviral & 281 \\
\hline $\begin{array}{l}\text { Polysaccharide coated } \\
\text { AgNPs }\end{array}$ & Inhibition of TCRV & Antiviral & 282 \\
\hline AgNPs & $\begin{array}{l}\text { Inhibitory action against Cryptosporidium } \\
\text { parvum in water purification }\end{array}$ & Antiprotozoal & 283,284 \\
\hline AgNPs & Prevention of leishmania & Antiprotozoal & 284,285 \\
\hline AgNPs & $\begin{array}{l}\text { Inhibitory action against Plasmodium } \\
\text { falciparum }\end{array}$ & Antiprotozoal & 286,287 \\
\hline AgNPs & Wound healing & Antibacterial and Antifungal & $288-290$ \\
\hline PtNPs & Prevention of Parkinson's disease & Antioxidant & 218,219 \\
\hline PtNPs & Prevention of bone loss & Antioxidant & 220 \\
\hline PtNPs and AF-PtNPs & ROS scavenger & Antioxidant & 221 \\
\hline PtNPs & $\begin{array}{l}\text { Prevention of UV-induced inflammatory } \\
\text { responses in skin }\end{array}$ & Antioxidant & 222 \\
\hline PtNPs & Inhibitory activity against $P$. aeruginosa & Antibacterial & 291 \\
\hline Ru nanoparticles & $\begin{array}{l}\text { Inhibition of Gram-positive and Gram- } \\
\text { negative bacteria }\end{array}$ & Antibacterial & 292 \\
\hline
\end{tabular}

Mycosynthesised AgNPs using different strains of fungi have shown significant efficacy against Staphylococcus aureus, Streptococcus pyrogenes, Salmonella enteric and Enterococcus faecalis. ${ }^{267}$ AgNPs associated with traditional antimicrobial drugs have been deployed to provide the possibility of more rational therapies. AgNPs synthesised using Aspergillus flavus and upon conjugation with several antibiotics such as ciprofloxacin, gentamicin, vancomycin and trimethoprim have been studied. ${ }^{293}$ When AgNPs were used in combination with gentamicin, ampicillin, vancomycin, and oflaxacin, there was an improvement in antimicrobial activities. This enhancing effect of AgNPs emphasises the potency of $\mathrm{Ag}$ in increasing the membrane permeability. ${ }^{294}$ One of the reports suggests that AgNPs enter the cell by disrupting the cell membrane and interfering with the cytoplasmic content. ${ }^{295}$ The size-dependent antibacterial activity of AgNPs has been investigated and it has been indicated that smaller AgNPs exhibit enhanced antibacterial activity as a result of relative increase in contact surface area. ${ }^{296}$ PEG-AgNPs of different sizes were tested for their antibacterial activities against Gram-positive (S. aureus) and Gram-negative (Salmonella typhimurium) bacteria, the results demonstrated that size modulation of PEG-AgNPs can significantly enhance the antimicrobial properties of AgNPs against both these pathogens. ${ }^{268}$ There are several reports which throw light on the antibacterial activity of AgNPs against MDR. ${ }^{269}$ It has been demonstrated that AgNPs and GNPs are equally effective against $E$. coli and Mycobacterium tuberculosis (MTB), but a higher antimicrobial activity has been reported by AgNPs. This result suggests that AgNPs can be used for TB therapies. In consistency with the above observation, it has been established that AgNPs coated with bovine serum albumin (BSA) offer better biocompatibility against TB without losing their effectiveness, as opposed to polyvinyl pyrrolidone (PVP)-AgNPs.
The antifungal property of colloidal silver is comparatively less studied in comparison to its antibacterial activity. Still, there are numerous reports which confirm that AgNPs can be a potent antifungal agent. AgNPs have shown significant activities against different fungal species such as Candida albicans, C. tropicalis, Trichophyton mentagrophytes, C. glabrata and C. krusei. ${ }^{269}$ Biosynthesised AgNPs seem to have antifungal properties against Phoma glomerata, $P$. herbarum, Fusarium semitectum, and Trichoderma species; they also showed synergistic effect when in conjugation with a standard antifungal agent such as fluconazole. 270 Antifungal action of AgNPs in combination with heterocyclic compounds, namely thiazolidine, phthalazine, pyrazolo, and hydrazide, were investigated against Aspergillus flavus and $C$. albicans. The results indicate an enhanced antifungal activity in combination with above mentioned compounds as compared to heterocycles alone. ${ }^{297}$ In a separate study, AgNPs and natamycin were tested against various strains of fungi among patients suffering from severe keratitis and the authors observed a higher antifungal activity of AgNPs in comparison to natamycin. ${ }^{271} \mathrm{~A}$ possible explanation for the antifungal properties of AgNPs might be due to its role in disrupting cell membrane integrity and by inhibiting the normal budding process in yeasts. ${ }^{298} \mathrm{AgNPs}$ are also emerging as one of the possible potent options for managing viral diseases due to their potential antiviral properties. ${ }^{299} \mathrm{AgNPs}$ are capable of acting on broad range of viruses and offer a lower probability of developing resistance against viruses as compared to conventional antivirals. AgNPs synthesised by biological processes tends to exhibit higher antiviral properties as compared to chemically synthesised particles. ${ }^{279,300}$ Kidney epithelial cells extracted from an African green monkey and co-incubated with AgNPs displayed significantly reduced plaque formation with Monkeypox virus (MPV). ${ }^{272}$ The 
preventive antiviral nature of AgNPs has been extended to HIV, where they are seen to prevent the host cells from binding with the virus in vitro. ${ }^{273,274}$ AgNPs effectively decrease HIV-1's infectivity by acting directly on the virus by binding to the glycoprotein gp120. ${ }^{275}$ This structural alteration in turn, decreases the CD4-dependent virion affinity, thereby preventing HIV-1 infection. ${ }^{275}$ Recent studies have yielded promising results regarding the antiviral property of AgNPs against influenza A H1N1 virus. ${ }^{278}$ The antiviral potency of AgNPs has been further demostrated against Herpes simplex virus types 1 and 2 (HSV-1 and HSV-2) and human parainfluenza virus types-3 (HPIV-3) in a dose-dependent manner. ${ }^{279} \mathrm{~A}$ similar study was carried out against adenovirus type 3 (AD3) where it was illustrated that AgNPs processed cytotoxic effect against AD3 by not only damaging the virus particles, but also disrupting the DNA structure. In addition, AgNPs can damage the capsid protein which inhibits the virus attachment to the host. ${ }^{281}$ Capping agents play a significant role in reducing infectivity and enhancing biological compatibility. AgNPs coated with stabilising agents such as PVP, PEG, and citrate have also been proved to be powerful antiviral agents, in a size-dependent manner. It has been shown that a polysaccharide coating on AgNPs protects the cell from the toxic effect of the nanoparticles, but also reduces the NP's activity against tacaribe virus (TCRV). ${ }^{282}$ In contrast, the same capping agent results in better antiviral activity efficiency against MPV. ${ }^{272}$ Other examples of coated AgNPs as effective antiviral agents have been offered in several studies such as HIV1,275-277 HSV, 280 and respiratory syncytial virus (RSV). ${ }^{301}$ PVP capped AgNPs have been used to prevent transmission of HIV-1 infection using an in vitro human cervical tissue-based organ culture 275 and also as a coating for polyurethane condoms in order to inactivate infectious microorganisms. ${ }^{280}$

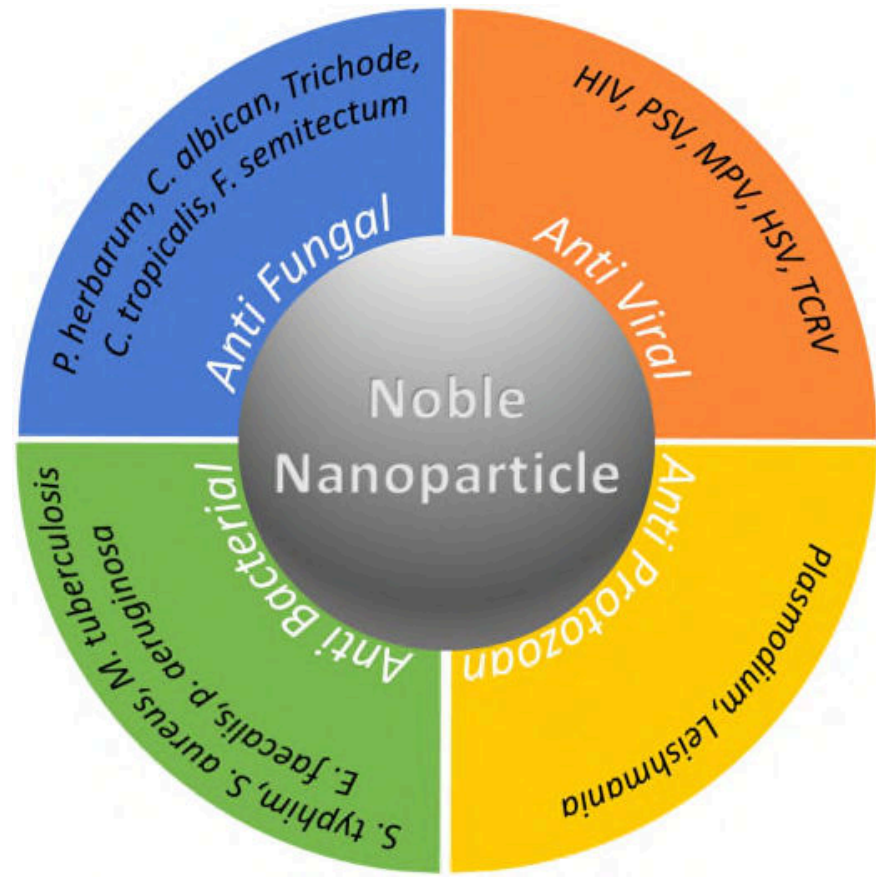

Fig. 7 Schematic diagram of anti-infective properties of NMN.

The studies showed effective reduction in HIV infection, but the mode of action is yet to be ascertained. One possible mechanism suggested is that AgNPs interact directly with surface glycoproteins and thereby interfere with the binding and fusion events during viral penetration into susceptible cells. Additionally, AgNPs are also able to inhibit post-entry stages of the HIV-1 life cycle by blocking various functional HIV-1 proteins or reducing the rate of proviral transcription by binding to the RNA or DNA moieties. The antiprotozoal activity of AgNPs has also been studied recently. The efficacy of AgNPs as an antiprotozoal agent against Cryptosporidium parvum was assessed and the disinfectant properties of AgNPs for water purification was demonstrated. ${ }^{283,284}$ Green-synthesised AgNPs using $F$. oxysporum have shown promising result against Leishmania amazonesis promastigotes both in vitro and in vivo. ${ }^{284}$ AgNPs inhibit the biological activity of Leishmania tropica and this effect was enhanced under UV irradiation. The enhancement in antileishmanial activity under UV light was attributed to the ability of AgNPs to release $\mathrm{Ag}^{+}$ions, leading to the interaction of the AgNPs with the parasitic surface lipophosphoglycan and glycoproteins, which are responsible for spreading infection. ${ }^{285}$ AgNPs have profound influence against plasmodia, biosynthesised AgNPs using Acanthaceae and leaf extract of Catharanthus roseus have demonstrated promising indication against Plasmodium falciparum in a size-dependent study. ${ }^{286,287}$ Wound healing promoted by AgNPs provides possible direction of research. Topical application of AgNPs in a mice model exhibited wound healing and reduced scar formation properties in a dose-dependent manner. ${ }^{288}$ When it was used for burns, AgNPs of $<20 \mathrm{~nm}$ in diameter at very low concentrations were able to work simultaneously as an antimicrobial as well as an antisuppressant against local systematic inflammation in vivo. Studies of AgNPs acting as skin wound-healing agents in vivo have been. It was observed that low concentrations of AgNPs ( $\sim 10 \mathrm{~nm}$ ) promoted wound closure and wound contraction by enhancing the proliferation and differentiation of keratinocytes and fibroblasts. ${ }^{289}$ Another study concerning the skin penetration efficacy of colloidal silver and silver nanoclusters has shown that they are able to penetrate into human stratum corneum as well as the outermost surface of the epidermis. ${ }^{290}$ Polymer conjugated AgNPs in the size range of $<50 \mathrm{~nm}$ can promote penetration through intact as well as damaged human skin; these future applications of AgNPs could have relatively long-lasting therapeutic benefits.

Studies on the antibacterial property of PtNPs performed with the pathogen, $P$. aeruginosa, observed that PtNPs showed sizedependent bacterio-toxic and bacterio-compatible properties. ${ }^{291}$ Ruthenium ( $\mathrm{Ru}$ ), rhodium (Rh), iridium (Ir) and osmium (Os) are the other so-called noble metals; they have gained considerable importance in the drug industry owing to their anticancer, antirheumatic, antimalarial, and antibacterial activities. Their assimilation into nanobiotechnology research is not as mature as other well-known nanomaterials such as gold, silver, platinum, and palladium. $\mathrm{Ru}$ is a $4 \mathrm{~d}$ transition metal belonging to the platinum group. ${ }^{302,303}$ Despite the limited use of Ru nanoparticles in biomedical and clinical research, they have impacted on several other important application areas including catalytic dehydrogenation, ${ }^{304}$ methanol fuel cells, ${ }^{305}$ synthesis of diesel fuels, ${ }^{306}$ degradation of azo dye, ${ }^{307}$ and removal of organic pollutants from water, ${ }^{308}$ to name but a few. Recently, one group showed the antibacterial activity of $\mathrm{Ru}$ nanoparticles. ${ }^{292}$ In this study, they synthesised Ru nanoparticles using leaf extract; green-synthesised Ru nanoparticles, in the size range of $\sim 40 \mathrm{~nm}$, were tested against gram-negative and grampositive bacteria in order to determine their antibacterial efficacy. The results obtained demonstrated that Ru nanostructures tend to be most effective against gram-positive bacteria. Ru nanoparticles attach themselves onto the bacterial membrane by electrostatic and coordinated covalent interactions, leading to generation of ROS within the bacterial cell and subsequent ultimate cell death. ${ }^{239}$ Hence, we could see Ru nanoparticles being applied for development of drugs against gram positive bacterial diseases. 

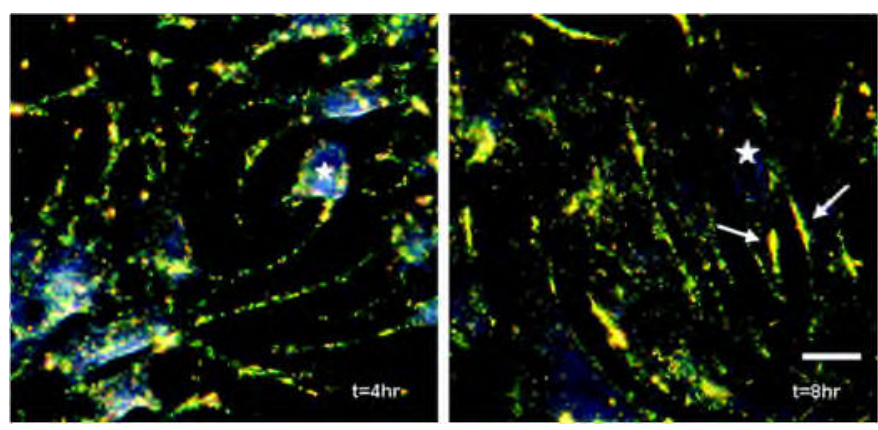

\section{Diagnostic and imaging potential of NMN}

Diagnosis and sensing applicability of NMN: The phenomenon of Localised Surface Plasmon Resonance (LSPR) in noble metal nanoparticles has been most widely used for the development of new biosensors. LSPR arises from the electromagnetic waves that travel along the surface of conductive metals and semiconductors. ${ }^{309}$ Upon excitation with an external light source, noble metal nanoparticles produce an intense absorption and scattering as a result of the collective oscillation of the conductive electrons present at their surface and conductive bands. Noble metals, especially gold and silver, have been employed in many biosensors.

Fig. 8 The arrangement of actin is followed as cells spread on a monolayer of collagen IV. Time points at $4 \mathrm{~h}$ (left) and $8 \mathrm{~h}$ (right) are shown. White stars indicate a cell body and arrows indicate actin alignment. Scale bar is $20 \mu \mathrm{m}$. Reprinted with permission from ${ }^{139}$

Table 4 Diagnostic application of noble metal nanoparticles.

\begin{tabular}{|c|c|c|}
\hline $\begin{array}{l}\text { Type of noble metal } \\
\text { nanoparticles }\end{array}$ & Application & References \\
\hline GNPs & Detection of DNA & 310-315 \\
\hline GNPs & $\begin{array}{l}\text { Detection of SNPS, UV-induced mutagenic or carcinogenic DNA } \\
\text { dimmers and detection of unamplified hepatitis C virus RNA }\end{array}$ & $316-319$ \\
\hline Citrate capped GNPs & Sensing of thiourea and melamine & 320,321 \\
\hline Fibrinogen functionalised GNPs & Detection of genes associated with sickle-cell anaemia & 313 \\
\hline Gold nanobeacons & Mutation associated with cystic fibrosis & 322,323 \\
\hline GNPs & Detection of HIV-1 p24 antigen & 324,325 \\
\hline GNPs & Detection of HBV genes & 326 \\
\hline GNPs & Detection of Mycobacterium tuberculosis DNA sequence & $327-329$ \\
\hline GNPs & Biomarkers for Alzheimer's disease & 330 \\
\hline Graphene oxide-GNPs & Detection of MB & 331 \\
\hline GNPs & Quantification of NAADP & 332 \\
\hline AgNPs & Detection of bombesin, a neurotransmitter tumour marker & 333 \\
\hline AgNPs & Sensing protein-protein and protein-small molecule interaction & 334,335 \\
\hline AgNPs & Glucose detection & 336,337 \\
\hline AgNPs & Detection of DNA & 338 \\
\hline Peptide functionalised GNPs & Anthrax biomarker detection & 339 \\
\hline GNPs/AgNPs & Detection of DNA sequence for HIV & $340-343$ \\
\hline GNPs-MBA conjugate & Hepatitis B virus antigen & 344 \\
\hline Gold nanobeacons & Detection of erbB-2 and ki- 67 breast cancer biomarkers & 345 \\
\hline Graphene oxide-PtNPs & Detection of cancer cells & 346,347 \\
\hline GNPs & Detection of $E$. coli & 348 \\
\hline $\begin{array}{l}\text { GNPs modified with 4-amino-1-(- } \\
\text { 3-mercapto-propyl)-pyridine } \\
\text { hexafluorophosphate }\end{array}$ & Sensing human IgG concentration & 349 \\
\hline Graphene oxide-GNPs & Detection of alpha-fetoprotein & 350 \\
\hline PdNPs & Detection of alpha-fetoprotein & 351 \\
\hline PdNPs & Detection of prostate specific antigen & 352 \\
\hline AgNPs-titanium phosphate & Immunodetection of IL- 6 & 353 \\
\hline Graphene oxide-AgNPs & Immunodetection of $E$. coli & 354 \\
\hline $\begin{array}{l}\text { 6-ferrocenyl hexanethiol } \\
\text { functionalised GNPs }\end{array}$ & Immunosensing of prostate specific antigen & 355 \\
\hline
\end{tabular}

LSPR leads to exceptionally high absorption and scattering properties within the UV-visible wavelength which confers the particles with higher sensitivity in comparison to conventional organic dyes, making them a perfect foil for colorimetric sensor applications. ${ }^{356,357}$ The sensing efficiency of GNPs depends upon their intrinsic localised surface plasmon resonance, with wavelengths around $510-530 \mathrm{~nm}$ for gold nano formulations of around 4-40 nm, which can be used for biosensing. ${ }^{358}$ This effect is generally absent in the individual atoms and the bulk form. ${ }^{359,360}$ The binding of molecules onto the particle surface changes the LSPR, which is reflected by the scattered light in dark field microscopy. ${ }^{361}$ In addition, SPR is drastically changed when the average distance between the Au particles changes during the formation of gold colloid aggregates. ${ }^{362}$ This attribute of GNPs has been utilised, for example, for the detection of DNA, ${ }^{310,311}$ by taking advantage of the binding affinity of single and ds-DNA onto their surface. Complementary charged GNPs interact electrostatically with the free bases of single stranded (ss)-DNA, which in turn provides colloidal stability to the nanoparticles in the presence of high salt 
concentrations. In contrast, dsDNA molecules adsorb less to the GNPs surface and hence are unable to provide colloidal stability under increasing ionic strength, leading to aggregation of GNPs, which results in LSPR and colour change simultaneously. GNPs conjugated with oligonucleotides that are complementary to the target sequence appear as a red solution in the absence of the target sequence, whereas in the presence of the target, hybridisation occurs and the solution changes to violet/blue due to LSPR. ${ }^{312}$ This approach has been successfully deployed for the detection of single nucleotide polymorphism (SNPS), UV induced mutagenic or carcinogenic DNA dimmers, and in the detection of unamplified hepatitis $C$ virus RNA isolated from clinical specimens. ${ }^{316-319}$ Citrate capped GNPs and AgNPs have been investigated for sensing thiourea and melamine using a colorimetric assay system. ${ }^{320,321}$ In this method, the presence of thiourea and melamine significantly reduces the overall surface charge of GNPs leading to their aggregation and this in turn is detected colorimetrically indicating the concentration of thiourea and melamine present. Detection of DNA, aptamers, and oligonucleotides has received considerable attention in recent years because it has important implications in medical diagnostic, food safety monitoring, and the drug industry. Many studies have been conducted using surface functionalised GNPs for the detection of DNA, aptamers, and oligonucleotides. ${ }^{313-}$ ${ }^{315}$ GNPs functionalised with thiol (-SH) modified ssDNA probes have been used to detect a single mismatch through a cross-linking approach in the presence of a complementary ssDNA. ${ }^{363,311} \mathrm{~A}$ noncross-linking approach was used for the specific detection of genes associated with sickle-cell anaemia using fibrinogen functionalised GNPs and a thrombin binding aptamer. ${ }^{313}$ Fluorescence-based noble metal nanoparticle biosensors have been developed by utilising the quenching property of these nanomaterials. This is not to be confused with plasmonic nanoparticles, where the surface electrons can couple with electromagnetic waves with wavelength much larger than the size of the particles. Two approaches have been used so far: (i) molecular nano-beacons, where noble metal nanoparticles are surface conjugated with fluorescent-labelled ssDNA which forms a hair-pin loop like structure; and (ii) noble metal nano-probes, which consist of noble metal nanoparticles functionalised with ssDNA that hybridise with another fluorescent-labelled ssDNA probe. Molecular nano-beacons have been used to detect single-base mismatches in DNA with a higher sensitivity as compared to conventional molecular beacons. $^{322}$ In another example, nano-beacons based on $13 \mathrm{~nm}$ GNPs have been successfully used to detect mutation associated with cystic fibrosis. ${ }^{323}$ In all these cases, the loop forming structure of the nano-beacon brings the fluorescent dye moiety in close proximity to the noble metal nanoparticle's surface resulting in quenching of the fluorescence intensity of the fluorophore. In the presence of a complementary DNA/RNA target, the hairpin structure is disrupted by hybridisation and restores the fluorescence of the labelled strands. A gold nanorods containing gelatin hydrogel is developed for rapid recognition of circulating tumour cells (Fig. 9). An innovative "chemical nose" technique has been developed using conjugates of GNPs and fluorophore which provides high sensitivity sensing of biomolecular targets (Fig. 10). ${ }^{364-366}$ This method was used for rapid and accurate differentiation between normal, cancerous, and metastatic cells. ${ }^{367}$ Appropriately functionalised gold nanoparticles can be used for a simple colorimetric test for small concentrations of aqueous heavy metal ions, which includes toxic heavy metals such as lead, cadmium and mercury. GNPs are aggregated in the solution in presence of divalent metal ions by ion-templated chelation process. ${ }^{368}$ The development of a fast and reliable method for glucose sensing is a prerequisite for the treatment and control of diabetes. ${ }^{369,370}$ Most electrochemical methods use enzymes such as glucose oxidase or glucose dehydrogenase to catalyses the specific oxidation of glucose. GNPs entrapped in a silica network can enhance the non-enzymatic oxidation of glucose providing one possible alternative to the use of enzyme electrodes under appropriate circumstances. $^{371}$ A sandwich interface containing chitosan/Au nanoparticles/glucose oxidase multilayer on platinum electrodes has been claimed to provide high sensitivity and a low detection limit for glucose, presumably due to the high electrochemically active surface area and diffusion characteristics of GNPs at the sandwich interface. ${ }^{372}$
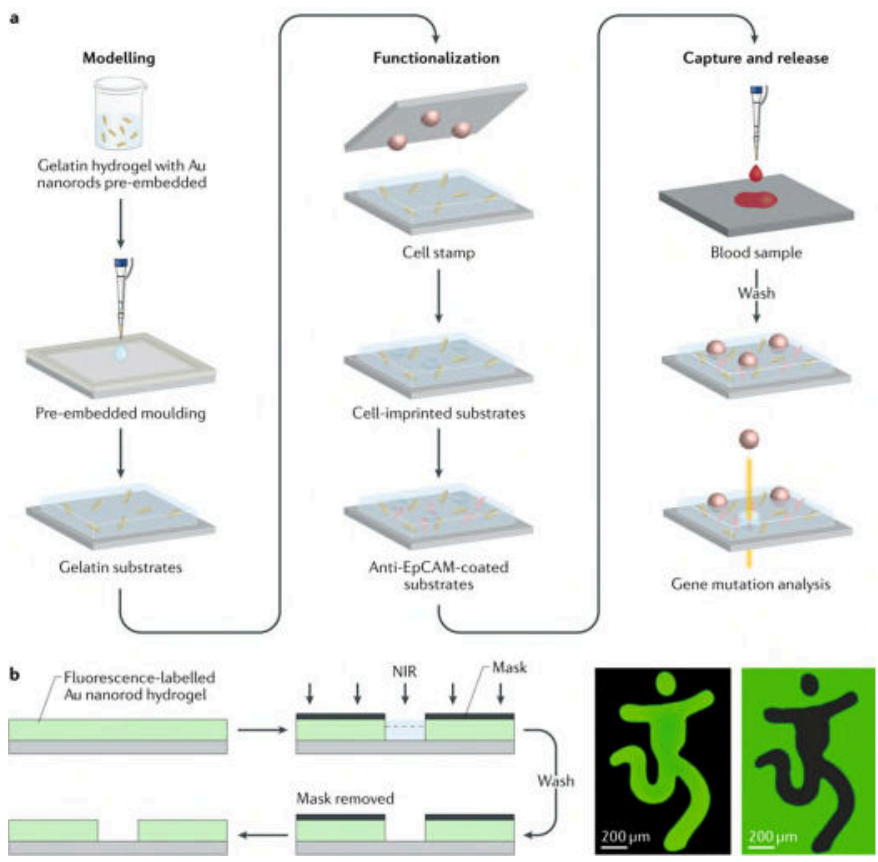

Fig. 9 (a) Near-infrared (NIR)-responsive cell-imprinted gelatin for capture and photothermal selective release of single circulating tumour cells (CTCs) from peripheral blood. The cell-imprinted substrate is fabricated by imprinting target cancer cells on a Au nanorod-embedded gelatin hydrogel. CTCs are then separated by anti-epithelial cell adhesion molecule (anti-EpCAM)-modified cell-imprinted gelatin. This is followed by selective site release of an individual cell by exposure to a cell-sized NIR laser spot. (b) Schematic showing the selective photodegradation of the thermoresponsive gel doped with Au nanorods. Fluorescence microscope image of the fluorescein isothiocyanate (FITC) gelatin with a mask on top (bottom left). Fluorescence microscope image of the FITC gelatin without the mask and after removal of the gel degraded via selected NIR irradiation (bottom right). Reprinted with permission from ${ }^{373}$

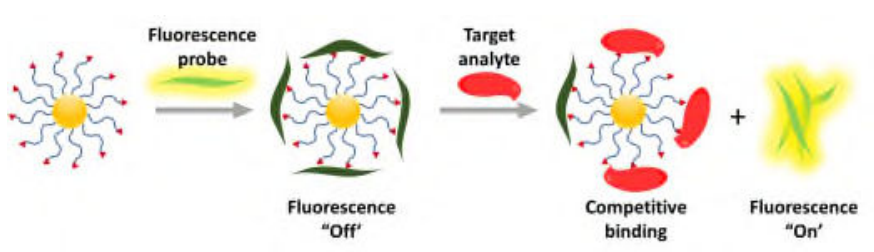

Fig. 10 Scheme illustration of GNP-based chemical nose for sensing of biomolecules based on competitive binding and fluorescence quenching. Modified from ref ${ }^{364}$

Antibody conjugated GNPs have been used for biological staining in electron microscopy and for radioactive labelling in vivo. The application of gold colloids in bio-diagnostics over conventional organic dyes and quantum dots offers a number of advantages which include reduced toxicity and contrast enhancing agents for imaging. Gold nano formulations can provide signal enhancement to standard enzyme-linked immunosorbent assays (ELISAs), such as immunochromatographic test strips where both primary and secondary antibodies are attached to GNPs. ${ }^{374}$ Surface modification of GNPs with Cy5-antibody as a fluorescence probe could replace the 
conventional ELISA assay, since this technique does not require a secondary antibody and offers high sensitivity. ${ }^{375}$ Gold nanoshells are capable of detecting nanogram quantities of various analytes present in whole-blood in chemiluminescent analysis of antibodies. This technique is far superior to ELISA in terms of technical proficiency. ${ }^{376}$ The intense light scattering by large GNPs makes them a potent probe for cancer detection. Immuno-targeting of antibody-GNPs to label cancer cells is achieved by conjugating them with antigens overexpressed in cancer cells. For example, cervical epithelial cancer cells ( $\mathrm{SiHa}$ cells), which overexpress the transmembrane glycoprotein, epithelial growth factor receptor (EGFR), were successfully detected by immune-targeted gold colloids. ${ }^{377}$ GNPs nanoprobes have also potentially simplified diagnosis of cancer by detecting SNPs and mutation. ${ }^{378,379} \mathrm{~A}$ new approach has been added in the already existing repertoire of GNPs in the diagnosis of cancer, wherein a combined solid-phase microextraction with gas chromatography/mass spectrometry has been employed for the identification of volatile organic compounds acting as biomarkers for lung cancer. ${ }^{380}$

Gold colloid bio-barcode amplification assays (BCA) can detect HIV-1 p24 antigen at very low concentration levels $(0.1 \mathrm{pg} / \mathrm{mL})$. The conventional detection limit with ELISA is reported as $1-15 \mathrm{pg} / \mathrm{mL}$, 324 while using GNPs there was a 100 to 150 -fold enhancement in the detection limit. ${ }^{325}$ Another, technique for reliable and sensitive method for HIV-1 virus is based on gold colloid labelled silver staining in conjunction with polymerase chain reaction (PCR). The results demonstrated the highly sensitive and accurate potential for HIV-1 diagnosis using GNPs. ${ }^{381}$ Functionalisation of gold colloids with Hepatitis $B$ virus (HBV) DNA gene probes could be used to detect HBV DNA directly. This fluorescence-based method was highly sensitive and cost effective and could in future replace the highly complex multi-gene detection chips. ${ }^{326}$ Diagnostic applications of gold nanoformulation probes have found their way into tuberculosis detection also. A target oligonucleotides sequence, suitable for mycobacteria identification was used here. At high ionic strength, aggregation of the nanoprobe takes place in the absence of any complementary DNA sequence specific to target oligonucleotides and turns the solution purple. On specific probe hybridisation to a complementary sequence (i.e. DNA from Mycobacterium tuberculosis), no aggregation of GNP nanoprobe occurs and the solution remains red. ${ }^{327}$ GNPs have been applied for the diagnosis of Alzheimer's disease biomarkers based on the SPR property of gold colloids. Here, gold nanoparticles are used to monitor the interaction between the antigen, amyloid- $\beta$ derived diffusible ligands (ADDLs) and specific anti-ADDL antibodies. ${ }^{330}$

GNPs have been used as nanoprobes for detection and differentiation of Mycobacterium tuberculosis (MB) from other members of $M$. tuberculosis complex (MBC). In one report, oligonucleotide modified GNPs were developed as a selective nanoprobe for DNA-based detection and differentiation of MB and $M B C$. The technique was highly selective for distinguishing between $\mathrm{MB}$ and MBC. ${ }^{328}$ In yet another approach, Mycobacterium bovis and $M B C$ were successfully differentiated by GNP nanoprobes. ${ }^{329}$ A new DNA-based biosensor for the highly sensitive detection of the specific IS6110 DNA sequence of MB has been achieved by using reduced graphene oxide-GNPs as a sensing platform and GNPs-polyaniline as a label for signal amplification. ${ }^{331}$ The nanoprobing activity of GNPs for sensing MB shows potential for use in clinical diagnostics. Noble metal nanoparticles have been used for enhancement of Raman signals in Surface-Enhanced Raman Scattering (SERS) for different types of analytes, and this has led to a wide variety of biosensors for the detection of nucleic acids, antibodies, proteins, and other biological molecules. ${ }^{382,383}$ Raman scattering arises from the inelastic scattering of photons that hit the analyte molecule in such a way that energy is either gained or lost so that the scattered photons are shifted in frequency. This interaction generates a narrow spectrum of bands unique for each analyte, and this signal is greatly enhanced in presence of noble metal nanoparticles by an order of $10^{5}$ to $10^{6}$ than the respective non-SERS Raman signals. ${ }^{384}$ This enhancement is mainly attributed to the LSPR properties of the noble metal nanostructures. ${ }^{385} \mathrm{~A}$ label-free SERS biosensor has been developed based on a glass surface coated with a layer of GNPs to detect and quantify nicotinic acid adenine dinucleotide phosphate (NAADP), which plays a crucial role in intracellular $\mathrm{Ca}^{2+}$ release. ${ }^{332}$ This labelfree SERS system allowed for a rapid detection of NAADP, making it a valuable tool for the study of normal and cancerous cells. In a similar approach, a surface covered with AgNPs were used instead of GNPs to detect bombesin, a neurotransmitter tumour marker and its analogues by SERS. ${ }^{333}$ This research group has also developed a protocol to monitor protein-protein and protein-small molecules interaction using AgNPs staining of the samples for producing active substrates for SERS. ${ }^{334,335}$ Another group of researchers used SERS to detect glucose levels by employing a self-assembled monolayer of decanethiol over an aggregated AgNPs film to increase glucose adsorption, which is otherwise minimal for bare-SERS substrates. ${ }^{336,337}$ SERS has also been used for detecting ssDNA by applying a slide derivatised with uncharged peptide nucleic acids which recognise and hybridise with specific, negatively charged ssDNA. This system mediated the adsorption of positively charged AgNPs upon hybridisation. ${ }^{338}$ The use of functionalised noble metal nanoparticles has been investigated for a more versatile and specific SERS-based sensing of biomolecules. In this method, SERS signals were generated by using a probe (DNA, antibody) functionalised noble metal nanoparticles and a Raman-labelled probe. This sensor system has been applied to detect a specific Anthrax biomarker by means of peptide functionalised GNPs, ${ }^{339}$ and detect specific DNA sequences such as HIV DNA using Raman-active dye labelled DNA on GNPs or AgNPs. ${ }^{340-343}$ Similarly, detection of hepatitis B virus antigen was reported using GNPs-antibody conjugates with 4mercaptobenzoic acid (MBA) acting as a Raman-active probe. ${ }^{344}$ Also, the detection of viral pathogens using monoclonal antibody conjugated GNPs and a Raman reporter has also been studied. ${ }^{386}$ In a separate study, a molecular nano-beacon approach using a Raman dye-labelled DNA functionalised on AgNPs was applied to detect and quantify a gag gene sequence of the HIV-1. ${ }^{387}$ Here, the presence of a complementary target decreased the SERS signal as a consequence of the disruption of the hairpin structure that would otherwise place the Raman dye in proximity to the NP's metallic surface. This method has been further expanded successfully to detect the erbB-2 and ki67 breast cancer biomarkers using gold nanobeacons. ${ }^{345}$

A nanocomposite of PtNPs and graphene oxide has been successfully used as signal transducer to develop a colour-based assay for the detection of cancer cells by deploying folic acid functionalised nanocomposite of PtNPs and graphene oxide. Folic acid acts as a recognition factor since folate receptors are over expressed on the cell membranes of different types of cancer cells. ${ }^{346}$ The result obtained above is due to the peroxidase-like activity of the nanocomposite, which catalyses the oxidation of $3,3^{\prime}, 5,5^{\prime}$ tetramethylbenzidine (TMB) by $\mathrm{H}_{2} \mathrm{O}_{2}$. Another example of the peroxidase activity of PtNPs has been applied in enzyme-linked immunosorbent assays (ELISAs), a nanohybrid of magnetic nanoparticles and PtNPs was immobilised on the surface of graphene oxide. This sandwich of nanocomposite was effectively used for the colorimetric detection of cancer cells via reaction of the peroxidase substrate, TMB. ${ }^{347}$ 
Electrochemical immunoassays (EIs) have been widely reported due to their high sensitivity, simplicity, and low cost. NMN-based electrochemical immunodetection offers added advantages such as high conductivity and large surface-to-volume ratio. These nanoscale materials are promising future candidates as signal tags for the development of electrochemical platforms for immunosensing. The tuneability of noble metal nanoparticles in terms of size, shape, and surface conjugation has yielded positive results in amplification and enhancement of electrochemical immunosensing signals. Development of an accurate and sensitive electrochemical immunosensor requires signal amplification and background noise reduction owing to the relatively weak electrochemical action of the immunocomplex. ${ }^{388,389}$ Enzyme labels are generally used for this purpose, but due to the instability issues related to most enzymes, there is interest in nano-templates as alternatives for signal enhancement. ${ }^{390-392}$ Preparation of non-enzymatic electrochemical immunoassays (NEEIs) based on nanoscale system can be used for two purposes. First, they can be applied to transform the electrochemical transducer matrix, which will result in low background noise and fast electron transfer, and secondly as tags for the amplification of the signals. NMN seem to be well suited to the development of NEEls because of their highly stable nature, conductivity, biocompatibility, and catalytic efficiency. ${ }^{393,394}$ The large surface area of noble metal nanoparticles together with their ease of surface functionalisation with biomolecules (e.g. antibodies), electroactive tags and polymers, makes them a promising and interesting candidate for these systems. GNPs and PtNPs of various sizes, shapes, and structures are inherently capable of catalysing oxidation, hydrogenation, and dehydrogenation of innumerable analytes, ${ }^{395}$ and these properties of noble metal nanosystems can be successfully employed for the development of sensitive, reliable and cost-effective NEEls. The introduction of GNPs in NEEls as electrode materials for the immobilisation of biomolecules has produced significant results. ${ }^{396}$ GNPs are capable of binding a wide range of substances to build up an efficient electrochemical transducer surface, containing amino acid, protein, porous silica, metal nanoparticles, and carbon nanomaterials. ${ }^{397-403}$ In this regard, an effective impedimetric immunoassay was developed based on GNPmodified graphene paper electrode for the rapid and sensitive detection of $E$. coli 0157: $\mathrm{H7} .{ }^{348}$ A biocompatible nanocomposite comprising of GNPs and 4-amino-1-(-3-mercapto-propyl)-pyridine hexafluorophosphate was developed for sensing human IgG concentration with high sensitivity. ${ }^{349}$ Another such nanocomposite containing GNP-graphene oxide and polydopamine-thionine was effectively used for developing a label-free electrochemical immunoassay system for determination of alpha-fetoprotein. ${ }^{350}$ The charge transfer and high conductivity properties of GNPs greatly enhanced the sensitivity of this detection method. Palladium nanoparticles (PdNPs) are another important noble metal nanoparticle, which has been utilised as electrode material due to its high catalytic efficiency. Palladium nanoplates, ultrathin metal films, have also been successfully used for amperometric immunoassay for the accurate detection of alpha-fetoprotein. ${ }^{351}$ The sensitive detection of these cancer biomarkers was due to excellent electrochemical properties of the nanoplates, which enhanced the electrochemical signal. PdNPs with a reduced graphene oxide-based electrochemical immunodetection system have been fabricated for the development of prostate-specific antigen. Low concentrations of these antigens could be detected using this decorated electrode due to the synergistic electrochemical activities of PdNPs and the reduced graphene oxide. ${ }^{352}$

Signal amplification is key to the development of efficient and highly specific electrochemical immunosensors with low limits of detection (LOD) and high sensitivity. Noble metal nanoparticles have been used for signal amplification in NEEls utilising 3 different strategies; (i) as electroactive labels, (ii) as carriers, and (iii) as electrocatalytic labels. Direct application of NMN as electroactive tags has shown promising results in signal enhancement. This method comprises two stages. Firstly, strong oxidants are used to dissolve the NMN into their metallic form, and secondly stripping voltammetry is employed for the sensitive detection of the dissolved ions. Utilising this method, a group of researchers synthesised a nanohybrid of AgNPs and titanium phosphate and applied it as a label for electrochemical immunodetection of human interleukin- $6 .{ }^{353}$ In the presence of the target antigen, the nanohybrid of AgNPs and titanium phosphate was anchored to the magnetically modified sensing array through sandwich-typed immunoreactions and upon addition of a strong oxidant, the $\mathrm{Ag}^{+}$ions are released from the complex. This system achieved an excellent LOD for IL-6. In a separate study, AgNPs and graphene oxide nanocomposite was used for electrochemical immunodetection of $E$. coli using solid-state voltammetry. ${ }^{354}$ GNPs have been used as carriers in NEEls for loading of multiple electroactive labels for the preparation of functionalised signal tags in order to enhance the immunoreaction system. The most commonly used electroactive labels are thionine, ferrocene and metal ions. The functionalisation of GNPs with 6-ferrocenyl hexanethiol for the development of a sensitive electrochemical immunosensor provided an efficient signal enhancing label for the determination of prostate specific antigen. ${ }^{355}$

In this era of enhanced environmental concern, catalytic reactions play an important role in the field of environmental and material sciences. ${ }^{404}$ Growth of pollution from industry and agricultural has posed a life-threatening challenge to human society, in the form of hazardous pollutants such as heavy metals ions, pesticides, dyes, toxic chemicals, pathogens, and contaminants. ${ }^{405,406}$ Various optical sensors have been developed for detecting heavy metal ions which include organic dyes, ${ }^{407,408}$ fluorescent polymers, ${ }^{409}$ and noble metal nanoparticles (Fig. 11). ${ }^{396,410-412}$ Among these sensors, noble metal nanoparticles have attracted considerable attention owing to their size, shape, chemical and optical properties, high surface-to-volume ratio, good stability, and excellent biocompatibility. ${ }^{396,413,414}$ In this section, we described some of the important sensing functionalities of NMN (Table 5).

Table 5 Noble metal nanoparticles as detection probes

\begin{tabular}{llll}
\hline Type of noble metal nanoparticles & Application & Property & References
\end{tabular}




\begin{tabular}{|c|c|c|c|}
\hline GSH modified GNPs & $\mathrm{Pb}^{2+}$ detection & LSPR & $415-417$ \\
\hline MTA modified GNPs & $\mathrm{Hg}^{2+}$ detection & LSPR & 418,419 \\
\hline Protein coated gold nanoclusters & $\mathrm{Hg}^{2+}$ and $\mathrm{CH}_{3} \mathrm{Hg}$ detection & Fluorescence & 420 \\
\hline BSA-GNPs nanoclusters & $\mathrm{Ag}^{+}$detection & Fluorescence & 307 \\
\hline Pepsin-gold nanoclusters & $\mathrm{Hg}^{2+}$ and $\mathrm{Pb}^{2+}$ sensing & Fluorescence & 421 \\
\hline BSA-gold nanoclusters & $\begin{array}{l}\text { Sensing of } \mathrm{H}_{2} \mathrm{O}_{2} \text { and pesticides (dithizone, fenitrothion and } \\
\text { paraoxonethyl) }\end{array}$ & Fluorescence & 422 \\
\hline AgNPs & $\mathrm{Ni}^{2+}, \mathrm{Co}^{2+}, \mathrm{Cd}^{2+}, \mathrm{Pb}^{2+}$ and $\mathrm{As}^{3+}$ detection & LSPR & 423 \\
\hline AgNPs & $\mathrm{Hg}^{2+}$ detection & LSPR & 424,425 \\
\hline Ag nanoclusters & $\mathrm{Hg}^{2+}$ sensing & Fluorescence & 426 \\
\hline $\begin{array}{l}\text { Polymethacrylic acid functionalised } \mathrm{Ag} \\
\text { nanoclusters }\end{array}$ & $\mathrm{Cu}^{2+}$ detection & Fluorescence & 427 \\
\hline PtNPs & $\mathrm{Hg}^{2+}$ detection & LSPR & 428 \\
\hline
\end{tabular}

GSH modified GNPs with a core size of 5-8 $\mathrm{nm}$ have been used for detecting $\mathrm{Pb}^{2+}$ ions in solution by a colorimetric method. GSH-GNPs could immediately aggregate in the presence of $\mathrm{Pb}^{2+}$ ions which results in a red shift in their SPR peak. ${ }^{415,416}$ This method is sizedependent, with a better sensitivity when the core size of the GNPs is bigger. Such colorimetric assays are popular because they can be easily observed with the naked eye or using a UV-vis spectrometer thus providing simple, cost-effective, sensitive, and selective detection of harmful environmental pollutants such as heavy metal ions. In another study, 11-mercaptoundecyl-trimethylammonium (MTA) conjugated GNPs have been investigated for $\mathrm{Hg}^{2+}$ ion sensing. ${ }^{418}$ The colour of the GNP solution changes from red to blue in the presence of $\mathrm{Hg}^{2+}$ ions, which is again evidenced in the UVvisible spectra with a red shift of the absorption peak. The high affinity between $\mathrm{Hg}^{2+}$ ions and GNPs have also been utilised for removal of mercury from water using a $\mathrm{GNP}-\mathrm{Al}_{2} \mathrm{O}_{3}$ nanocomposite. ${ }^{419}$ The shape of noble metal nanoparticles proves to be a potent regulator in sensing capabilities of heavy metal ions. For example, decahedral GNPs can detect $\mathrm{Pb}^{2+}$ ions at 1000-fold lower LOD than their spherical counterparts. ${ }^{416}$ Similarly, AgNPs with different shapes such as nanospheres, nanoplates and nanorods have been applied for constructing colorimetric sensors for $\mathrm{Co}^{2+}$ ions. Spherical AgNPs showed the highest sensitivity for $\mathrm{Ni}^{2+}, \mathrm{CO}^{2+}, \mathrm{Cd}^{2+}, \mathrm{Pb}^{2+}$, and $\mathrm{As}^{3+}$ ions, ${ }^{423}$ whereas $\mathrm{Ag}$ nanorods possessed greater selectivity for $\mathrm{Co}^{2+}$ ions over other metal ions in the solution. It has been shown that AgNPs provide a lower LOD for $\mathrm{Hg}^{2+}$ ions than GNPs because the molar extinction co-efficient of AgNPs is about 100-fold greater. ${ }^{424}$ This property has been utilised to make cost-effective assays for $\mathrm{Hg}^{2+}$ ion detection using mercury-specific oligonucleotides.425 In the presence of $\mathrm{Hg}^{2+}$ ions, the unfolded nucleotides were linked with $\mathrm{Hg}^{2+}$ ions, which resulted in aggregation of AgNPs in solution as reflected calorimetrically. PtNPs can also be used for sensing mercury. PtNPs used for this purpose catalyse the reaction between TMB and $\mathrm{H}_{2} \mathrm{O}_{2}$, which leads to a blue coloured product. However, in the presence of trace amounts of $\mathrm{Hg}^{2+}$ ions, this catalytic activity of PtNPs is inhibited. ${ }^{428}$ GNPs functionalised with different organic ligands such as thiolates, amino acids, peptides, and DNA, have been described as sensitive colorimetric detectors for heavy metal ions. ${ }^{425,429}$ For example, citrate coated GNPs aggregate in presence of $\mathrm{Hg}^{2+}$ ions and lysine, because of the strong bond formation between $\mathrm{Hg}^{2+}-\mathrm{Au}$ (Fig. 12). ${ }^{430}$ In another example, peptide functionalised GNPs can be deployed for sensing $\mathrm{Co}^{2+}, \mathrm{Hg}^{2+}, \mathrm{Pb}^{2+}$, $\mathrm{Pd}^{2+}$, and $\mathrm{Pt}^{2+}$ ions, respectively. ${ }^{417}$

Moving on to the next property of NMN, that is fluorescence which confers attractive attributes for sensing heavy metal contaminants due to higher emission. ${ }^{431,432} \mathrm{~A}$ desirable sensor system with strong fluorescence can be developed by fine tuning the size, shape, composition, and surface functionalisation of noble metal nanoclusters. Metal nanoclusters with smaller size (i.e. fewer number of metal atoms) often produce higher fluorescence due to their smaller size and larger surface area and these fluorescent probes can be used for sensing heavy metal ions as environmental pollutants. ${ }^{433}$ Protein coated gold nanoclusters as a highly fluorescent probe have been successfully used for the detection of $\mathrm{Hg}^{2+}$ ions and $\mathrm{CH}_{3} \mathrm{Hg}^{+}$species with low LOD. ${ }^{420}$ Traces of $\mathrm{Ag}^{+}$ions are similarly tested using BSA conjugated gold nanoclusters, where the presence of $\mathrm{Ag}^{+}$ions leads to the formation of $\mathrm{Ag}-\mathrm{Au}$ alloy nanoclusters which in turn produce an increased fluorescent intensity. ${ }^{434} \mathrm{Ag}$ nanoclusters also exhibit similar fluorescent probing activity for detecting $\mathrm{Hg}^{2+}$ ions due to strong interaction between $\mathrm{Ag}^{+}$ and $\mathrm{Hg}^{2+}$ ions. ${ }^{426}$ Metallophilic interaction between metal cores with a closed-shell electronic configuration can be applied for detecting heavy metals ions. As in the case with $\mathrm{Ag}$ and $\mathrm{Au}$ nanoclusters, a trace amount of $\mathrm{Hg}^{2+}$ ions could be effectively detected using this property, which leads to fluorescence quenching of the nanoclusters. ${ }^{435}$ Polymethacrylic acid-functionalised $\mathrm{Ag}$ nanoclusters were used to detect $\mathrm{Cu}^{2+}$ ions, which quenche the fluorescence of Ag nanoclusters in solution. ${ }^{427}$ In a separate study, pepsin-conjugated Au nanoclusters were applied for sensing $\mathrm{Pb}^{2+}$ ions via fluorescence enhancement and can also be used for $\mathrm{Hg}^{2+}$ ion detection by a fluorescence quenching phenomenon. ${ }^{421}$ The sensing capabilities of noble metal nanoparticles is not limited to heavy metal ions; they can also be utilised for $\mathrm{H}_{2} \mathrm{O}_{2}$ and pesticide sensing as well. For example, BSA stabilised gold nanoclusters can detect $\mathrm{H}_{2} \mathrm{O}_{2}$ and common pesticides such as dithizone, fenitrothion, and paraoxonethyl, using fluorescence detection. ${ }^{422}$ Low levels of pesticides such as endosulfan have been sensed by GNPs as well. ${ }^{436}$ 
Table 6 Biomedical imaging applications of noble metal nanoparticles via LSPR properties.

\begin{tabular}{lll}
\hline $\begin{array}{l}\text { Type of noble metal } \\
\text { nanoparticles }\end{array}$ & Applications & References \\
\hline Gold nanoshells & $\begin{array}{l}\text { Imaging of prostate cancer } \\
\text { cells }\end{array}$ & 437 \\
\hline Gold nanobeacons & $\begin{array}{l}\text { Imaging of sentinel lymph } \\
\text { nodes }\end{array}$ & 438 \\
\hline Gold nanoshells & $\begin{array}{l}\text { Contrast agents in dark- } \\
\text { field microscopy for HER 2, } \\
\text { a cancer biomarker }\end{array}$ \\
\hline $\begin{array}{l}\text { Gold nanoshells } \\
\text { Gold nanorods, } \\
\text { nanocages and } \\
\text { nanoclusters }\end{array}$ & $\begin{array}{l}\text { Imaging of live HER 2 } \\
\text { overexpressing cancer cells }\end{array}$ & \\
\hline PEG-GNPs & $\begin{array}{l}\text { In vivo imaging of cancer } \\
\text { cells }\end{array}$ & 440,441 \\
\hline Gold nanoshells & Imaging of tumour cells & 442,443 \\
\hline Gold nanoshells & $\begin{array}{l}\text { Imaging of tumours in } \\
\text { mice model }\end{array}$ & 444 \\
\hline
\end{tabular}

Importance of NMN for imaging purposes: The ability of NMN to absorb and scatter light in the NIR region makes them one of the most potent candidates as contrast agents in biomedical imaging (Table 6). ${ }^{441,446,447}$ The highly permeable nature of human skin and tissues to NIR radiation has led to the development of minimally invasive deep tissue diagnostic imaging methods with noble metal nanoparticles acting as contrast enhancer vectors. The application of noble metal nanostructures in in vivo imaging techniques allows certain advantages over conventional NIR organic dyes, such as avoiding rapid photobleaching, better detection sensitivity, improved stability in biological systems, and better multiplexing capability. ${ }^{447}$ NMN with light scattering properties enhance the contrast of imaging systems, such as dark-field or dual-photon luminescence microscopy, and also facilitate combined imaging techniques to produce a synergistic effect over single imaging method. ${ }^{448,449}$ Since the LSPR of noble metal nanomaterials is located within the NIR region, they have been applied in different imaging modalities like Photo-Acoustic Imaging (PAI), Photo-Acoustic Tomography (PAT) and dark-field and two photon microscopies. In one study, gold nanorods conjugated with an antibody and simultaneously tuned to the NIR region with PAI have been effectively used to image early-stage prostate cancer cells. Here, the gold nanorods resulted in enhanced contrast images between healthy/non-targeted tissue and cancerous/targeted tissue. ${ }^{437}$ Gold nanorods as contrast agents for in vivo imaging using a laser based PAl system have also been reported. 444 In a complementary approach, gold nanobeacons (2-4 nm) conjugated with PAI were applied for the detection of sentinel lymph nodes in ex vivo tissue specimens. ${ }^{438}$ In dark-field microscopy, the NIR scattering properties of gold nanoshells has been exploited as contrast for targeting human epidermal growth factor receptor 2 (HER2), a biomarker for cancer. ${ }^{188}$ These gold nanoshells were also used to image live HER2overexpressing cancer cells using two-photon microscopy. ${ }^{439}$ Gold nanoshells, nanorods, nanocages, and nanoclusters have shown considerable promise as contrast agents for in vivo cancer imaging due to their significant absorbance and scattering in the NIR region. ${ }^{440,441}$ These nanoformulations of gold are also used as contrast agents for Surface-Enhanced Raman Scattering (SERS), Photo-Acoustic Imaging (PAI), Computed Tomography (CT), Magnetic Resonance Imaging (MRI), and Optical Coherence Tomography (OCT) ${ }^{442,450-455}$ The use of $~ 30 \mathrm{~nm}$ PEG coated GNPs for in vivo $\mathrm{CT}$ was shown to increase image contrast by reducing both the radiation dosage needed and other toxic outcomes associated with using conventional contrast agents. ${ }^{442}$ The intense light scattering by gold nanoshells has been used to enhance image contrast in OCT to improve diagnostic imaging of tumours in a mice model as a result of nanoshell accumulation near the tumour site. ${ }^{444}$ Similarly, in PAI and PAT, the image of circulating gold nanoshells in the vasculature of a rat brain has been shown to enhance image contrast, allowing for a more detailed description of vasculature structures at greater depths. ${ }^{445}$ These applications of gold nanostructures are attractive because they provide higher photostability, quantum yield, detection sensitivity, stability in biological systems, and hydrophilicity than conventional organic dyes. Additionally, the intense scattering property of these gold colloids has played an important role in enhancement of image contrast in dark-field microscopy and dual-photon luminescence microscopy. ${ }^{456}$ The application of SERS in conjugation with NMN has also been described for the detection and intracellular molecular imaging of living cells and tissues. In this case, $60 \mathrm{~nm}$ GNPs coated with PEG and a tumour targeting antibody were able to detect tumours both in vitro and in vivo through SERS imaging. ${ }^{443}$ Here, GNPs were used to detect tumour biomarkers such as epidermal growth factor receptors on cancer cells and in xenograft tumour models more efficiently than NIR-emitting quantum dots. Specific cancer biomarkers like phospholipase Cg1 (PCg1) were also imaged in live HEK293 cell lines by NMN using SERS microscopy. ${ }^{457}$ SERS using GNPs attached to a Raman absorption reporter species has been demonstrated to highlight cellular and molecular structures which provide structural information on the cellular milieu inside live cells. ${ }^{458,459}$

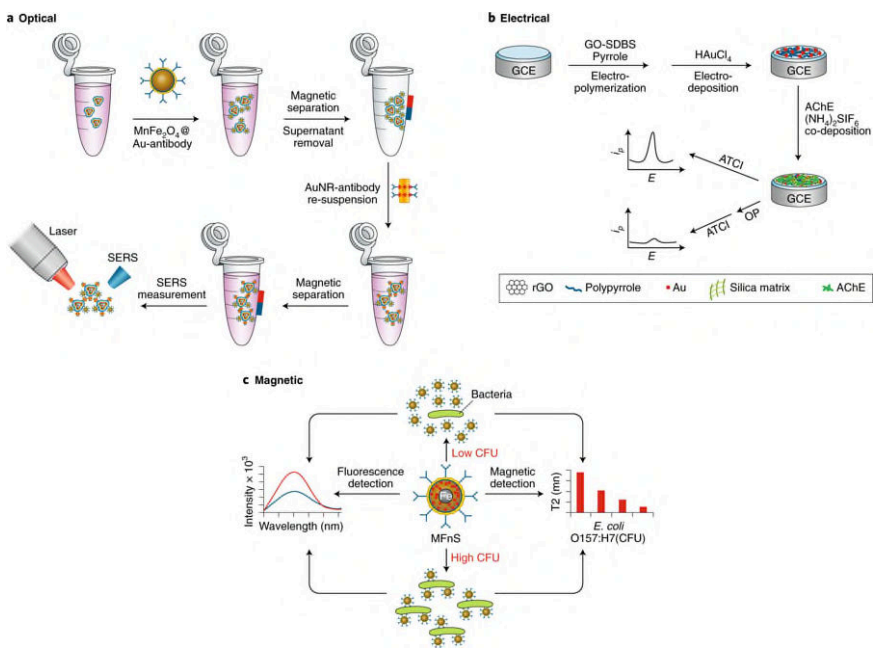

Fig. 11 (a) Surface-Enhanced Raman spectroscopy (SERS)-based detection of magnetically separated bacteria. (b) Preparation and use of a gold/reduced graphene oxide ( $\mathrm{rGO}$ ) nanocomposite-based biosensor and its application for the electrochemical detection of organophosphorus pesticides (OP). (c) Combined magneto-fluorescence approach for detection of bacteria using fluorophore labelled magnetic nanoparticles. Reprinted with permission from ref ${ }^{460}$ 


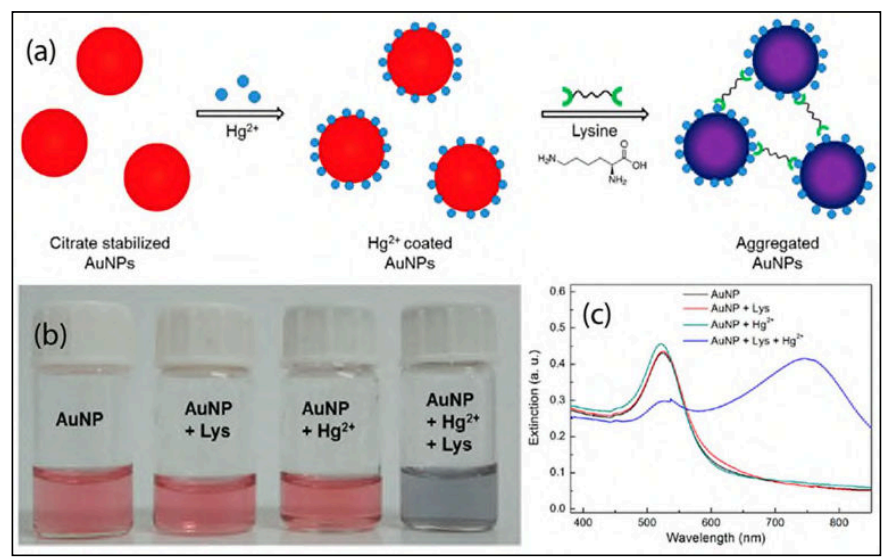

Fig. 12 Schematic representing the $\mathrm{Hg}^{2+}$ sensing mechanism of the colorimetric assay, (b) Photographs of AuNP solutions showing that the colour change occurring only in the presence of lysine $(0.4 \mathrm{mM})$ and $\mathrm{Hg}^{2+}(10 \mu \mathrm{M})$ and (c) extinction spectra of the AuNP solutions. Reproduced with permission from ref ${ }^{430}$

\section{Toxicity Challenge of NMN}

The incorporation of noble metal nanostructures in this diverse range of applications has led to increasing concern about their possible toxic impact on human beings and the environment (Fig. 13). In general, human beings are exposed to these nanomaterials via inhalation, ingestion, and dermal contact. ${ }^{461}$ Reports suggest that NMN tend to exert their toxicity when they either circulate in the bloodstream to organs, tissues and cells, or get absorbed in the spleen or bone marrow (Table 7). These absorbed nanomaterials evoke oxidative stress, immune response, cellular apoptosis, and DNA damage upon their entry into the mitochondria and the nuclei. ${ }^{462}$ Depending on the size of the nanoparticles, their typical fate after intravenously injection is summarised in Fig. 14. ${ }^{463}$ Clearance of NMN is a big challenge because these materials are not biodegradable and tend to accumulate in organs such as liver and spleen. ${ }^{464}$ The extended persistence of noble metal material can result in unforeseen toxic and adverse effect. The clearance of NPs depends on size, shape, and charges (Fig. 14). The two major clearance pathways of NPs are renal and hepatic pathways. The renal pathway is the rapid removal mechanism for clearing vascular compartments and is the desired clearance pathway for NPs. ${ }^{465}$ The general size threshold for renal clearance versus hepatic clearance is estimated to be 6 to $8 \mathrm{~nm}$ based on the permeability of the glomerular filtration barrier. ${ }^{465}$ Therefore one strategy to fabricate safe noble NPs is to make them extremely small. ${ }^{466,467}$ However, if the size of NPs becomes too small, they will be cleared from the circulation system prematurely, limiting their ability to carry out the designed action in vivo. 468 To overcome this dilemma, researchers have created so-called ultrasmall-in-nano architecture, where ultrasmall noble NPs are assembled into clusters by biodegradable agents. ${ }^{469,470}$ These nano-architectures are engineered to degrade over a certain period of time into NPs that are small enough to be excreted via the renal pathway. By using poly(L-lysine) as the assembly agent, Voliani and coworkers fabricated gold ultrasmall-innano architectures, which exhibit high photothermal efficiency and are promising for hyperthermia cancer treatment. 470

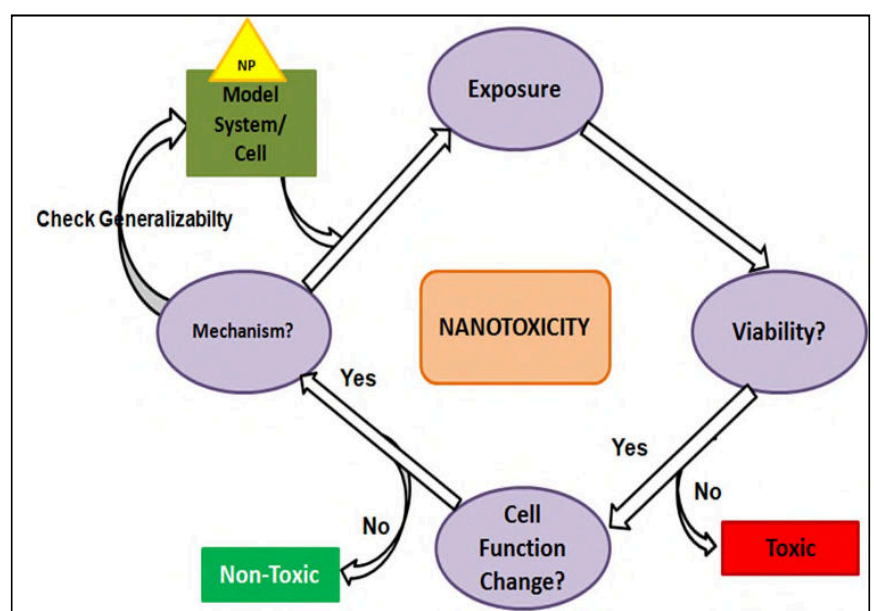

Fig. 13 Schematic representation of toxic effect on animal model system by metallic nanoparticle exposure.

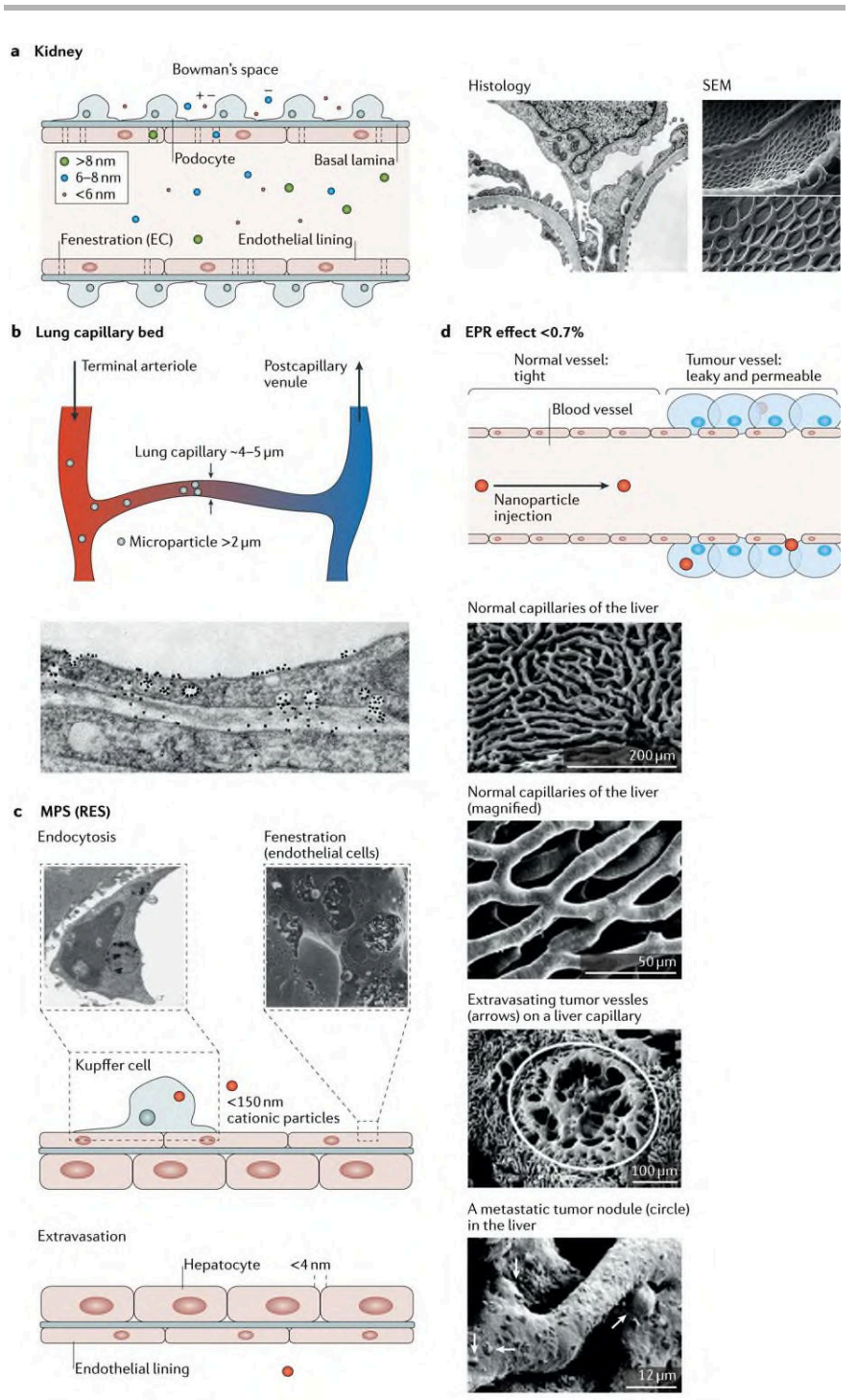

Fig. 14 The fate of nanoparticles and their accumulation and clearance sites. (a) Schematic illustration of kidney filtration or renal clearance of NPs, SEM images and histology of glomerular cell surface (endothelial lining). (b) Schematic illustration lung capillary beds filtration of NPs in the lungs. (c) Schematic illustration of nanoparticle clearance mechanism in liver via endocytosis by Kupffer cells (histology) and fenestration by endothelial cells (SEM); (d) Schematic illustration of the enhanced permeation and 
retention (EPR). SEM images of normal and cancerous tissues. MPS, mononuclear phagocytic system; RES, reticuloendothelial system. Reprinted with permission from ref 464

A size-dependent toxicity study was performed for GNPs on different cell lines such as fibroblast, epithelial cells, macrophages and melanoma cells. The study demonstrated that GNPs in the size range of 1.4-5 nm exhibit toxicity to all the above-mentioned cells, whereas $15 \mathrm{~nm}$ GNPs exposure to cells has no profound negative side effects even after 3 days of treatment. ${ }^{471,472}$ In a separate study, it was demonstrated that bare GNPs can induced cell-specific killing in a concentration dependent fashion and the accumulation of GNPs is localised in specific cellular domains (Fig. 15). ${ }^{194}$ Co-incubation of immune cells with citrate capped GNPs $(10 \mathrm{~nm})$ showed a little adverse effect on the immunocellular phenotypes and cell death, even after 48 hours of treatment, whereas the cytokine profile (IL-1, IL-6, IL-10 and IL-12) significantly changes which implicates the activation of the immune response upon GNPs treatment. ${ }^{473}$

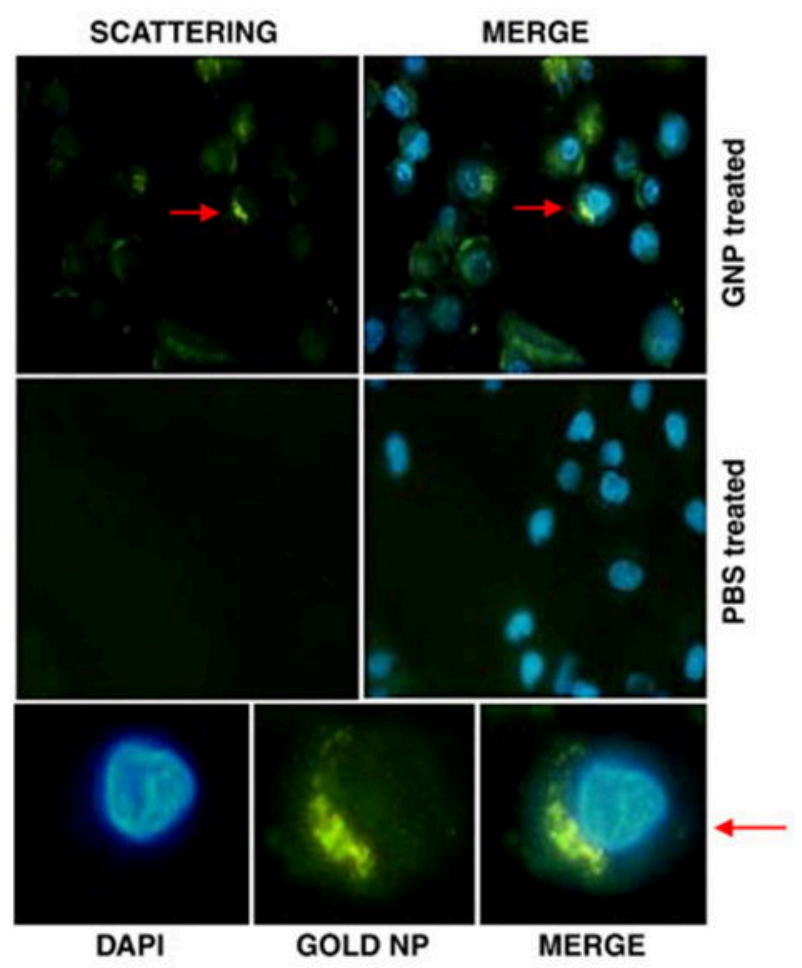

Fig. 15 Intracellular localisation of GNPs in A549 cells. Upper panel: The left column is the scattering of GNPs in the presence and absence of GNPs after excitation in the ultraviolet-visible range $(300-450 \mathrm{~nm})$. The right column shows the coexistence of nucleus (DAPI) and GNP scattering, in the presence and absence of GNPs. Lower panel: Magnified version of the red arrow marked cell. Reprinted with permission from ref 194

It has been reported that $15 \mathrm{~nm}$ GNPs coated with triphenylphosphine are fairly unreactive in comparison to $1.4 \mathrm{~nm}$ GNPs, which cause mitochondrial disruption and generation of free radicals. ${ }^{474}$ Similarly, stress related genes were up-regulated upon treatment with $1.4 \mathrm{~nm}$ GNPs, but not with $15 \mathrm{~nm}$ GNPs, as revealed by gene array analysis. ${ }^{474}$ In another study, the epigenetic modulation was observed in lung fibroblasts upon exposure to $20 \mathrm{~nm}$ GNPs. Here, GNP treatment caused up-regulation of microRNA-115, down regulation of PROS-1 gene and condensation of chromatin in the nucleus. ${ }^{475}$ Gold colloids of $20 \mathrm{~nm}$ in size can also trigger oxidative stress autophagy in human lung fibroblasts, ${ }^{476}$ which results in elevated lipid peroxidation levels, up-regulation of many autophagy related genes (ATG-7), increase in inflammatory enzyme cyclooxigenase-2 (COX-2), and polynucleotidekinase 3'-phosphate (PNK) gene production. ${ }^{476}$ In another example, keratinocytes (HaCaT), when exposed to $1.5 \mathrm{~nm}$ GNPs of different charge (positive, negative and neutral), exhibited a noticeable disruption of cellular structure in a dose-dependent manner. ${ }^{477}$ The surface charge of GNPs determines the extent of biological response, with charged GNPs promoting apoptosis whereas neutral GNPs lead to necrosis. ${ }^{478}$ Similarly, when positively charged GNPs $(2 \mathrm{~nm})$ of varying surface hydrophobicity were tested in HeLa cells, the experimental outcome revealed that the higher the hydrophobicity, the greater the observed acute toxicity and production of ROS. ${ }^{479}$ It was found that larger surface charge density (effective electric field) of negatively charged GNPs results in higher degree of fluctuation in the cytotoxicity (Fig. 16). ${ }^{480}$ Recent investigation has revealed that $10 \mathrm{~nm}$ GNPs are widely dispersed throughout the body, whereas larger particles were observed only in the liver, blood, and spleen. ${ }^{481}$ In a similar study, Wistar-Kyoto rats treated with 10, 20 and $50 \mathrm{~nm}$ GNPs for 3-7 days, showed hepatotoxicity and renal toxicity. Smaller sized GNPs had a more deleterious effect than larger particles with concomitant generation of ROS, which led to necrosis, renal tubular modulations, higher Kupffer cell hyperplasia, and central veins intimae disruption. ${ }^{482}$ In a separate observation, it was illustrated that GNPs stabilised with non-toxic stabilisers, in this case PEG, also showed size-dependent harmful effects. PEG-GNPs of smaller hydrodynamic diameter $(5,10$ and $30 \mathrm{~nm})$ accumulated in the liver and spleen, whereas much larger nanoparticles $(60 \mathrm{~nm})$ did not agglomerate in either of these organs. ${ }^{483}$ Size and surface charge distribution of GNPs also seem to have a profound negative influence on aquatic life. In a study conducted in vivo in a zebra fish model, it was observed that upon exposure to GNPs functionalised with cationic ligands $(\sim 1.3 \mathrm{~nm})$, fish embryos exhibited harmful side effects, which included morphological changes such as abnormally small and less pigmented eyes. ${ }^{484}$ Depending upon the route of administration, the toxicity profile of NMN varies. For instance, the toxicological features of $13.5 \mathrm{~nm}$ GNPs are determined on the route of administration. ${ }^{485}$ In this study, mice were injected with GNPs through (i) oral administration, (ii) intraperitoneal administration (IP), and (iii) tail vein injection. Tail vein injection showed minimal toxic effects to white blood cells and platelet counts, on the other hand GNPs administered orally or intraperitoneally exhibited higher level of toxicity with reduction in red blood cell count. ${ }^{485}$ The inclusion of AgNPs as an effective and tested antimicrobial agent and in other therapeutic applications has posed an intriguing question regarding their safety profile. The usage of AgNPs for industrial benefits has directly or indirectly presented an enormous threat to human health and environment alike. 486,487 The size, shape, and surface composition of AgNPs are the major contributing factors which affect their intracellular uptake and cytotoxicity. ${ }^{472}$ The noxious side effects of AgNPs have been studied thoroughly and in a detailed manner using numerous models like zebra fish, ${ }^{258}$ mice, rats, ${ }^{488}$ fresh water flea, ${ }^{489}$ stem-cells derived fibroblast, and $L 929$ cell line. ${ }^{490}$ The deleterious effect of AgNPs leads to harmful ROS generation and lipid peroxidation, which in turn causes DNA damage, necrosis, and apoptosis. ${ }^{491-493}$

In another independent study, it was concluded that AgNPs exert their cytotoxic effect in a size-, shape-, and dose-dependent manner on red blood cells and hepatic stellate cells. ${ }^{494}$ 


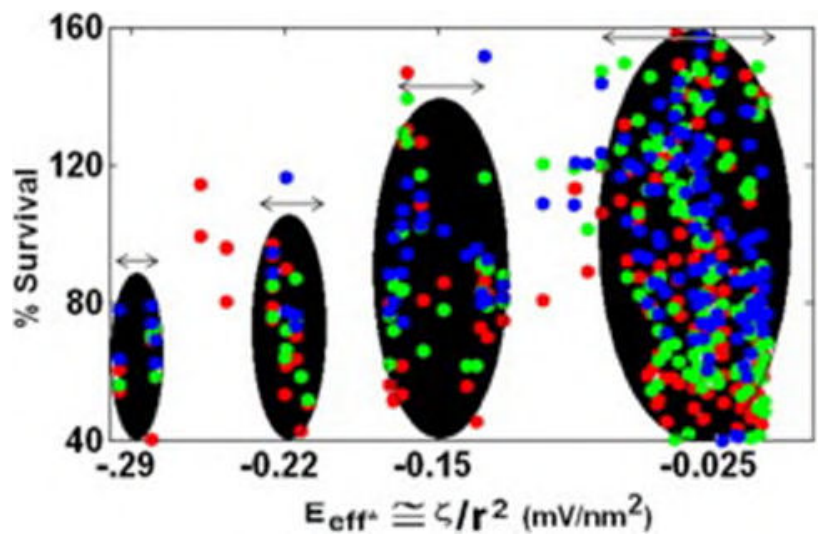

Fig. 16 Cellular survival rate as function of effective electric field for negatively charged GNPs. ${ }^{480}$

A Trojan-horse effect has been suggested in relation to the dose and time-dependent harmful side effects of AgNPs in the RAW246.7 cell line. In this case, after exposure to the nanoparticles, intracellular glutathione (GSH) level decreased, leading to a cascade of reactions which included increased secretion of nitric oxide and increased expression of TNF- $\alpha$ and matrix metalloproteinase, ${ }^{495}$ with a complete arrest of the cells at G1 phase of the cell cycle. A cytotoxic study of AgNPs in rat liver cells (BRL 3A) observed that after 24 hours of incubation with AgNPs, 496 there was a significant decrease in the functional attributes of mitochondria and leakage of lactate dehydrogenase (LDH). AgNP toxicity is mediated through oxidative stress, which increases ROS and decreases GSH production. ${ }^{496}$ Further investigations clarified the mechanism of cytotoxicity of AgNPs using human Chang liver cells, ${ }^{497}$ where it was elucidated that the AgNPs create a loss of mitochondrial membrane potential (MMP) by regulating the expression of the mitochondrial-dependent apoptotic pathway (Bax and $\mathrm{Bcl}-2$ ). ${ }^{497}$ This decrease in MMP results in the release of cytochrome $C$, which in turn activates caspase- 3 and caspase-9. In a more recent and detailed study, it was illustrated that AgNPs contribute to cellular damage. ${ }^{498}$ In this experiment, the bioenergetics of rat liver mitochondria was determined upon exposure to AgNPs and it was shown that AgNPs create an increase in the permeability of the inner mitochondrial membrane leading to mitochondrial depolarisation. This functional loss of mitochondrial activity results in an uncoupling effect on the oxidative phosphorylation system. ${ }^{498}$ AgNPs, when incubated with liver cells such as human Chang liver and Chinese hamster lung fibroblasts for 24 hours in a dose-dependent study, exhibited overloading of mitochondrial $\mathrm{Ca}^{2+}$ ions and greater endoplasmic reticulum (ER) stress. ${ }^{499}$ AgNPs can lead to increased phosphorylation of PERK and IRE1 along with an up-regulation of GRP78/Bip, which are ER stress markers, and altogether this induced ER stress upon AgNPs exposure ultimately leading to cellular apoptosis. ${ }^{499}$ AgNPs also exhibit cytotoxic effect in coronary endothelial cells (CECs) and aortic rings isolated from rats. ${ }^{500}$ In this study, it was observed that AgNPs induce
NO-dependent proliferation in a dose and size-dependent manner in $\mathrm{CECs}{ }^{500}$ Intravenous administration of AgNPs in Balb/c mice revealed that particles were mostly taken up by the reticuloendothelial system (spleen and liver). ${ }^{501}$ However, other reports suggest enhanced liver enzyme activity, higher uptake by local macrophages, increased inflammatory response, and liver damage. ${ }^{501}$ The effect of inhalation of AgNPs was performed using Sprague-Dawley rats with $18 \mathrm{~nm}$ AgNPs. ${ }^{502}$ The rats were exposed to the silver colloids in a wholebody inhalation chamber and the end results indicated that AgNPs reduce lung function and produce inflammatory lesions in the lungs. Oral administration of AgNPs $(60 \mathrm{~nm})$ in both male and female rats were extensively studied for a one-month period. ${ }^{488}$ This demonstrated that although AgNP treatment did not result in a significant change in body mass index, blood chemistry analysis revealed elevated liver damage as indicated by changes in alkaline phosphatase (ALP) and cholesterol in both groups. ${ }^{488}$

Size-dependent studies on the toxic effects of $\operatorname{AgNPs}(22,42,71,323$ $\mathrm{nm}$ ) by oral administration in mice showed increased toxicity with higher immune cell infiltration (B cell and higher CD8+ T cell) and increased level of TGF- $\beta$ and cytokine production (IL-10 and IL-12) in $22 \mathrm{~nm}$ AgNPs treated mice, whereas larger particles did not produce any alarming side effects. ${ }^{487}$ In another study, 20, 80 and $110 \mathrm{~nm}$ AgNPs were administered through tail veins and it was concluded that larger nanoparticles mostly accumulate in spleen followed by liver and lung, while $20 \mathrm{~nm}$ AgNPs mainly get deposited in the liver and then the kidney and spleen. ${ }^{503}$ Concentration dependent dermal toxicity of AgNPs conducted on male guinea pigs showed that at low dose, AgNP-treated animals exhibited a reduction in the thickness of the epidermis and dermis with an increase of inflammatory Langerhans cells. ${ }^{504}$ However, when given at higher dose, skin toxicity was apparently observed as a result of disrupted collagen fibres as well as higher macrophage infiltration with acidophilic cytoplasm. ${ }^{504}$

There are relatively fewer reports regarding the toxicity of PtNPs. One report studied the cytotoxic effects of 3 different noble metal nanoparticles (GNPs, AgNPs and PtNPs) using a zebra fish model. It was confirmed that PtNPs induce an increase in the hatching time, a drop-in heart rate, and a reduced touch response in this model. ${ }^{505}$ Another study conducted on mice reports that PtNPs cause acute hepatic injury as evidenced by an increased level of serum biomarkers of liver injury and inflammatory cytokines. ${ }^{506,507}$ Cytotoxic effect of PtNPs on skin suggest that nanoparticles of larger size and coated with an uncharged non-toxic stabiliser such as PVP have no significant toxic effect, while on the contrary, much smaller sized PtNPs showed deleterious side effects on primary keratinocytes leading to decreased cell metabolism. ${ }^{508}$ The presence of these nanomaterials in our day-to-day life is becoming inevitable and therefore a more detailed and thorough investigation needs to be conducted concerning the long-term usage of these engineered nanoparticles for the betterment of human life and society.

Table 7 Toxicity of noble metal nanoparticles.

\begin{tabular}{llc}
\hline $\begin{array}{l}\text { Type of noble metal } \\
\text { nanoparticles }\end{array}$ & Toxicity & References \\
\hline
\end{tabular}




\begin{tabular}{|c|c|c|}
\hline GNPs $(1.4-5 \mathrm{~nm})$ & Changes in cytokine profile (IL-1, IL-6, IL-10, IL-12) & $471-473$ \\
\hline GNPs $(1.4 \mathrm{~nm})$ & Mitochondrial disruption and generation of free radicals & 474 \\
\hline GNPs $(1.4 \mathrm{~nm})$ & Up-regulation of stress related genes & 474 \\
\hline GNPs $(20 \mathrm{~nm})$ & $\begin{array}{l}\text { Epigenetic modulation, up-regulation of microRNA-115, down regulation of PROS-1 gene } \\
\text { and condensation of chromatin in the nucleus }\end{array}$ & 475 \\
\hline GNPs $(20 \mathrm{~nm})$ & $\begin{array}{l}\text { Triggers oxidative stress autophagy in lung fibroblasts, increase in lipid peroxidation levels, } \\
\text { up-regulation of many autophagy related gene, increase in COX-2 and PNK gene production }\end{array}$ & 476 \\
\hline GNPs $(1.5 \mathrm{~nm})$ & Disruption of cellular structure & 477 \\
\hline $\begin{array}{l}\text { GNPs ( } 1.5 \mathrm{~nm} \text {, charged and } \\
\text { neutral) }\end{array}$ & Charged GNPs leads to apoptosis while uncharged GNPs leads to necrosis & 478 \\
\hline GNPs (2 nm) & Production of ROS, renal tubular modulations & 479,482 \\
\hline GNPs $(>10 \mathrm{~nm})$ & Deposited in liver, blood and spleen and showed hepatotoxicity and renal toxicity & 481,482 \\
\hline PEG-GNPs (5-30 nm) & Accumulates in the liver and spleen & 483 \\
\hline AgNPs & $\begin{array}{l}\text { ROS generation, lipid peroxidation, DNA damage, necrosis, apoptosis, decrease in } \\
\text { intracellular GSH levels, increased nitric oxide secretion, increased TNF- } \alpha \text { and increased } \\
\text { expression of matrix metalloproteinase }\end{array}$ & $491-495$ \\
\hline AgNPs & Loss of functional attributes of mitochondria and leakage of LDH & 496 \\
\hline AgNPs & Loss of MMP, regulation of expression of mitochondrial dependent apoptotic pathways & 497,498 \\
\hline AgNPs & Overloading of mitochondrial $\mathrm{Ca}^{2+}$ and up-regulation of ER stress biomarkers & 499 \\
\hline AgNPs & $\begin{array}{l}\text { Accumulates in liver and spleen, enhanced liver enzyme activity, higher uptake of local } \\
\text { macrophages, increased inflammatory response and liver damage }\end{array}$ & 501 \\
\hline AgNPs & Reduction in liver function and production of inflammatory lesions in the lungs & 502 \\
\hline AgNPs & Liver damage & 488 \\
\hline AgNPs $(22 \mathrm{~nm})$ & Higher immune cell infiltration and increased levels of TGF- $\beta$ and cytokine production & 487 \\
\hline AgNPs & Collagen fibres disruption and increase of inflammatory Langerhans cells & 504 \\
\hline PtNPs & Increases hatching time period, drop in heart rate in zebra fish model & 505 \\
\hline PtNPs & $\begin{array}{l}\text { Acute hepatic injury in liver, increased level of serum biomarkers of liver injury and } \\
\text { inflammatory cytokines }\end{array}$ & 506,507 \\
\hline PtNPs & Decrease of cellular metabolism & 508 \\
\hline
\end{tabular}




\section{Control Perspectives for the Use of NMN in Biomedical Field}

Nanobiotechnology faces a major challenge due to the uncontrolled and unethical use of NMN in a wide array of applications, which can lead to serious and deleterious toxicity to humans and environment. The unparalleled advantages presented by NMN would be of no use unless the burden related to their toxicity is addressed and resolved wisely. In order to nullify or minimise the side effects of NMN, various strategies are being employed by researchers worldwide, such as capping the nanomaterials with suitable compounds which aid in reducing the toxicity, preventing aggregation of noble metal nanoparticles, and last but not least, engineering the size, geometry, and biocompatibility of the nanoparticles for their successful applications in biotechnology.

Capping agents of nanomaterials contribute significantly in the activity profile of NMN. It has been reported that several attributes of capping agents increase the toxicity levels of NMN, hence in order to synthesise biocompatible nanoparticles, it is of primary importance that the capping agents are chosen wisely. In this regard, the use of non-toxic polyvinyl pyrrolidone (PVP) or polyvinyl alcohol (PVA) as a colloid stabiliser has been suggested by various research groups. PVP and gum Arabic (GA) coated AgNPs have shown promising result in reducing the toxic side effects of AgNPs. ${ }^{509}$ The wide acceptance of AgNPs as an antimicrobial agent has led to an enormous amount of AgNPs being released in the sewage water bodies, which results in the loss of flora and fauna. This harmful effect of AgNPs can be addressed by using sulphate anions in the sewage water thereby preventing or reducing the highly toxic effect of AgNPs. ${ }^{510}$ The functional attributes of NMN are directly positively proportional to their surface area. In the case of agglomeration or aggregation of NMN, reduction in surface area occurs and this is ultimately reflected in activity loss. Hence, the problem of particle aggregation should be one of the main focus for nanotechnologists. In one study, it has been shown that bovine serum albumin (BSA) provides a better colloidal stability to GNPs as a capping agent than does citrate anions. This is because the electrostatic repulsion offered by citrate anion can be compromised by $\mathrm{Na}^{+}$ions from the saline solution, which leads to aggregation of GNPs, while BSA adsorbed on to the surface of the GNPs helps to prevent agglomeration even under harsh conditions. ${ }^{511}$ In another study, the aggregation behaviour of platinum colloids was studied in solution using tetradecyltrimethylammonium bromide $\left(C_{14} T A B\right)$, cetyltrimethylammonium bromide $\left(C_{16} T A B\right)$ and nonylphenolethoxylate (NP9). TEM analysis revealed that the aggregation of PtNPs reduced considerably when CTAB and NP9 were used as surfactants. ${ }^{512}$ In addition to polyethylene glycol (PEG), PVP, natural polymers such as dextran, chitosan, pullulan, and surfactants like sodium oleate and dodecylamine have also shown promising results in preventing aggregation of NMN. ${ }^{513}$ Another important aspect of nanotechnology lies in controlling the size of the nanoparticles and maintaining reproducibility, since the chemical properties of bulk noble metals are different in comparison to their nanoscale version. Citrate ions represent one of the most widely accepted reductants for the synthesis of metallic nanomaterials. Size-controlled synthesis of AgNPs was successfully achieved using citrate ions owing to the slow crystal growth as a result of interaction between silver and citrate ions. ${ }^{514}$ In a separate experiment, sizecontrolled preparation of AgNPs was performed using silver and glucose under autoclaved condition. By regulating the concentration of glucose, the researchers were able to produce AgNPs of small, medium, and large sizes in a controlled and reproducible manner. Also, the caramel formed during the autoclaving of glucose functions as the stabilising agent for AgNPs, which in turn reduces their toxicity and increases the biocompatibility of the AgNPs. ${ }^{515}$ In a similar manner, size-controlled synthesis of GNPs was also conducted by UV irradiation at room temperature in the presence of air (5-20 nm). In this study, medium sized and larger GNPs $(25-110 \mathrm{~nm})$ were also successfully obtained by using ascorbic acid as a reductant. ${ }^{516}$ Therefore, by utilising the above-mentioned strategies for noble metal nanoparticles, the toxicity indices of these particles can be checked, which will help to expand their usefulness for biotechnological applications.

\section{Future prospects}

In this review, we have endeavoured to illustrate the ever growing and increasingly broad applications of noble metal nanomaterials in the therapeutics, diagnostics, and biosensing fields. Nanostructures have yielded significant positive results towards the betterment of human health, which is being reflected in their wide range of applications in the health sector.

Metallic nanoparticles have found significant utility over a diverse spectrum of biomedical activities such as imaging, sensing, and therapeutics. They have provided an invaluable advance in the detection, diagnosis, and therapy of different human cancers and this has led to the development of a completely new discipline, nano-oncology. Colloids of gold, silver, platinum, and palladium have been widely used and accepted in clinical trials for treatment of cancer. Nanostructures have attracted considerable interest as theranostic agents, but their pharmacokinetics, biodistribution, side effects, and safety profile within the human body, need more thorough investigation for future applications. ${ }^{360,517-519}$ The antibacterial, antifungal, antiviral, and antimicrobial properties of plasmonic nanomaterials are already well established and this could be a future strategic approach for the design and development of nanodrugs in the pharmaceutical industries. Toxicological studies based on numerous nanocomposites have provided sufficient data regarding their non-toxicity, but possible toxic side effects upon incorporation into the human body cannot be ruled out completely. The biocompatibility issue related to nanomaterials can be addressed by considering: (i) the dose of nanoparticles used and (ii) the surface modulation. These two aspects in conjunction provide a reliable and sufficient approach to the use of nanomaterials in clinical applications. It is of utmost importance to test nanoparticles and biological interactions in order to modify the nanostructures for optimal biocompatibility and thereby prevent damage to healthy tissues. There are other lesser known NMN such as Rh, Ru, Ir, and 
Os nanocomposites, whose diagnostic, sensing, and therapeutic abilities need to be understood in more detail and there is still much work to be done in the area to realise the full benefits of nanobiotechnology in the field of healthcare and environmental preservation.

\section{Acknowledgements}

APFT gratefully acknowledges funding from the Swedish Research Council VR 2015-04434 DIABETSENS. HP and MA acknowledge funding from MIIC, PDF grant and seed grant from Linköping University, Sweden. HP acknowledge EU H2O20 Marie Sklodowska- Curie Individual Fellowship (Grant no. 706694) from European Commission.

\section{References}

$1 \quad$ G. Schlamp, Noble Metals and Their Alloys, Mater. Sci. Technol., , DOI:10.1002/9783527603978.mst0087.

2 K. U. Kainer, Metal Matrix Composites: Custom-made Materials for Automotive and Aerospce Engineering, WileyVCH Verlag GmbH \& Co. KGaA, Weinheim, FRG, 2006.

3 J. Begerow, J. Neuendorf, M. Turfeld, W. Raab and L. Dunemann, Long-term urinary platinum, palladium, and gold excretion of patients after insertion of noble-metal dental alloys, Biomarkers, 1999, 4, 27-36. S. Caroli, A. Alimonti, F. Petrucci, B. Bocca, M. Krachler, F. Forastiere, M. T. Sacerdote and S. Mallone, Assessment of exposure to platinum-group metals in urban children, Spectrochim. Acta - Part B At. Spectrosc., 2001, 56, 12411248.

$6 \quad$ N. Sanvicens and M. P. Marco, Multifunctional nanoparticles - properties and prospects for their use in human medicine, Trends Biotechnol., 2008, 26, 425-433.

P. Eaton, I. Gomes, P. Quaresma, A. Miranda, E. Pereira, R. Franco, P. Baptista and G. Doria, Gold nanoparticles for the development of clinical diagnosis methods, Anal. Bioanal. Chem., 2007, 391, 943-950. X. Huang, P. K. Jain, I. H. El-Sayed and M. A. El-Sayed, Gold nanoparticles: Interesting optical properties and recent applications in cancer diagnostics and therapy, Nanomedicine, 2007, 2, 681-693. J. F. Hainfeld, F. A. Dilmanian, D. N. Slatkin and H. M. Smilowitz, Radiotherapy enhancement with gold nanoparticles, J. Pharm. Pharmacol., 2008, 60, 977-985. J. F. Hainfeld, D. N. Slatkin and H. M. Smilowitz, The use of gold nanoparticles to enhance radiotherapy in mice, Phys. Med. Biol., , DOI:10.1088/0031-9155/49/18/N03.

L. R. Hirsch, R. J. Stafford, J. A. Bankson, S. R. Sershen, B. Rivera, R. E. Price, J. D. Hazle, N. J. Halas and J. L. West, Nanoshell-mediated near-infrared thermal therapy of tumors under magnetic resonance guidance, Proc. Natl. Acad. Sci., 2003, 100, 13549-13554. G. Han, P. Ghosh and V. M. Rotello, Multi-functional gold nanoparticles for drug delivery., Adv. Exp. Med. Biol., 2007, 620, 48-56.

M. Thomas and A. M. Klibanov, Conjugation to gold nanoparticles enhances polyethylenimine's transfer of plasmid DNA into mammalian cells, Proc. Natl. Acad. Sci., 2003, 100, 9138-9143.

Q. Zhang, A. G. Schwartz, L. V. Wang, J. Chen, C. M. Cobley, C. Kim, Y. Xia, K. H. Song, J. Xie, M. Rycenga, Y. Cheng and M. S. Yavuz, Gold nanocages covered by smart polymers for controlled release with near-infrared light, Nat. Mater., 2009, 8, 935-939. D. A. Giljohann, J. E. Millstone, K. L. Young, M. R. Jones, C. A. Mirkin and D. S. Seferos, Plasmonically Controlled Nucleic Acid Dehybridization with Gold Nanoprisms, ChemPhysChem, 2009, 10, 1461-1465. S. Bhattacharyya, R. A. Kudgus, R. Bhattacharya and P. Mukherjee, Inorganic nanoparticles in cancer therapy, Pharm. Res., 2011, 28, 237-259.

17 P. Ghosh, G. Han, M. De, C. K. Kim and V. M. Rotello, Gold nanoparticles in delivery applications, Adv. Drug Deliv. Rev., 2008, 60, 1307-1315. N. Nishiyama, Nanomedicine: Nanocarriers shape up for long life, Nat. Nanotechnol., 2007, 2, 203-204. J. Xie, S. Lee and X. Chen, Nanoparticle-based theranostic agents, Adv. Drug Deliv. Rev., 2010, 62, 1064-1079. T. K. Sau, A. L. Rogach, F. Jäckel, T. A. Klar and J. Feldmann, Properties and applications of colloidal nonspherical noble metal nanoparticles, Adv. Mater., 2010, 22, 1805-1825. W. Parak, 2008 Gold : Chemistry, Materials and Catalysis Issue Please take a look at the full table of contents to access the, Chem. Soc. Rev., 2008, 37, 1909-30. W. Zhao, J. M. Karp, M. Ferrari and R. Serda, Bioengineering nanotechnology: towards the clinic, Nanotechnology, 2011, 22, 490201-490201. J. Conde, J. Rosa, J. C. Lima and P. V. Baptista, Nanophotonics for Molecular Diagnostics and Therapy Applications, Int. J. Photoenergy, 2012, 2012, 1-11. 
K. K. Jain, Nanomedicine: Application of nanobiotechnology in medical practice, Med. Princ. Pract., 2008, 17, 89101.

K. V. Mahesh, S. K. Singh and M. Gulati, A comparative study of top-down and bottom-up approaches for the preparation of nanosuspensions of glipizide, Powder Technol., 2014, 256, 436-449.

C. Li, J. H. Hsieh, M. Hung, B. Q. Huang, Y. L. Song, J. Denayer, P. Aubry, G. Bister, G. Spronck, P. Colson, B. Vertruyen, V. Lardot, F. Cambier, C. Henrist, R. Cloots, P. R. S. Patil, P. R. S. Patil, E. A. Ennaoui, D. Chatzikyriakou, A. Maho, R. Cloots, C. Henrist, G. Leftheriotis, M. Liveri, M. Galanopoulou, I. D. Manariotis, P. Yianoulis and Lado Filipovic, Ultrasonic spray pyrolysis for nanoparticles synthesis, J. Mater. Sci., 2004, 9, 3647-3657.

K. L. Lusker, J. R. Li and J. C. Garno, Nanostructures of functionalized gold nanoparticles prepared by particle lithography with organosilanes, Langmuir, 2011, 27, 13269-13275.

X. Yu, J. T. Pham, C. Subramani, B. Creran, Y. C. Yeh, K. Du, D. Patra, O. R. Miranda, A. J. Crosby and V. M. Rotello, Direct patterning of engineered ionic gold nanoparticles via nanoimprint lithography, Adv. Mater., 2012, 24, 63306334.

M. C. Lim, S. H. Kim, K. Park, Y. R. Kim, J. H. Kim, G. Ok and S. W. Choi, Facile synthesis of self-aligned gold nanoparticles by crack templated reduction lithography, RSC Adv., 2017, 7, 13228-13231.

G. L. Davies, J. O’Brien and Y. K. Gun'ko, Rare Earth Doped Silica Nanoparticles via Thermolysis of a Single Source Metallasilsesquioxane Precursor, Sci. Rep., 2017, 7, 1-8.

A. Tuchscherer, D. Schaarschmidt, S. Schulze, M. Hietschold and H. Lang, Gold nanoparticles generated by thermolysis of 'all-in-one' gold(i) carboxylate complexes, Dalt. Trans., 2012, 41, 2738-2746.

N. Kamil Othman, M. A. Abdul Hamid, E. Saion, A. Abedini and A. R. Daud, A review on radiation-induced nucleation and growth of colloidal metallic nanoparticles, Nanoscale Res. Lett., 2013, 8, 1-10.

J. Amblard, J. Belloni, H. Remita, J. Khatouri, C. de Cointet, M. Mostafavi, R. de Keyzer and M. Treguer, Dose Rate Effects on Radiolytic Synthesis of Gold-Silver Bimetallic Clusters in Solution, J. Phys. Chem. B, 2002, 102, 43104321.

M. Schulz-Dobrick, K. V. Sarathy and M. Jansen, Surfactant-free synthesis and functionalization of gold nanoparticles, J. Am. Chem. Soc., 2005, 127, 12816-12817.

J. Liu, K. He, W. Wu, T. Bin Song and M. G. Kanatzidis, In Situ Synthesis of Highly Dispersed and Ultrafine Metal Nanoparticles from Chalcogels, J. Am. Chem. Soc., 2017, 139, 2900-2903.

N. H. Chou, X. Ke, P. Schiffer and R. E. Schaak, Room-temperature chemical synthesis of shape-controlled indium nanoparticles, J. Am. Chem. Soc., 2008, 130, 8140-8141.

L. Rodríguez-Sánchez, M. C. Blanco and M. A. López-Quintela, Electrochemical Synthesis of Silver Nanoparticles, J. Phys. Chem. B, 2002, 104, 9683-9688.

A. Uehara, S. G. Booth, S. Y. Chang, S. L. M. Schroeder, T. Imai, T. Hashimoto, J. F. W. Mosselmans and R. A. W. Dryfe, Electrochemical Insight into the Brust-Schiffrin Synthesis of Au Nanoparticles, J. Am. Chem. Soc., 2015, 137, 15135-15144.

B. Wiley, Y. Yin, Y. Xiong, J. Chen, Y. Xia and S. Aloni, Understanding the Role of Oxidative Etching in the Polyol Synthesis of Pd Nanoparticles with Uniform Shape and Size, J. Am. Chem. Soc., 2005, 127, 7332-7333.

K. Okitsu, M. Ashokkumar and F. Grieser, Sonochemical synthesis of gold nanoparticles: Effects of ultrasound frequency, J. Phys. Chem. B, 2005, 109, 20673-20675.

A. M. Golsheikh, N. M. Huang, H. N. Lim and R. Zakaria, One-pot sonochemical synthesis of reduced graphene oxide uniformly decorated with ultrafine silver nanoparticles for non-enzymatic detection of $\mathrm{H} 2 \mathrm{O} 2$ and optical detection of mercury ions, RSC Adv., 2014, 4, 36401-36411.

J. Chen, P. Mela, M. Möller and M. C. Lensen, Microcontact deprinting: A technique to pattern gold nanoparticles, ACS Nano, 2009, 3, 1451-1456.

G. Walters and I. P. Parkin, The incorporation of noble metal nanoparticles into host matrix thin films: Synthesis, characterisation and applications, J. Mater. Chem., 2009, 19, 574-590.

D. Debnath, S. H. Kim and K. E. Geckeler, The first solid-phase route to fabricate and size-tune gold nanoparticles at room temperature, J. Mater. Chem., 2009, 19, 8810-8816.

S. De, R. Luque, M. Ojeda, C. Xu and A. M. Balu, Mechanochemical synthesis of advanced nanomaterials for catalytic applications, Chem. Commun., 2015, 51, 6698-6713.

C. Zhu, D. Du, A. Eychmüller and Y. Lin, Engineering Ordered and Nonordered Porous Noble Metal Nanostructures: Synthesis, Assembly, and Their Applications in Electrochemistry, Chem. Rev., 2015, 115, 8896-8943. P. Y. Ho, S. C. Yiu, D. Y. Wu, C. L. Ho and W. Y. Wong, One-step synthesis of platinum nanoparticles by pyrolysis of a polyplatinyne polymer, J. Organomet. Chem., 2017, 849-850, 4-9.

P. C. Lee and D. Meisel, Adsorption and surface-enhanced Raman of dyes on silver and gold sols, J. Phys. Chem., 1982, 86, 3391-3395.

X. Dong, X. Ji, H. Wu, L. Zhao, J. Li and W. Yang, Shape Control of Silver Nanoparticles by Stepwise Citrate Reduction: Supporting Information, J. Phys. Chem. C, 2009, 113, S1-S3. 
N. T. K. Thanh, N. Maclean and S. Mahiddine, Mechanisms of Nucleation and Growth of Nanoparticles in Solution, Chem. Rev., 2014, 114, 7610-7630. J. Turkevich, P. C. Stevenson and J. Hillier, A study of the nucleation and growth processes in the synthesis of colloidal gold, Discuss. Faraday Soc., 1951, 11, 55. G. FRENS, Controlled Nucleation for the Regulation of the Particle Size in Monodisperse Gold Suspensions, Nat. Phys. Sci., 1973, 241, 20-22. X. Ji, X. Song, J. Li, Y. Bai, W. Yang and X. Peng, Size control of gold nanocrystals in citrate reduction: The third role of citrate, J. Am. Chem. Soc., 2007, 129, 13939-13948. T. S. Ahmadi, Z. L. Wang, T. C. Green, A. Henglein and M. A. El-Sayed, Shape-Controlled Synthesis of Colloidal Platinum Nanoparticles, Science (80-. )., 1996, 272, 1924-1925. J. Zhang and J. Fang, A General Strategy for Preparation of Pt 3d-Transition Metal (Co, Fe, Ni) Nanocubes, J. Am. Chem. Soc., 2009, 131, 18543-18547. Controlling the Metal Distribution in Pt/M Catalysts, Ind. Eng. Chem. Res., 2019, 58, 2503-2513. D. S. Bae, E. J. Kim, J. H. Bang, S. W. Kim, K. S. Han, J. K. Lee, B. I. Kim and J. H. Adair, Synthesis and characterization of silver nanoparticles by a reverse micelle process, Met. Mater. Int., 2005, 11, 291-294. J. N. Solanki and Z. V. P. Murthy, Controlled size silver nanoparticles synthesis with water-in-oil microemulsion method: A topical review, Ind. Eng. Chem. Res., 2011, 50, 12311-12323. J. Rajput, A. R. Kumar and S. Zinjarde, A simple microemulsion based method for the synthesis of gold nanoparticles, Mater. Lett., 2009, 63, 2672-2675. K. Holmberg, Organic reactionsin microemulsions Krister, Curr. Opin. Colloid Interface Sci., 2003, 8, 145-155. V. Amendola and M. Meneghetti, What controls the composition and the structure of nanomaterials generated by laser ablation in liquid solution?, Phys. Chem. Chem. Phys., 2013, 15, 3027-3046.

C. Rehbock, V. Merk, L. Gamrad, R. Streubel and S. Barcikowski, Size control of laser-fabricated surfactant-free gold nanoparticles with highly diluted electrolytes and their subsequent bioconjugation, Phys. Chem. Chem. Phys., 2013, 15, 3057-3067.

T. Tsuji, T. Yahata, M. Yasutomo, K. Igawa, M. Tsuji, Y. Ishikawa and N. Koshizaki, Preparation and investigation of the formation mechanism of submicron-sized spherical particles of gold using laser ablation and laser irradiation in liquids, Phys. Chem. Chem. Phys., 2013, 15, 3099-3107.

E. Jiménez, K. Abderrafi, R. Abargues, J. L. Valdés and J. P. Martínez-Pastor, Laser-ablation-induced synthesis of SiO2-capped noble metal nanoparticles in a single step, Langmuir, 2010, 26, 7458-7463.

S. Horikoshi, T. Sumi and N. Serpone, A hybrid microreactor/microwave high-pressure flow system of a novel concept design and its application to the synthesis of silver nanoparticles, Chem. Eng. Process. Process Intensif., 2013, 73, 59-66.

J. A. Gerbec, D. Magana, A. Washington and G. F. Strouse, Microwave-enhanced reaction rates for nanoparticle synthesis, J. Am. Chem. Soc., 2005, 127, 15791-15800.

M. T. Reetz and W. Helbig, Size-Selective Synthesis of Nanostructured Transition Metal Clusters, J. Am. Chem. Soc., 1994, 116, 7401-7402.

G. R. Nasretdinova, R. R. Fazleeva, R. K. Mukhitova, I. R. Nizameev, M. K. Kadirov, A. Y. Ziganshina and V. V. Yanilkin, Electrochemical synthesis of silver nanoparticles in solution, Electrochem. commun., 2015, 50, 69-72. C. Li, T. Sato and Y. Yamauchi, Electrochemical Synthesis of One-Dimensional Mesoporous Pt Nanorods Using the Assembly of Surfactant Micelles in Confined Space, Angew. Chemie Int. Ed., 2013, 52, 8050-8053.

J. A. Dahl, B. L. S. Maddux and J. E. Hutchison, Toward greener nanosynthesis, Chem. Rev., 2007, 107, 2228-2269. P. Raveendran, J. Fu and S. L. Wallen, Completely 'Green' Synthesis and Stabilization of Metal Nanoparticles, J. Am. Chem. Soc., 2003, 125, 13940-13941.

N. Vigneshwaran, R. P. Nachane, R. H. Balasubramanya and P. V. Varadarajan, A novel one-pot 'green' synthesis of stable silver nanoparticles using soluble starch, Carbohydr. Res., 2006, 341, 2012-2018.

P. Raveendran, J. Fu and S. L. Wallen, A simple and 'green' method for the synthesis of Au, Ag, and Au-Ag alloy nanoparticles, Green Chem., 2006, 8, 34-38.

$H$. Huang and X. Yang, Synthesis of chitosan-stabilized gold nanoparticles in the absence/presence of tripolyphosphate, Biomacromolecules, 2004, 5, 2340-2346.

X. Yan, P. Zhu and J. Li, Self-assembly and application of diphenylalanine-based nanostructures, Chem. Soc. Rev., 2010, 39, 1877-1890.

A. Dasgupta, J. H. Mondal and D. Das, Peptide hydrogels, RSC Adv., 2013, 3, 9117-9149.

S. Roy, A. Dasgupta, S. Debnath, P. K. Das, D. Das and R. N. Mitra, Water Gelation of an Amino Acid-Based Amphiphile, Chem. - A Eur. J., 2006, 12, 5068-5074.

R. N. Mitra and P. K. Das, In situ preparation of gold nanoparticles of varying shape in molecular hydrogel of peptide amphiphiles, J. Phys. Chem. C, 2008, 112, 8159-8166. 

silver nanoparticles using Aspergillus flavus NJP08: A mechanism perspective, Nanoscale, 2011, 3, 635-641. T. Klaus, R. Joerger, E. Olsson and C.-G. Granqvist, Silver-based crystalline nanoparticles, microbially fabricated, Proc. Natl. Acad. Sci., 2002, 96, 13611-13614. A. R. Shahverdi, A. Fakhimi, H. R. Shahverdi and S. Minaian, Synthesis and effect of silver nanoparticles on the antibacterial activity of different antibiotics against Staphylococcus aureus and Escherichia coli, Nanomedicine Nanotechnology, Biol. Med., 2007, 3, 168-171.

D. Venkataraman, K. Kalimuthu, S. Gurunathan, R. Suresh Babu and M. Bilal, Biosynthesis of silver nanocrystals by Bacillus licheniformis, Colloids Surfaces B Biointerfaces, 2008, 65, 150-153. K. Kalishwaralal, V. Deepak, S. Ram Kumar Pandian and S. Gurunathan, Biological synthesis of gold nanocubes from Bacillus licheniformis, Bioresour. Technol., 2009, 100, 5356-5358. J. Venkatesan, P. Manivasagan, S. K. Kim, A. V. Kirthi, S. Marimuthu and A. A. Rahuman, Marine algae-mediated synthesis of gold nanoparticles using a novel Ecklonia cava, Bioprocess Biosyst. Eng., 2014, 37, 1591-1597. Y. Nangia, N. Wangoo, S. Sharma, J. S. Wu, V. Dravid, G. S. Shekhawat and C. Raman Suri, Facile biosynthesis of phosphate capped gold nanoparticles by a bacterial isolate Stenotrophomonas maltophilia, Appl. Phys. Lett., 2009, 94, 1-4.

B. Nair and T. Pradeep, Coalescence of Nanoclusters and Formation of Submicron Crystallites Assisted by Lactobacillus Strains, Cryst. Growth Des., 2002, 2, 293-298. S. V. Gaidhani, R. K. Yeshvekar, U. U. Shedbalkar, J. H. Bellare and B. A. Chopade, Bio-reduction of hexachloroplatinic acid to platinum nanoparticles employing Acinetobacter calcoaceticus, Process Biochem., 2014, 49, 2313-2319. deposition of platinum nanoparticles on the bacterium Shewanella algae, J. Biotechnol., 2007, 128, 648-653. P. Mukherjee, A. Ahmad, D. Mandal, S. Senapati, S. R. Sainkar, M. I. Khan, R. Ramani, R. Parischa, P. V. Ajayakumar, M. Alam, M. Sastry and R. Kumar, Bioreduction of AuCl4- lons by the Fungus, Verticillium sp. and Surface Trapping of the Gold Nanoparticles Formed D.M. and S.S. thank the Council of Scientific and Industrial Research (CSIR), Government of India, for financial assistance., Angew. Chemie Int. Ed., 2001, 40, 3585.

P. Mukherjee, S. Senapati, D. Mandal, A. Ahmad, M. I. I. Khan, R. Kumar and M. Sastry, Extracellular Synthesis of Gold Nanoparticles by the Fungus Fusarium oxysporum, ChemBioChem, 2002, 3, 461.

J. Xie, J. Y. Lee, D. I. C. Wang and Y. P. Ting, Silver Nanoplates: From Biological to Biomimetic Synthesis, ACS Nano, 2007, 1, 429-439. water green alga Pithophora oedogonia (Mont.) Wittrock and evaluation of their antibacterial activity, Appl. Nanosci., 2015, 5, 703-709. G. Singaravelu, J. S. Arockiamary, V. G. Kumar and K. Govindaraju, A novel extracellular synthesis of monodisperse gold nanoparticles using marine alga, Sargassum wightii Greville, Colloids Surfaces B Biointerfaces, 2007, 57, 97101.

. Peralta-Videa, P. Santiago, H. E. Troiani, J. G. Parsons, J. L. Gardea-Torresdey, M. J. Yacaman and E. Gomez, Formation and Growth of Au Nanoparticles inside Live Alfalfa Plants, Nano Lett., 2002, 2, 397-401. nanoparticles using Neem (Azadirachta indica) leaf broth, J. Colloid Interface Sci., 2004, 275, 496-502. J. Yu, D. Xu, H. N. Guan, C. Wang, L. K. Huang and D. F. Chi, Facile one-step green synthesis of gold nanoparticles using Citrus maxima aqueous extracts and its catalytic activity, Mater. Lett., 2016, 166, 110-112. G. Balasubramani, R. Ramkumar, N. Krishnaveni, R. Sowmiya, P. Deepak, D. Arul and P. Perumal, GC-MS analysis of bioactive components and synthesis of gold nanoparticle using Chloroxylon swietenia DC leaf extract and its larvicidal activity, J. Photochem. Photobiol. B Biol., 2015, 148, 1-8. M. Nasrollahzadeh, S. Mohammad Sajadi, A. Rostami-Vartooni, M. Alizadeh and M. Bagherzadeh, Green synthesis of the Pd nanoparticles supported on reduced graphene oxide using barberry fruit extract and its application as a recyclable and heterogeneous catalyst for the reduction of nitroarenes, J. Colloid Interface Sci., 2016, 466, 360368.

100 K. Elangovan, D. Elumalai, S. Anupriya, R. Shenbhagaraman, P. K. Kaleena and K. Murugesan, Phyto mediated biogenic synthesis of silver nanoparticles using leaf extract of Andrographis echioides and its bio-efficacy on anticancer and antibacterial activities, J. Photochem. Photobiol. B Biol., 2015, 151, 118-124. P. K. Jain, X. Huang, I. H. El-Sayed and M. A. El-Sayed, Noble Metals on the Nanoscale: Optical and Photothermal Properties and Some Applications in Imaging, Sensing, Biology, and Medicine, Acc. Chem. Res., 2008, 41, 15781586.

102 Y. H. Su, S.-L. Tu, S.-W. Tseng, Y.-C. Chang, S.-H. Chang and W.-M. Zhang, Influence of surface plasmon resonance on the emission intermittency of photoluminescence from gold nano-sea-urchins, Nanoscale, 2010, 2, 2639. 

on the Catalytic Activity of Noble Metal Nanoparticles on Reduced Graphene Oxide for Oxygen Evolution Reactions in Lithium-Air Batteries, Nano Lett., 2015, 15, 4261-4268.

104 M.-A. Neouze and U. Schubert, Surface Modification and Functionalization of Metal and Metal Oxide Nanoparticles by Organic Ligands, Monatshefte für Chemie - Chem. Mon., 2008, 139, 183-195. F. Mirkhalaf, J. Paprotny and D. J. Schiffrin, Synthesis of Metal Nanoparticles Stabilized by Metal-Carbon Bonds, J. Am. Chem. Soc., 2006, 128, 7400-7401.

K. Kawai, T. Narushima, K. Kaneko, H. Kawakami, M. Matsumoto, A. Hyono, H. Nishihara and T. Yonezawa, Synthesis and antibacterial properties of water-dispersible silver nanoparticles stabilized by metal-carbon $\sigma$ bonds, Appl. Surf. Sci., 2012, 262, 76-80.

107 V. K. R. Kumar and K. R. Gopidas, Synthesis and characterization of gold-nanoparticle-cored dendrimers stabilized by metal-carbon bonds, Chem. - An Asian J., 2010, 5, 887-896. J. J. Gooding, F. Mearns, W. Yang and J. Liu, Self-Assembled Monolayers into the 21st Century: Recent Advances and Applications, Electroanalysis, 2003, 15, 81-96.

109 L. Laurentius, S. R. Stoyanov, S. Gusarov, A. Kovalenko, R. Du, G. P. Lopinski and M. T. McDermott, Diazoniumderived aryl films on gold nanoparticles: Evidence for a carbon-gold covalent bond, ACS Nano, 2011, 5, 4219-4227. W. Chen, N. B. Zuckerman, X. Kang, D. Ghosh, J. P. Konopelski and S. Chen, Alkyne-Protected Ruthenium Nanoparticles, J. Phys. Chem. C, 2010, 114, 18146-18152. X. Kang, Y. Song and S. Chen, Nitrene-functionalized ruthenium nanoparticles, J. Mater. Chem., 2012, 22, 19250. P. Hu, Y. Song, L. Chen and S. Chen, Electrocatalytic activity of alkyne-functionalized AgAu alloy nanoparticles for oxygen reduction in alkaline media, Nanoscale, 2015, 7, 9627-9636.

113 R. A. Sperling and W. J. Parak, Surface modification, functionalization and bioconjugation of colloidal Inorganic nanoparticles, Philos. Trans. R. Soc. A Math. Phys. Eng. Sci., 2010, 368, 1333-1383. T. R. Ray, B. Lettiere, J. de Rutte and S. Pennathur, Quantitative Characterization of the Colloidal Stability of Metallic Nanoparticles Using UV-vis Absorbance Spectroscopy, Langmuir, 2015, 31, 3577-3586. E. Roduner, Size matters: Why nanomaterials are different, Chem. Soc. Rev., 2006, 35, 583-592. Philos. Trans. R. Soc. A Math. Phys. Eng. Sci., 2010, 368, 1385-1404. J. He, T. Kunitake and A. Nakao, Facile In Situ Synthesis of Noble Metal Nanoparticles in Porous Cellulose Fibers, Chem. Mater., 2003, 15, 4401-4406.

118 J. Gargiulo, S. Cerrota, E. Cortés, I. L. Violi and F. D. Stefani, Connecting Metallic Nanoparticles by Optical Printing, Nano Lett., 2016, 16, 1224-1229.

119 A. Kirillova, C. Schliebe, G. Stoychev, A. Jakob, H. Lang and A. Synytska, Hybrid Hairy Janus Particles Decorated with Metallic Nanoparticles for Catalytic Applications, ACS Appl. Mater. Interfaces, 2015, 7, 21218-21225. N. Chakroune, G. Viau, S. Ammar, L. Poul, D. Veautier, M. M. Chehimi, C. Mangeney, F. Villain and F. Fiévet, Acetate- and Thiol-Capped Monodisperse Ruthenium Nanoparticles: XPS, XAS, and HRTEM Studies, Langmuir, 2005, 21, 6788-6796.

V. L. Nguyen, M. Ohtaki, T. Matsubara, M. T. Cao and M. Nogami, New Experimental Evidences of Pt-Pd Bimetallic Nanoparticles with Core-Shell Configuration and Highly Fine-Ordered Nanostructures by High-Resolution Electron Transmission Microscopy, J. Phys. Chem. C, 2012, 116, 12265-12274.

J. C. Azcárate, M. H. Fonticelli and E. Zelaya, Radiation Damage Mechanisms of Monolayer-Protected Nanoparticles via TEM Analysis, J. Phys. Chem. C, 2017, 121, 26108-26116.

123 K. A. Perrine and A. V. Teplyakov, Metallic Nanostructure Formation Limited by the Surface Hydrogen on Silicon, Langmuir, 2010, 26, 12648-12658.

124 G. A. Wurtz, J. Hranisavljevic and G. P. Wiederrecht, Electromagnetic Scattering Pathways for Metallic Nanoparticles: A Near-Field Optical Study, Nano Lett., 2003, 3, 1511-1516. M. Glidden and M. Muschol, Characterizing Gold Nanorods in Solution Using Depolarized Dynamic Light Scattering, J. Phys. Chem. C, 2012, 116, 8128-8137. T. Zheng, S. Bott and Q. Huo, Techniques for Accurate Sizing of Gold Nanoparticles Using Dynamic Light Scattering with Particular Application to Chemical and Biological Sensing Based on Aggregate Formation, ACS Appl. Mater. Interfaces, 2016, 8, 21585-21594. J. D. Padmos and P. Zhang, Surface structure of organosulfur stabilized silver nanoparticles studied with X-ray absorption spectroscopy, J. Phys. Chem. C, 2012, 116, 23094-23101. G. Corthey, L. J. Giovanetti, J. M. Ramallo-López, E. Zelaya, A. A. Rubert, G. A. Benitez, F. G. Requejo, M. H. Fonticelli and R. C. Salvarezza, Synthesis and Characterization of Gold@Gold(I)-Thiomalate Core@Shell Nanoparticles, ACS Nano, 2010, 4, 3413-3421. H. Sharma and R. Singhal, Synthesis of Ag metallic nanoparticles by $120 \mathrm{keV} \mathrm{Ag} \mathrm{-} \mathrm{ion} \mathrm{implantation} \mathrm{in} \mathrm{TiO} 2$ matrix, Radiat. Eff. Defects Solids, 2017, 172, 896-902. 

Gold Nanoparticle with a Curvature-Dependent $\beta$-Sheet Structure, ACS Nano, 2012, 6, 1416-1426.

131 J. K. Navin, M. E. Grass, G. A. Somorjai and A. L. Marsh, Characterization of Colloidal Platinum Nanoparticles by MALDI-TOF Mass Spectrometry, Anal. Chem., 2009, 81, 6295-6299.

132 F. Laborda, J. Jiménez-Lamana, E. Bolea and J. R. Castillo, Selective identification, characterization and determination of dissolved silver(i) and silver nanoparticles based on single particle detection by inductively coupled plasma mass spectrometry, J. Anal. At. Spectrom., 2011, 26, 1362.

J. Lee, J. Yang, S. G. Kwon and T. Hyeon, Nonclassical nucleation and growth of inorganic nanoparticles, Nat. Rev. Mater., 2016, 1, 16034.

134 D. Parial, H. K. Patra, A. K. Dasgupta and R. Pal, Screening of different algae for green synthesis of gold nanoparticles, Eur. J. Phycol., 2012, 47, 22-29.

D. Parial, H. K. Patra, P. Roychoudhury, A. K. Dasgupta and R. Pal, Gold nanorod production by cyanobacteria-a green chemistry approach, J. Appl. Phycol., 2012, 24, 55-60.

136 M. Azharuddin, S. Sahana, H. Datta and A. K. Dasgupta, Corneal Penetration of Gold Nanoparticles-Therapeutic Implications, J. Nanosci. Nanotechnol., 2014, 14, 5669-5675.

137 H. K. Patra and A. P. F. Turner, The potential legacy of cancer nanotechnology: cellular selection, Trends Biotechnol., 2014, 32, 21-31.

138 H. M. E. Azzazy and M. M. H. Mansour, In vitro diagnostic prospects of nanoparticles, Clin. Chim. Acta, 2009, 403, $1-8$.

139 S. Kumar, N. Harrison, R. Richards-Kortum and K. Sokolov, Plasmonic nanosensors for imaging intracellular biomarkers in live cells, Nano Lett., 2007, 7, 1338-1343.

140 B. D. Chithrani and W. C. W. Chan, Elucidating the Mechanism of Cellular Uptake and Removal of Protein-Coated Gold Nanoparticles of Different Sizes and Shapes, Nano Lett., 2007, 7, 1542-1550.

141 W. Jiang, B. Y. S. Kim, J. T. Rutka and W. C. W. Chan, Nanoparticle-mediated cellular response is size-dependent, Nat. Nanotechnol., 2008, 3, 145-150.

142 J. Pelka, H. Gehrke, M. Esselen, M. Türk, M. Crone, S. Bräse, T. Muller, H. Blank, W. Send, V. Zibat, P. Brenner, R. Schneider, D. Gerthsen and D. Marko, Cellular Uptake of Platinum Nanoparticles in Human Colon Carcinoma Cells and Their Impact on Cellular Redox Systems and DNA Integrity, Chem. Res. Toxicol., 2009, 22, 649-659.

143 J. A. Khan, R. A. Kudgus, A. Szabolcs, S. Dutta, E. Wang, S. Cao, G. L. Curran, V. Shah, S. Curley, D. Mukhopadhyay, J. D. Robertson, R. Bhattacharya and P. Mukherjee, Designing Nanoconjugates to Effectively Target Pancreatic Cancer Cells In Vitro and In Vivo, PLoS One, 2011, 6, e20347.

144 C. M. Goodman, C. D. McCusker, T. Yilmaz and V. M. Rotello, Toxicity of Gold Nanoparticles Functionalized with Cationic and Anionic Side Chains, Bioconjug. Chem., 2004, 15, 897-900.

145 A. Verma and F. Stellacci, Effect of Surface Properties on Nanoparticleâ\&\#128;\&\#147;Cell Interactions, Small, 2010, 6, 12-21.

146 A. Verma, O. Uzun, Y. Hu, Y. Hu, H.-S. Han, N. Watson, S. Chen, D. J. Irvine and F. Stellacci, Surface-structureregulated cell-membrane penetration by monolayer-protected nanoparticles, Nat. Mater., 2008, 7, 588-595.

147 S. S. Agasti, A. Chompoosor, C.-C. You, P. Ghosh, C. K. Kim and V. M. Rotello, Photoregulated Release of Caged Anticancer Drugs from Gold Nanoparticles, J. Am. Chem. Soc., 2009, 131, 5728-5729.

148 C. K. Kim, P. Ghosh, C. Pagliuca, Z.-J. Zhu, S. Menichetti and V. M. Rotello, Entrapment of Hydrophobic Drugs in Nanoparticle Monolayers with Efficient Release into Cancer Cells, J. Am. Chem. Soc., 2009, 131, 1360-1361.

149 N. Ferrara and R. S. Kerbel, Angiogenesis as a therapeutic target, Nature, 2005, 438, 967-974.

150 N. Ferrara, R. D. Mass, C. Campa and R. Kim, Targeting VEGF-A to Treat Cancer and Age-Related Macular Degeneration, Annu. Rev. Med., 2007, 58, 491-504.

151 D. Bisacchi, R. Benelli, C. Vanzetto, N. Ferrari, F. Tosetti and A. Albini, Anti-angiogenesis and angioprevention: Mechanisms, problems and perspectives, Cancer Detect. Prev., 2003, 27, 229-238.

152 A. Grothey and E. Galanis, Targeting angiogenesis: Progress with anti-VEGF treatment with large molecules, Nat. Rev. Clin. Oncol., 2009, 6, 507-518.

153 T. A. Yap, C. P. Carden and S. B. Kaye, Beyond chemotherapy: targeted therapies in ovarian cancer, Nat. Rev. Cancer, 2009, 9, 167-181.

154 M. Ferrari, Cancer nanotechnology: opportunities and challenges, Nat. Rev. Cancer, 2005, 5, 161-171.

155 P. Mukherjee, R. Bhattacharya, P. Wang, L. Wang, S. Basu, J. A. Nagy, A. Atala, D. Mukhopadhyay and S. Soker, Antiangiogenic Properties of Gold Nanoparticles, Clin. Cancer Res., 2005, 11, 3530-3534.

156 R. Bhattacharya, P. Mukherjee, Z. Xiong, A. Atala, S. Soker and D. Mukhopadhyay, Gold Nanoparticles Inhibit VEGF165-Induced Proliferation of HUVEC Cells, Nano Lett., 2004, 4, 2479-2481.

157 R. R. Arvizo, S. Rana, O. R. Miranda, R. Bhattacharya, V. M. Rotello and P. Mukherjee, Mechanism of antiangiogenic property of gold nanoparticles: role of nanoparticle size and surface charge, Nanomedicine Nanotechnology, Biol. Med., 2011, 7, 580-587. 

properties of silver nanoparticles, Biomaterials, 2009, 30, 6341-6350. lymphocytic leukemia (BCLL): enhancing apoptosis, J. Nanobiotechnology, 2007, 5, 4.

160 R. Bhattacharya, C. R. Patra, R. Verma, S. Kumar, P. R. Greipp and P. Mukherjee, Gold Nanoparticles Inhibit the Proliferation of Multiple Myeloma Cells, Adv. Mater., 2007, 19, 711-716.

161 Y. He, Z. Du, S. Ma, Y. Liu, D. Li, H. Huang, S. Jiang, S. Cheng, W. Wu, K. Zhang and X. Zheng, Effects of greensynthesized silver nanoparticles on lung cancer cells in vitro and grown as xenograft tumors in vivo, Int. J. Nanomedicine, 2016, 11, 1879-1887.

162 J. A. Jacob and A. Shanmugam, Silver nanoparticles provoke apoptosis of Dalton's ascites lymphoma in vivo by mitochondria dependent and independent pathways, Colloids Surfaces B Biointerfaces, 2015, 136, 1011-1016. R. L. Manthe, S. P. Foy, N. Krishnamurthy, B. Sharma and V. Labhasetwar, Tumor Ablation and Nanotechnology, Mol. Pharm., 2010, 7, 1880-1898.

164 F. S. De Rosa and M. V. L. B. Bentley, Photodynamic therapy of skin cancers: Sensitizers, clinical studies and future directives, Pharm. Res., 2000, 17, 1447-1455.

165 S. Lal, S. E. Clare and N. J. Halas, Nanoshell-Enabled Photothermal Cancer Therapy: Impending Clinical Impact, Acc. Chem. Res., 2008, 41, 1842-1851.

166 R. Weissleder, A clearer vision for in vivo imaging, Nat. Biotechnol., 2001, 19, 316-317.

167 M. Johannsen, U. Gneveckow, L. Eckelt, A. Feussner, N. WaldÖFner, R. Scholz, S. Deger, P. Wust, S. A. Loening and A. Jordan, Clinical hyperthermia of prostate cancer using magnetic nanoparticles: Presentation of a new interstitial technique, Int. J. Hyperth., 2005, 21, 637-647.

168 J. J. Fairbairn, M. W. Khan, K. J. Ward, B. W. Loveridge, D. W. Fairbairn and K. L. O'Neill, Induction of apoptotic cell DNA fragmentation in human cells after treatment with hyperthermia, Cancer Lett., 1995, 89, 183-188.

169 C. M. Pitsillides, E. K. Joe, X. Wei, R. R. Anderson and C. P. Lin, Selective Cell Targeting with Light-Absorbing Microparticles and Nanoparticles, Biophys. J., 2003, 84, 4023-4032.

170 X. Huang, P. K. Jain, I. H. El-Sayed and M. A. El-Sayed, Determination of the Minimum Temperature Required for Selective Photothermal Destruction of Cancer Cells with the Use of Immunotargeted Gold Nanoparticles, Photochem. Photobiol., 2006, 82, 412.

V. Raji, J. Kumar, C. S. Rejiya, M. Vibin, V. N. Shenoi and A. Abraham, Selective photothermal efficiency of citrate capped gold nanoparticles for destruction of cancer cells, Exp. Cell Res., 2011, 317, 2052-2058.

172 D. Bartczak, O. L. Muskens, S. Nitti, T. Sanchez-Elsner, T. M. Millar and A. G. Kanaras, Interactions of Human Endothelial Cells with Gold Nanoparticles of Different Morphologies, Small, 2012, 8, 122-130.

173 G. von Maltzahn, J.-H. Park, A. Agrawal, N. K. Bandaru, S. K. Das, M. J. Sailor and S. N. Bhatia, Computationally Guided Photothermal Tumor Therapy Using Long-Circulating Gold Nanorod Antennas, Cancer Res., 2009, 69, 3892-3900.

174 M. A. Sirotkina, V. V. Elagin, M. V. Shirmanova, M. L. Bugrova, L. B. Snopova, V. A. Kamensky, V. A. Nadtochenko, N. N. Denisov and E. V. Zagaynova, OCT-guided laser hyperthermia with passively tumor-targeted gold nanoparticles, J. Biophotonics, 2010, 3, 718-727.

175 J. Cardinal, J. R. Klune, E. Chory, G. Jeyabalan, J. S. Kanzius, M. Nalesnik and D. A. Geller, Noninvasive radiofrequency ablation of cancer targeted by gold nanoparticles, Surgery, 2008, 144, 125-132.

176 S. H. Cho, Estimation of tumour dose enhancement due to gold nanoparticles during typical radiation treatments: a preliminary Monte Carlo study, Phys. Med. Biol., 2005, 50, N163-N173.

177 J. F. Hainfeld, F. A. Dilmanian, Z. Zhong, D. N. Slatkin, J. A. Kalef-Ezra and H. M. Smilowitz, Gold nanoparticles enhance the radiation therapy of a murine squamous cell carcinoma, Phys. Med. Biol., 2010, 55, 3045-3059.

178 T. Kong, J. Zeng, X. Wang, X. Yang, J. Yang, S. McQuarrie, A. McEwan, W. Roa, J. Chen and J. Z. Xing, Enhancement of Radiation Cytotoxicity in Breast-Cancer Cells by Localized Attachment of Gold Nanoparticles, Small, 2008, 4, 1537-1543.

179 L. E. Taggart, G. R. Dickson, S. J. Mcmahon, W. B. Hyland, M. F. Muir, C. Trainor, A. R. Hounsell, J. M. O. Sullivan, G. Schettino, F. J. Currell, D. G. Hirst and K. M. Prise, Cell type-dependent uptake, localization, and Cytotoxicity of 1. 9 Nm Gold Nanoparticles, Int. J. Nanomedicine, 2012, 7, 2673-2685.

180 R. R. Arvizo, O. R. Miranda, M. A. Thompson, C. M. Pabelick, R. Bhattacharya, J. D. Robertson, V. M. Rotello, Y. S. Prakash and P. Mukherjee, Effect of Nanoparticle Surface Charge at the Plasma Membrane and Beyond, Nano Lett., 2010, 10, 2543-2548.

181 E. C. Cho, Q. Zhang and Y. Xia, The effect of sedimentation and diffusion on cellular uptake of gold nanoparticles, Nat. Nanotechnol., 2011, 6, 385-391.

182 C. Minelli, S. B. Lowe and M. M. Stevens, Engineering nanocomposite materials for cancer therapy, Small, 2010, 6, 2336-2357. 

transferrin-containing gold nanoparticles, Proc. Natl. Acad. Sci., 2009, 107, 1235-1240. P. F. Jiao, H. Y. Zhou, L. X. Chen and B. Yan, Cancer-targeting multifunctionalized gold nanoparticles in imaging and therapy., Curr. Med. Chem., 2011, 18, 2086-102.

185 X. Li, H. Zhou, L. Yang, G. Du, A. S. Pai-Panandiker, X. Huang and B. Yan, Enhancement of cell recognition in vitro by dual-ligand cancer targeting gold nanoparticles, Biomaterials, 2011, 32, 2540-2545. D. P. O'Neal, L. R. Hirsch, N. J. Halas, J. D. Payne and J. L. West, Photo-thermal tumor ablation in mice using near infrared-absorbing nanoparticles, Cancer Lett., 2004, 209, 171-176.

187 K. Jans, G. Borghs, S. Muyldermans, G. Maes, L. Lagae, B. Van de Broek, H.-L. Gijs, A. D'Hollander and N. Devoogdt, Specific Cell Targeting with Nanobody Conjugated Branched Gold Nanoparticles for Photothermal Therapy, ACS Nano, 2011, 5, 4319-4328.

C. Loo, A. Lowery, N. Halas, J. West and R. Drezek, Immunotargeted Nanoshells for Integrated Cancer Imaging and Therapy, Nano Lett., 2005, 5, 709-711. W.-K. Rhim, J.-S. Kim and J.-M. Nam, Lipid-Gold-Nanoparticle Hybrid-Based Gene Delivery, Small, 2008, 4, 16511655.

190 F. Chen, Z. Zhong, C. Hu, R. Zhuo and Q. Peng, Low Molecular Weight Polyethylenimine Conjugated Gold Nanoparticles as Efficient Gene Vectors, Bioconjug. Chem., 2010, 21, 836-843. A. M. Chen, O. Taratula, D. Wei, H. Yen, T. Thomas, T. J. Thomas, T. Minko and H. He, Labile Catalytic Packaging of DNA / siRNA : Control of Gold Nanoparticles " out " of, 2010, 4, 3679-3688. Y. Cheng, A. C. Samia, J. Li, M. E. Kenney, A. Resnick and C. Burda, Delivery and efficacy of a cancer drug as a function of the bond to the gold nanoparticle surface, Langmuir, 2010, 26, 2248-2255.

193 S. D. Brown, P. Nativo, J. A. Smith, D. Stirling, P. R. Edwards, B. Venugopal, D. J. Flint, J. A. Plumb, D. Graham and N. J. Wheate, Gold nanoparticles for the improved anticancer drug delivery of the active component of oxaliplatin, $J$. Am. Chem. Soc., 2010, 132, 4678-4684.

194 H. K. Patra, S. Banerjee, U. Chaudhuri, P. Lahiri and A. K. Dasgupta, Cell selective response to gold nanoparticles, Nanomedicine Nanotechnology, Biol. Med., 2007, 3, 111-119.

195 N. L. Rosi, D. A. Giljohann, C. S. Thaxton, A. K. R. Lytton-Jean, M. S. Han and C. A. Mirkin, Oligonucleotide-Modified Gold Nanoparticles for Intracellular Gene Regulation (Supporting Online Material), Science (80-. )., 2006, 312, 1027. D. A. Giljohann, D. S. Seferos, A. E. Prigodich, P. C. Patel and C. A. Mirkin, Gene regulation with polyvalent siRNAnanoparticle conjugates. (Supplementary Information), J. Am. Chem. Soc., 2009, 131, 2072-3.

197 P. S. Ghosh, C. Kim, G. Han, N. S. Forbes and V. M. Rotello, Efficient Gene Delivery Vectors by Tuning the Surface Charge Density of, J. Am. Chem. Soc., 2008, 2, 2213-2218.

198 C. K. Kim, P. Ghosh and V. M. Rotello, Multimodal drug delivery using gold nanoparticles, Nanoscale, 2009, 1, 6167.

199 M. E. Kenney, J. P. Basilion, C. Burda, A.-M. Broome, Y. Cheng and J. D. Meyers, Deep Penetration of a PDT Drug into Tumors by Noncovalent Drug-Gold Nanoparticle Conjugates, J. Am. Chem. Soc., 2011, 133, 2583-2591.

200 B. Kim, N. S. Forbes, V. M. Rotello, G. Han, R. Hong and J. M. Fernández, Glutathione-Mediated Delivery and Release Using Monolayer Protected Nanoparticle Carriers, J. Am. Chem. Soc., 2006, 128, 1078-1079. H. Ishida, J. Nakanishi, T. Shimizu, K. Yamaguchi, Y. Horiike, H. Nakayama and Y. Kikuchi, Light-Regulated Activation of Cellular Signaling by Gold Nanoparticles That Capture and Release Amines, J. Am. Chem. Soc., 2009, 131, 38223823.

202 J. H. Bahng, P. Podsiadlo, N. A. Kotov, N. W. S. Kam, V. A. Sinani and J. Lee, Gold Nanoparticles Enhance the AntiLeukemia Action of a 6-Mercaptopurine Chemotherapeutic Agent, Langmuir, 2007, 24, 568-574.

203 B. Kim, G. Han, B. J. Toley, C. K. Kim, V. M. Rotello and N. S. Forbes, Tuning payload delivery in tumour cylindroids using gold nanoparticles, Nat. Nanotechnol., 2010, 5, 465-472.

204 A. C. Anselmo and S. Mitragotri, A Review of Clinical Translation of Inorganic Nanoparticles, AAPS J., 2015, 17, 1041-1054.

205 D. Paithankar, B. H. Hwang, G. Munavalli, A. Kauvar, J. Lloyd, R. Blomgren, L. Faupel, T. Meyer and S. Mitragotri, Ultrasonic delivery of silica-gold nanoshells for photothermolysis of sebaceous glands in humans: Nanotechnology from the bench to clinic, J. Control. Release, 2015, 206, 30-36. Y. Ge, N. Gu, W. Ma, Y. Zhang, X. Zhou, Y. Zhao, H. Zhou, Z. Huang, D. Guo, J. Wu, X. Zhang and L. Zhu, Antileukemia activity of PVP-coated silver nanoparticles via generation of reactive oxygen species and release of silver ions, Biomaterials, 2013, 34, 7884-7894.

207 J. A. Coulter, W. B. Hyland, J. Nicol and F. J. Currell, Radiosensitising nanoparticles as novel cancer therapeutics Pipe dream or realistic prospect?, Clin. Oncol., 2013, 25, 593-603.

208 W. He, Y. T. Zhou, W. G. Wamer, M. D. Boudreau and J. J. Yin, Mechanisms of the pH dependent generation of hydroxyl radicals and oxygen induced by Ag nanoparticles, Biomaterials, 2012, 33, 7547-7555. 

N. Thajuddin, K. Premkumar and A. Ganapathi, Biogenic silver nanoparticles for cancer treatment: An experimental report, Colloids Surfaces B Biointerfaces, 2013, 106, 86-92.

210 S. Gurunathan, J. W. Han, A. A. Dayem, V. Eppakayala, J. H. Park, S. G. Cho, K. J. Lee and J. H. Kim, Green synthesis of anisotropic silver nanoparticles and its potential cytotoxicity in human breast cancer cells (MCF-7), J. Ind. Eng. Chem., 2013, 19, 1600-1605.

211 J.-H. Kim, V. Eppakayala, M. Jeyaraj, J. W. Han and S. Gurunathan, Cytotoxicity of Biologically Synthesized Silver Nanoparticles in MDA-MB-231 Human Breast Cancer Cells, Biomed Res. Int., 2013, 2013, 1-10.

212 J. Liu, Y. Zhao, Q. Guo, Z. Wang, H. Wang, Y. Yang and Y. Huang, TAT-modified nanosilver for combating multidrugresistant cancer, Biomaterials, 2012, 33, 6155-6161.

213 K. R. Barnes and S. J. Lippard, Cisplatin and related anticancer drugs: recent advances and insights., Met. Ions Biol. Syst., 2004, 42, 143-177.

214 H. Gehrke, J. Pelka, C. G. Hartinger, H. Blank, F. Bleimund, R. Schneider, D. Gerthsen, S. Bräse, M. Crone, M. Türk and D. Marko, Platinum nanoparticles and their cellular uptake and DNA platination at non-cytotoxic concentrations, Arch. Toxicol., 2011, 85, 799-812.

215 E. Porcel, S. Liehn, H. Remita, N. Usami, K. Kobayashi, Y. Furusawa, C. Le Sech and S. Lacombe, Platinum nanoparticles: A promising material for future cancer therapy?, Nanotechnology, 2010, 21, 085103. C. Le Sech, K. Kobayashi, K. Takakura, H. Frohlich and N. Usami, Enhancement of X-Ray-Induced Breaks in DNA Bound to Molecules Containing Platinum: A Possible Application to Hadrontherapy, Radiat. Res., 2006, 157, 32-37. P. V. Asharani, N. Xinyi, M. P. Hande and S. Valiyaveettil, DNA damage and p53-mediated growth arrest in human cells treated with platinum nanoparticles, Nanomedicine, 2010, 5, 51-64.

218 K. Eid, A. Eldesouky, A. Fahmy, A. Shahat and R. AbdElaal, Calcium Phosphate Scaffold Loaded with Platinum Nanoparticles for Bone Allograft, Am. J. Biomed. Sci., 2013, 242-249.

219 J. Nellore, C. Pauline and K. Amarnath, Bacopa monnieri Phytochemicals Mediated Synthesis of Platinum Nanoparticles and Its Neurorescue Effect on 1-Methyl Parkinsonism in Zebrafish, J. Neurodegener. Dis., 2013, 2013, 1-8.

220 W. K. Kim, J. C. Kim, H. J. Park, O. J. Sul, M. H. Lee, J. S. Kim and H. S. Choi, Platinum nanoparticles reduce ovariectomy-induced bone loss by decreasing osteoclastogenesis, Exp. Mol. Med., 2012, 44, 432-439.

221 L. Zhang, L. Laug, W. Münchgesang, E. Pippel, U. Gösele, M. Brandsch and M. Knez, Reducing stress on cells with apoferritin-encapsulated platinum nanoparticles, Nano Lett., 2010, 10, 219-223.

222 T. Shimizu, Y. Miyamoto, T. Kondo, A. Honda, Y. Yoshihisa, H. Shimizu, Q.-L. Zhao, R. Abe, K. Matsui and T. Makino, Protective effects of platinum nanoparticles against UV-light-induced epidermal inflammation, Exp. Dermatol., 2010, 19, 1000-1006.

223 R. R. Arvizo, S. Bhattacharyya, R. A. Kudgus, K. Giri, R. Bhattacharya and P. Mukherjee, Intrinsic therapeutic applications of noble metal nanoparticles: Past, present and future, Chem. Soc. Rev., 2012, 41, 2943-2970. Q. Wang, X. Cui, J. Chen, X. Zheng, C. Liu, T. Xue, H. Wang, Z. Jin, L. Qiao and W. Zheng, Well-dispersed palladium nanoparticles on graphene oxide as a non-enzymatic glucose sensor, RSC Adv., 2012, 2, 6245-6249. S. Mubeen, T. Zhang, B. Yoo, M. A. Deshusses and N. V. Myung, Palladium nanoparticles decorated single-walled carbon nanotube hydrogen sensor, J. Phys. Chem. C, 2007, 111, 6321-6327.

226 B. L. French, L. M. Davis, E. S. Munzinger, J. W. J. Slavin, P. C. Christy, D. W. Thompson and R. E. Southward, Palladium-polyimide nanocomposite membranes: Synthesis and characterization of reflective and electrically conductive surface-metallized films, Chem. Mater., 2005, 17, 2091-2100.

227 E. S. Snow, B. V Shanabrook, D. Park, R. Leon, D. Leonard, J. L. Merz, P. M. Petroff, E. Betzig, T. D. Harris, L. N. Pfeiffer, C. P. Lutz, D. M. Eigler, G. Goldoni, F. Rossi, E. Molinari, G. Martino, R. Girlanda, A. Knorr, P. Thomas, S. W. Koch, O. Hollricher, O. Marti, R. D. Grober, D. Gammon, D. S. Katzer, T. Gmitter, J. P. Harbison, R. Bhat, P. Wolanin, A. Gafni, D. G. Steel, M. Jiang, D. G. Steel, R. Zimmermann, F. Spectroscopy and M. Sargent, Hydrogen Sensors and Switches from Electrodeposited Palladium Mesowire Arrays, 2001, 293, 2227-2231.

228 L. M. Davis, J. M. Compton, D. E. Kranbuehl, D. W. Thompson and R. E. Southward, Reflective and electrically conductive palladium surface-metallized polyimide nanocomposite membranes, J. Appl. Polym. Sci., 2006, 102, 2708-2716.

229 Z. Chang, H. Fan, K. Zhao, M. Chen, P. He and Y. Fang, Electrochemical DNA biosensors based on palladium nanoparticles combined with carbon nanotubes, Electroanalysis, 2008, 20, 131-136. P. T. Finger, A. Berson and A. Szechter, Palladium-103 plaque radiotherapy for choroidal melanoma, Ophthalmology, 2003, 106, 606-613. B. Woodward, Platin. Met. Rev., 2012, 56, 213-217.

232 J. T. Weiss, J. C. Dawson, K. G. Macleod, W. Rybski, C. Fraser, C. Torres-Sánchez, E. E. Patton, M. Bradley, N. O. Carragher and A. Unciti-Broceta, Extracellular palladium-catalysed dealkylation of 5-fluoro-1-propargyl-uracil as a bioorthogonally activated prodrug approach, Nat. Commun., 2014, 5, 3277. 

O. Carragher, Development and Bioorthogonal Activation of Palladium-Labile Prodrugs of Gemcitabine, J. Med. Chem., 2014, 57, 5395-5404.

234 X. Huang, S. Tang, X. Mu, Y. Dai, G. Chen, Z. Zhou, F. Ruan, Z. Yang and N. Zheng, Freestanding palladium nanosheets with plasmonic and catalytic properties, Nat. Nanotechnol., 2011, 6, 28-32. X. Huang, S. Tang, J. Yang, Y. Tan and N. Zheng, Etching growth under surface confinement: An effective strategy to prepare mesocrystalline Pd nanocorolla, J. Am. Chem. Soc., 2011, 133, 15946-15949. S. Tang, X. Huang and N. Zheng, Silica coating improves the efficacy of Pd nanosheets for photothermal therapy of cancer cells using near infrared laser, Chem. Commun., 2011, 47, 3948-3950.

237 S. Tang, M. Chen and N. Zheng, Sub-10-nm Pd nanosheets with renal clearance for efficient near-infrared photothermal cancer therapy, Small, 2014, 10, 3139-3144. Nanoparticles as a Platform for the Chemo-Photothermal Treatment of Cancer Cells, Small, 2012, 8, 3816-3822. A. M. Watson, X. Zhang, R. Alcaraz De La Osa, J. M. Sanz, F. González, F. Moreno, G. Finkelstein, J. Liu and H. O. Everitt, Rhodium nanoparticles for ultraviolet plasmonics, Nano Lett., 2015, 15, 1095-1100.

240 H. Gu, P. L. Ho, E. Tong, L. Wang and B. Xu, Presenting vancomycin on nanoparticles to enhance antimicrobial activities, Nano Lett., 2003, 3, 1261-1263.

241 A. Rai, A. Prabhune and C. C. Perry, Antibiotic mediated synthesis of gold nanoparticles with potent antimicrobial activity and their application in antimicrobial coatings, J. Mater. Chem., 2010, 20, 6789-6798.

242 C. C. Berry, J. M. de la Fuente, M. Mullin, S. Wai Ling Chu and A. S. G. Curtis, Notice of Violation of IEEE Publication Principles Nuclear Localization of HIV-1 Tat Functionalized Gold Nanoparticles, IEEE Trans. Nanobioscience, 2007, 6, 262-269.

243 M.-C. Bowman, T. E. Ballard, C. J. Ackerson, D. L. Feldheim, D. M. Margolis and C. Melander, Inhibition of HIV Fusion with Multivalent Gold Nanoparticles, J. Am. Chem. Soc., 2008, 130, 6896-6897.

244 J. M. B. Res, R. Kesarkar, G. Oza, S. Pandey, R. Dahake, S. Mukherjee, A. Chowdhary, M. Sharon, J. Phata and W. Ambernath, Gold nanoparticles : effective as both entry inhibitors and virus neutralizing agents against HIV, J. Microbiol. Biotech. Res., 2012, 2, 276-283.

245 B. Arnáiz, O. Martínez-Ávila, J. M. Falcon-Perez and S. Penadés, Cellular uptake of gold nanoparticles bearing HIV gp120 oligomannosides, Bioconjug. Chem., 2012, 23, 814-825.

246 M. Gajendiran, S. M. J. Yousuf, V. Elangovan and S. Balasubramanian, Gold nanoparticle conjugated PLGA-PEG-SAPEG-PLGA multiblock copolymer nanoparticles: Synthesis, characterization, in vivo release of rifampicin, J. Mater. Chem. B, 2014, 2, 418-427.

247 X. Zhou, X. Zhang, X. Yu, X. Zha, Q. Fu, B. Liu, X. Wang, Y. Chen, Y. Chen, Y. Shan, Y. Jin, Y. Wu, J. Liu, W. Kong and J. Shen, The effect of conjugation to gold nanoparticles on the ability of low molecular weight chitosan to transfer DNA vaccine, Biomaterials, 2008, 29, 111-117.

248 Y. S. Chen, Y. C. Hung, W. H. Lin and G. S. Huang, Assessment of gold nanoparticles as a size-dependent vaccine carrier for enhancing the antibody response against synthetic foot-and-mouth disease virus peptide, Nanotechnology, 2010, 21, 195101.

249 I.-H. Lee, S.-H. Im, S. Kim, H.-K. Kwon, S. Jon, T.-S. Lee, M. K. Yu, S. An, J.-H. Lee and D. Kim, Imageable AntigenPresenting Gold Nanoparticle Vaccines for Effective Cancer Immunotherapy In Vivo, Angew. Chemie Int. Ed., 2012, 51, 8800-8805.

250 R. Cao-Milán and L. M. Liz-Marzán, Gold nanoparticle conjugates: recent advances toward clinical applications, Expert Opin. Drug Deliv., 2014, 11, 741-752.

251 J. P. M. Almeida, A. Y. Lin, E. R. Figueroa, A. E. Foster and R. A. Drezek, In vivo Gold Nanoparticle Delivery of Peptide Vaccine Induces Anti-Tumor Immune Response in Prophylactic and Therapeutic Tumor Models, Small, 2015, 11, 1453-1459.

252 N. Leys, R. Van Houdt, S. Silver, J. Mahillon and K. Mijnendonckx, Antimicrobial silver: uses, toxicity and potential for resistance, BioMetals, 2013, 26, 609-621.

253 M. Rai, K. Kon, A. Ingle, N. Duran, S. Galdiero and M. Galdiero, Broad-spectrum bioactivities of silver nanoparticles: The emerging trends and future prospects, Appl. Microbiol. Biotechnol., 2014, 98, 1951-1961.

254 M. E. Samberg, P. E. Orndorff and N. A. Monteiro-Riviere, Antibacterial efficacy of silver nanoparticles of different sizes, surface conditions and synthesis methods, Nanotoxicology, 2011, 5, 244-253. M. E. Samberg, S. J. Oldenburg and N. A. Monteiro-Riviere, Evaluation of silver nanoparticle toxicity in skin in vivo and keratinocytes in vitro, Environ. Health Perspect., 2010, 118, 407-413.

256 M. E. Samberg, E. G. Loboa, S. J. Oldenburg and N. A. Monteiro-Riviere, Silver nanoparticles do not influence stem cell differentiation but cause minimal toxicity, Nanomedicine, 2012, 7, 1197-1209.

257 L. Loomba and T. Scarabelli, Metallic nanoparticles and their medicinal potential. Part I: Gold and silver colloids, Ther. Deliv., 2013, 4, 859-873. 

Nanotechnology, 2008, 19, 255102.

P. V Asharani, G. Low, K. Mun, M. P. Hande and S. Valiyaveettil, Cytotoxicity and Genotoxicity of Silver, Acsn, 2009, 3, 279-290.

260 S. Arora, J. Jain, J. M. Rajwade and K. M. Paknikar, Cellular responses induced by silver nanoparticles: In vitro studies, Toxicol. Lett., 2008, 179, 93-100.

261 I. Sondi and B. Salopek-Sondi, Silver nanoparticles as antimicrobial agent: A case study on E. coli as a model for Gram-negative bacteria, J. Colloid Interface Sci., 2004, 275, 177-182. M. Banerjee, S. Mallick, A. Paul, A. Chattopadhyay and S. S. Ghosh, Heightened reactive oxygen species generation in the antimicrobial activity of a three component iodinated chitosan?silver nanoparticle composite, Langmuir, 2010, 26, 5901-5908.

263 S. Pal, Y. K. Tak and J. M. Song, Does the antibacterial activity of silver nanoparticles depend on the shape of the nanoparticle? A study of the gram-negative bacterium Escherichia coli, J. Biol. Chem., 2015, 290, 1712-1720.

S. Wang, M. J. Yaszemski, L. Lu, C. Secreto, D. Mukhopadhyay, C. Patra, P. Mukherjee, N. Bone, R. Bhattacharya, N. E. Kay, P. C. Banerjee, Y. K. Lee, N. Bone, Y. K. Lee, C. Patra, S. Wang, L. Lu, C. Secreto, P. C. Banerjee, M. J. Yaszemski, N. E. Kay, D. Mukhopadhyay, L. Lu, C. Secreto, D. Mukhopadhyay, C. Patra, P. Mukherjee, N. Bone, R. Bhattacharya, N. E. Kay, P. C. Banerjee, Y. K. Lee, N. Bone, Y. K. Lee, C. Patra, S. Wang, L. Lu, C. Secreto, P. C. Banerjee, M. J. Yaszemski, N. E. Kay, D. Mukhopadhyay, L. Lu, C. Secreto, D. Mukhopadhyay, C. Patra, P. Mukherjee, N. Bone, R. Bhattacharya, N. E. Kay, P. C. Banerjee, Y. K. Lee, N. Bone, Y. K. Lee, C. Patra, S. Wang, L. Lu, C. Secreto, P. C. Banerjee, M. J. Yaszemski, N. E. Kay, D. Mukhopadhyay, L. Lu, C. Secreto, D. Mukhopadhyay, C. Patra, P. Mukherjee, N. Bone, R. Bhattacharya, N. E. Kay, P. C. Banerjee, Y. K. Lee, N. Bone, Y. K. Lee, C. Patra, S. Wang, L. Lu, C. Secreto, P. C. Banerjee, M. J. Yaszemski, N. E. Kay and D. Mukhopadhyay, Potential therapeutic application of gold nanoparticles in B-chronic lymphocytic leukemia (BCLL): enhancing apoptosis, J. Nanobiotechnology, 2007, 5, 4.

265 C.-Y. Tsai, A.-L. Shiau, S.-Y. Chen, Y.-H. Chen, P.-C. Cheng, M.-Y. Chang, D.-H. Chen, C.-H. Chou, C.-R. Wang and C.-L. $\mathrm{Wu}$, Amelioration of collagen-induced arthritis in rats by nanogold, Arthritis Rheum., 2007, 56, 544-554.

266 X. Huang, P. K. Jain, I. H. El-Sayed and M. A. El-Sayed, Determination of the Minimum Temperature Required for Selective Photothermal Destruction of Cancer Cells with the Use of Immunotargeted Gold Nanoparticles, Photochem. Photobiol., 2006, 82, 412.

267 L. S. Devi and S. R. Joshi, Antimicrobial and synergistic effects of silver nanoparticles synthesized using: Soil fungi of high altitudes of Eastern Himalaya, Mycobiology, 2012, 40, 27-34.

268 K. Shameli, M. Bin Ahmad, S. D. Jazayeri, P. Shabanzadeh, P. Sangpour, H. Jahangirian and Y. Gharayebi, Investigation of antibacterial properties silver nanoparticles prepared via green method, Chem. Cent. J., 2012, 6, 469.

269 M. K. Rai, S. D. Deshmukh, A. P. Ingle and A. K. Gade, Silver nanoparticles: The powerful nanoweapon against multidrug-resistant bacteria, J. Appl. Microbiol., 2012, 112, 841-852.

270 M. Gajbhiye, J. Kesharwani, A. Ingle, A. Gade and M. Rai, Fungus-mediated synthesis of silver nanoparticles and their activity against pathogenic fungi in combination with fluconazole, Nanomedicine Nanotechnology, Biol. Med., 2009, 5, 382-386.

271 Y. Xu, C. Gao, X. Li, Y. He, L. Zhou, G. Pang and S. Sun, In Vitro Antifungal Activity of Silver Nanoparticles Against Ocular Pathogenic Filamentous Fungi, J. Ocul. Pharmacol. Ther., 2013, 29, 270-274.

272 Y. W. Choi, S. M. Hussain, J. L. Speshock, J. V. Rogers and C. V. Parkinson, A Preliminary Assessment of Silver Nanoparticle Inhibition of Monkeypox Virus Plaque Formation, Nanoscale Res. Lett., 2008, 3, 129-133.

273 H. H. Lara, L. Ixtepan-Turrent, E. N. Garza-Treviño and C. Rodriguez-Padilla, PVP-coated silver nanoparticles block the transmission of cell-free and cell-associated HIV-1 in human cervical culture, J. Nanobiotechnology, 2010, 8, 111.

274 J. L. Elechiguerra, J. L. Burt, J. R. Morones, A. Camacho-, X. Gao, H. H. Lara and M. J. Yacaman, Antibacterial Effects of Silver and Gold Nanoparticles on the Growth of Bacteria, 2009, 42, 2087.

275 H. H. Lara, N. V. Ayala-Nuñez, L. Ixtepan-Turrent and C. Rodriguez-Padilla, Mode of antiviral action of silver nanoparticles against HIV-1, J. Nanobiotechnology, 2010, 8, 1-10.

276 H. H. Lara, L. Ixtepan-Turrent, E. N. Garza Treviño and D. K. Singh, Use of silver nanoparticles increased inhibition of cell-associated HIV-1 infection by neutralizing antibodies developed against HIV-1 envelope proteins, $J$. Nanobiotechnology, 2011, 9, 1-9.

277 R. W.-Y. Sun, R. Chen, N. P.-Y. Chung, C.-M. Ho, C.-L. S. Lin and C.-M. Che, Silver nanoparticles fabricated in Hepes buffer exhibit cytoprotective activities toward HIV-1 infected cells, Chem. Commun., 2005, 5059.

278 D. Xiang, Q. Chen, L. Pang and C. Zheng, Inhibitory effects of silver nanoparticles on H1N1 influenza A virus in vitro, J. Virol. Methods, 2011, 178, 137-142. 
activity of mycosynthesized silver nanoparticles against herpes simplex virus and human parainfluenza virus type 3, Int. J. Nanomedicine, 2013, 8, 4303.

D. Baram-Pinto, S. Shukla, N. Perkas, A. Gedanken and R. Sarid, Inhibition of Herpes Simplex Virus Type 1 Infection by Silver Nanoparticles Capped with Mercaptoethane Sulfonate, Bioconjug. Chem., 2009, 20, 1497-1502.

$\mathrm{N}$. Chen, Y. Zheng, J. Yin, X. Li and C. Zheng, Inhibitory effects of silver nanoparticles against adenovirus type 3 in vitro, J. Virol. Methods, 2013, 193, 470-477. nanoparticles with Tacaribe virus, J. Nanobiotechnology, 2010, 8, 1-9.

L. S. Abebe, Y. H. Su, R. L. Guerrant, N. S. Swami and J. A. Smith, Point-of-Use Removal of Cryptosporidium parvum from Water: Independent Effects of Disinfection by Silver Nanoparticles and Silver lons and by Physical Filtration in Ceramic Porous Media, Environ. Sci. Technol., 2015, 49, 12958-12967. N. Durán, B. Rossi-Bergmann, P. D. Marcato, W. Pacienza-Lima and R. de Conti, Therapeutic Potential of Biogenic Silver Nanoparticles in Murine Cutaneous Leishmaniasis, J. Nano Res., 2012, 20, 89-97.

A. Allahverdiyev, E. Ş. Abamor, BAGIROVA, C. B. USTUNDAG, KAYA, KAYA and RAFAILOVICH, Antileishmanial effect of silver nanoparticles and their enhanced antiparasitic activity under ultraviolet light, Int. J. Nanomedicine, 2011, 6, 2705.

C. Panneerselvam, S. Ponarulselvam and K. Murugan, Potential Anti-plasmodial Activity of Synthesized Silver Nanoparticle using Andrographis paniculata Nees (Acanthaceae), Arch. Appl. Sci. Res., 2011, 3, 208-217. S. Ponarulselvam, C. Panneerselvam, K. Murugan, N. Aarthi, K. Kalimuthu and S. Thangamani, Synthesis of silver nanoparticles using leaves of Catharanthus roseus Linn. G. Don and their antiplasmodial activities, Asian Pac. J. Trop. Biomed., 2012, 2, 574-580. J. Tian, K. K. Y. Wong, C.-M. Ho, C.-N. Lok, W.-Y. Yu, C.-M. Che, J.-F. Chiu and P. K. H. Tam, Topical Delivery of Silver Nanoparticles Promotes Wound Healing, ChemMedChem, 2007, 2, 129-136. X. Liu, P. Lee, C. Ho, V. C. H. Lui, Y. Chen, C. Che, P. K. H. Tam and K. K. Y. Wong, Silver Nanoparticles Mediate Differential Responses in Keratinocytes and Fibroblasts during Skin Wound Healing, ChemMedChem, 2010, 5, 468475.

F. F. Larese, F. D'Agostin, M. Crosera, G. Adami, N. Renzi, M. Bovenzi and G. Maina, Human skin penetration of silver nanoparticles through intact and damaged skin, Toxicology, 2009, 255, 33-37. J. Gopal, N. Hasan, M. Manikandan and H. F. Wu, Bacterial toxicity/compatibility of platinum nanospheres, nanocuboids and nanoflowers, Sci. Rep., 2013, 3, 1-8. K. Gopinath, V. Karthika, S. Gowri, V. Senthilkumar, S. Kumaresan and A. Arumugam, Antibacterial activity of ruthenium nanoparticles synthesized using Gloriosa superba L. leaf extract, J. Nanostructure Chem., 2014, 4, 4-9. Ali, Jamal, Ahmed, Hameed, U. Kiran and S. Z. Naqvi, Combined efficacy of biologically synthesized silver nanoparticles and different antibiotics against multidrug-resistant bacteria, Int. J. Nanomedicine, 2013, 3187. J. R. Morones, J. L. Elechiguerra, A. Camacho, K. Holt, J. B. Kouri, J. T. Ramírez and M. J. Yacaman, The bactericidal effect of silver nanoparticles, Nanotechnology, 2005, 16, 2346-2353.

P. Kanmani and S. T. Lim, Synthesis and structural characterization of silver nanoparticles using bacterial exopolysaccharide and its antimicrobial activity against food and multidrug resistant pathogens, Process Biochem., 2013, 48, 1099-1106. nanocomposites with a new waterborne polyurethane, Int. J. Nanomedicine, 2010, 5, 1017-1028. N. G. Kandile, H. T. Zaky, M. I. Mohamed and H. M. Mohamed, Silver nanoparticles effect on antimicrobial and antifungal activity of new heterocycles, Bull. Korean Chem. Soc., 2010, 31, 3530-3538.

298 S.-K. Moon, B. K. Suh, K.-J. Kim, W. S. Sung, D. G. Lee, J. G. Kim and J.-S. Choi, Antifungal activity and mode of action of silver nano-particles on Candida albicans, BioMetals, 2008, 22, 235-242. S. Galdiero, A. Falanga, M. Vitiello, M. Cantisani, V. Marra and M. Galdiero, Silver nanoparticles as potential antiviral agents, Molecules, 2011, 16, 8894-8918.

300 B. De Gusseme, L. Sintubin, L. Baert, E. Thibo, T. Hennebel, G. Vermeulen, M. Uyttendaele, W. Verstraete and N. Boon, Biogenic silver for disinfection of water contaminated with viruses, Appl. Environ. Microbiol., 2010, 76, 1082-1087.

301 X. X. Yang, C. M. Li and C. Z. Huang, Curcumin modified silver nanoparticles for highly efficient inhibition of respiratory syncytial virus infection, Nanoscale, 2016, 8, 3040-3048. Discovery of face-centered-cubic ruthenium nanoparticles: Facile size-controlled synthesis using the chemical reduction method, J. Am. Chem. Soc., 2013, 135, 5493-5496. 
Active Heterogeneous Catalyst for Hydrogenation of Monoaromatics, J. Am. Chem. Soc., 2007, 129, 14213-14223. H. Liu, C. Song, L. Zhang, J. Zhang, H. Wang and D. P. Wilkinson, A review of anode catalysis in the direct methanol fuel cell, J. Power Sources, 2006, 155, 95-110.

306 J. Kang, S. Zhang, Q. Zhang and Y. Wang, Ruthenium nanoparticles supported on carbon nanotubes as efficient catalysts for selective conversion of synthesis gas to diesel fuel, Angew. Chemie - Int. Ed., 2009, 48, 2565-2568. S. Gupta, C. Giordano, M. Gradzielski and S. K. Mehta, Microwave-assisted synthesis of small Ru nanoparticles and their role in degradation of congo red, J. Colloid Interface Sci., 2013, 411, 173-181. N. Perkas, D. Pham Minh, P. Gallezot, A. Gedanken and M. Besson, Platinum and ruthenium catalysts on mesoporous titanium and zirconium oxides for the catalytic wet air oxidation of model compounds, Appl. Catal. B Environ., 2005, 59, 121-130.

309 B. C. Kress, Subwavelength Optics, F. Guid. to Digit. Micro-Optics, 2015, 424, 824-830.

310 R. Elghanian, J. J. Storhoff, R. C. Mucic, R. L. Letsinger and C. A. Mirkin, Selective colorimetric detection of polynucleotides based on the distance-dependent optical properties of gold nanoparticles, Science (80-. )., 1997, 277, 1078-1081.

311 C. A. Mirkin, R. L. Letsinger, R. C. Mucic and J. J. Storhoff, A DNA-based method for rationally assembling nanoparticles into macroscopic materials, Nature, 1996, 382, 607-609.

312 J. M. Nam, S. I. Stoeva and C. A. Mirkin, Bio-Bar-Code-Based DNA Detection with PCR-like Sensitivity, J. Am. Chem. Soc., 2004, 126, 5932-5933.

313 Y. F. Huang, Y. W. Lin, Z. H. Lin and H. T. Chang, Aptamer-modified gold nanoparticles for targeting breast cancer cells through light scattering, J. Nanoparticle Res., 2009, 11, 775-783.

314 L. A. Gearheart, H. J. Ploehn and C. J. Murphy, Oligonucleotide adsorption to gold nanoparticles: A surfaceenhanced Raman spectroscopy study of intrinsically bent DNA, J. Phys. Chem. B, 2001, 105, 12609-12615.

315 F. A. Aldaye and H. F. Sleiman, Sequential self-assembly of a DNA hexagon as a template for the organization of gold nanoparticles, Angew. Chemie - Int. Ed., 2006, 45, 2204-2209.

316 S. M. Shawky, D. Bald and H. M. E. Azzazy, Direct detection of unamplified hepatitis C virus RNA using unmodified gold nanoparticles, Clin. Biochem., 2010, 43, 1163-1168.

317 H. Lee, T. Kang, K. A. Yoon, S. Y. Lee, S. W. Joo and K. Lee, Colorimetric detection of mutations in epidermal growth factor receptor using gold nanoparticle aggregation, Biosens. Bioelectron., 2010, 25, 1669-1674.

318 H. Lee, S. W. Joo, S. Y. Lee, C. H. Lee, K. A. Yoon and K. Lee, Colorimetric genotyping of single nucleotide polymorphism based on selective aggregation of unmodified gold nanoparticles, Biosens. Bioelectron., 2010, 26, 730-735.

319 J. H. Kim and B. H. Chung, Naked eye detection of mutagenic DNA photodimers using gold nanoparticles, Biosens. Bioelectron., 2011, 26, 2805-2809.

320 F. Wei, R. Lam, S. Cheng, S. Lu, D. Ho and N. Li, Rapid detection of melamine in whole milk mediated by unmodified gold nanoparticles, Appl. Phys. Lett., 2010, 96, 133702.

G. L. Wang, Y. M. Dong, X. Y. Zhu, W. J. Zhang, C. Wang and H. J. Jiao, Ultrasensitive and selective colorimetric detection of thiourea using silver nanoprobes, Analyst, 2011, 136, 5256-5260.

322 C. C. Wang, S. M. Wu, H. W. Li and H. T. Chang, Biomedical Applications of DNA-Conjugated Gold Nanoparticles, ChemBioChem, 2016, 1052-1062.

323 V. Beni, K. Hayes, T. M. Lerga and C. K. O'Sullivan, Development of a gold nano-particle-based fluorescent molecular beacon for detection of cystic fibrosis associated mutation, Biosens. Bioelectron., 2010, 26, 307-313. A. Nakatsuma, M. Kaneda, H. Kodama, M. Morikawa, S. Watabe, K. Nakaishi, M. Yamashita, T. Yoshimura, T. Miura, M. Ninomiya and E. Ito, Detection of HIV-1 p24 at attomole level by ultrasensitive ELISA with Thio-NAD cycling, PLoS One, 2015, 10, 1-9.

325 S. Tang and I. Hewlett, Nanoparticle-Based Immunoassays for Sensitive and Early Detection of HIV-1 Capsid (p24) Antigen, J. Infect. Dis., 2010, 201, S59-S64.

326 D. Xi, X. Luo, Q. Ning, Q. Lu, K. Yao and Z. Liu, The detection of HBV DNA with gold nanoparticle gene probes, J. Nanjing Med. Univ., 2007, 21, 207-212.

327 P. V. Baptista, M. Koziol-Montewka, J. Paluch-Oles, G. Doria and R. Franco, Gold-nanoparticle-probe-based assay for rapid and direct detection of Mycobacterium tuberculosis DNA in clinical samples [5], Clin. Chem., 2006, 52, 1433-1434. nanoparticle probes assay for identification of Mycobacterium tuberculosis and Mycobacterium tuberculosis complex from clinical specimens, Mol. Cell. Probes, 2009, 23, 240-246. mycobacteria of the Mycobacterium tuberculosis complex, Clin. Microbiol. Infect., 2010, 16, 1464-1469. 

Mycobacterium tuberculosis, based on signal amplification of graphene and a gold nanoparticle-polyaniline nanocomposite, Analyst, 2014, 139, 5460-5465.

332 E. A. Vitol, E. Brailoiu, Z. Orynbayeva, N. J. Dun, G. Friedman and Y. Gogotsi, Surface-enhanced raman spectroscopy as a tool for detecting Ca2+ mobilizing second messengers in cell extracts, Anal. Chem., 2010, 82, 6770-6774.

E. Podstawka and Y. Ozaki, Surface-enhanced Raman difference between Bombesin and its modified analogues on the colloidal and electrochemically roughen silver surfaces, Biopolymers, 2008, 89, 807-819. S. R. Scattering, X. X. Han, G. G. Huang, B. Zhao and Y. Ozaki, Label-Free Highly Sensitive Detection of Proteins in Aqueous Solutions Using Absorbance Wavelength / nm Raman shift / cm, 2009, 81, 1-3. W. Q. Xu, B. Zhao, X. X. Han, Y. Kitahama, Y. Ozaki, J. Guo and Y. Tanaka, Simplified Protocol for Detection of Protein-Ligand Interactions via Surface-Enhanced Resonance Raman Scattering and Surface-Enhanced Fluorescence, Anal. Chem., 2008, 80, 6567-6572.

J. M. Yuen, N. C. Shah, J. T. Walsh, M. R. Glucksberg and R. P. Van Duyne, Transcutaneous Glucose Sensing by Surface-Enhanced Spatially Offset Raman Spectroscopy in a Rat Model, Anal. Chem., 2010, 82, 8382-8385.

337 K. E. Shafer-Peltier, C. L. Haynes, M. R. Glucksberg and R. P. Van Duyne, Toward a glucose biosensor based on surface-enhanced Raman scattering, J. Am. Chem. Soc., 2003, 125, 588-593.

338 L. Fabris, M. Dante, G. Braun, S. J. Lee, N. O. Reich, M. Moskovits, T.-Q. Nguyen and G. C. Bazan, A Heterogeneous PNA-Based SERS Method for DNA Detection, J. Am. Chem. Soc., 2007, 129, 6086-6087.

339 K. Ryu, A. J. Haes, H. Y. Park, S. Nah, J. Kim, H. Chung, M. Y. Yoon and S. H. Han, Use of peptide for selective and sensitive detection of an Anthrax biomarker via peptide recognition and surface-enhanced Raman scattering, J. Raman Spectrosc., 2010, 41, 121-124.

340 M. Culha, D. Stokes, L. R. Allain and T. Vo-Dinh, Surface-Enhanced Raman Scattering Substrate Based on a SelfAssembled Monolayer for Use in Gene Diagnostics, Anal. Chem., 2003, 75, 6196-6201.

341 T. Vo-Dinh, L. R. Allain and D. L. Stokes, Cancer gene detection using surface-enhanced Raman scattering (SERS), J. Raman Spectrosc., 2002, 33, 511-516.

342 T. Vo-Dinh, K. Houck and D. L. Stokes, Surface-Enhanced Raman Gene Probes, Anal. Chem., 1994, 66, 3379-3383.

343 T. Vo-Dinh, F. Yan and M. B. Wabuyele, Surface-enhanced Raman scattering for medical diagnostics and biological imaging, J. Raman Spectrosc., 2005, 36, 640-647.

344 S. S. Xu, X. Ji, W. Xu, X. Li, L. Wang, Y. Bai, B. Zhao and Y. Ozaki, Immunoassay using probe-labelling immunogold nanoparticles with silver staining enhancement via surface-enhanced Raman scattering, Analyst, 2004, 129, 63. H.-N. Wang and T. Vo-Dinh, Multiplex detection of breast cancer biomarkers using plasmonic molecular sentinel nanoprobes, Nanotechnology, 2009, 20, 065101.

346 L.-N. Zhang, H.-H. Deng, F.-L. Lin, X.-W. Xu, S.-H. Weng, A.-L. Liu, X.-H. Lin, X.-H. Xia and W. Chen, In Situ Growth of Porous Platinum Nanoparticles on Graphene Oxide for Colorimetric Detection of Cancer Cells, Anal. Chem., 2014, 86, 2711-2718.

347 M. II Kim, M. S. Kim, M.-A. Woo, Y. Ye, K. S. Kang, J. Lee and H. G. Park, Highly efficient colorimetric detection of target cancer cells utilizing superior catalytic activity of graphene oxide-magnetic-platinum nanohybrids, Nanoscale, 2014, 6, 1529-1536.

348 Y. Wang, J. Ping, Z. Ye, J. Wu and Y. Ying, Impedimetric immunosensor based on gold nanoparticles modified graphene paper for label-free detection of Escherichia coli O157:H7, Biosens. Bioelectron., 2013, 49, 492-498.

349 R. Li, K. Wu, C. Liu, Y. Huang, Y. Wang, H. Fang, H. Zhang and C. Li, 4-Amino-1-(3-mercapto-propyl)-pyridine Hexafluorophosphate Ionic Liquid Functionalized Gold Nanoparticles for IgG Immunosensing Enhancement, Anal. Chem., 2014, 86, 5300-5307.

350 H.-P. Peng, Y. Hu, A.-L. Liu, W. Chen, X.-H. Lin and X.-B. Yu, Label-free electrochemical immunosensor based on multi-functional gold nanoparticles-polydopamine-thionine-graphene oxide nanocomposites film for determination of alpha-fetoprotein, J. Electroanal. Chem., 2014, 712, 89-95.

351 H. Wang, H. Li, Y. Zhang, Q. Wei, H. Ma, D. Wu, Y. Li, Y. Zhang and B. Du, Label-free immunosensor based on Pd nanoplates for amperometric immunoassay of alpha-fetoprotein, Biosens. Bioelectron., 2014, 53, 305-309.

352 V. Kumar, S. Srivastava, S. Umrao, R. Kumar, G. Nath, G. Sumana, P. S. Saxena and A. Srivastava, Nanostructured palladium-reduced graphene oxide platform for high sensitive, label free detection of a cancer biomarker, RSC Adv., 2014, 4, 2267-2273.

353 J. Peng, L.-N. Feng, Z.-J. Ren, L.-P. Jiang and J.-J. Zhu, Synthesis of Silver Nanoparticle-Hollow Titanium Phosphate Sphere Hybrid as a Label for Ultrasensitive Electrochemical Detection of Human Interleukin-6, Small, 2011, 7, 2921-2928.

354 X. Jiang, K. Chen, J. Wang, K. Shao, T. Fu, F. Shao, D. Lu, J. Liang, M. F. Foda and H. Han, Solid-state voltammetrybased electrochemical immunosensor for Escherichia coli using graphene oxide-Ag nanoparticle composites as labels, Analyst, 2013, 138, 3388. 
J. Yang, W. Wen, X. Zhang and S. Wang, Electrochemical immunosensor for the prostate specific antigen detection based on carbon nanotube and gold nanoparticle amplification strategy, Microchim. Acta, 2015, 182, 1855-1861. J. Wilcoxon, Optical absorption properties of dispersed gold and silver alloy nanoparticles, J. Phys. Chem. B, 2009, 113, 2647-2656.

P. K. Jain, K. S. Lee, I. H. El-Sayed and M. A. El-Sayed, Calculated absorption and scattering properties of gold nanoparticles of different size, shape, and composition: Applications in biological imaging and biomedicine, $J$. Phys. Chem. B, 2006, 110, 7238-7248.

S. Kawata, WITH SURFACE Edited by.

K. S. Lee and M. A. El-Sayed, Gold and silver nanoparticles in sensing and imaging: Sensitivity of plasmon response to size, shape, and metal composition, J. Phys. Chem. B, 2006, 110, 19220-19225.

M.-C. Daniel and D. Astruc, Gold Nanoparticles: Assembly, Supramolecular Chemistry, Quantum-Size-Related Properties, and Applications toward Biology, Catalysis, and Nanotechnology, Chem. Rev., 2004, 104, 293-346. T. A. Klar, T. Franzl, J. Feldmann, A. Nichtl, G. Raschke, K. Kürzinger, S. Kowarik and C. Sönnichsen, Biomolecular Recognition Based on Single Gold Nanoparticle Light Scattering, Nano Lett., 2003, 3, 935-938.

P. K. Jain, S. Eustis and M. A. El-Sayed, Plasmon coupling in nanorod assemblies: Optical absorption, discrete dipole approximation simulation, and exciton-coupling model, J. Phys. Chem. B, 2006, 110, 18243-18253.

B. Dubertret, M. Calame and A. J. Libchaber, Single-mismatch detection using gold-quenched fluorescent oligonucleotid, Nat. Biotechnol., 2001, 19, 365-370.

O. R. Miranda, B. Creran and V. M. Rotello, Array-based sensing with nanoparticles: 'Chemical noses' for sensing biomolecules and cell surfaces, Curr. Opin. Chem. Biol., 2010, 14, 728-736.

S. Rana, H. Akpinar, R. R. Arvizo, M. De, U. H. F. Bunz, V. M. Rotello and O. R. Miranda, Sensing of proteins in human serum using conjugates of nanoparticles and green fluorescent protein, Nat. Chem., 2009, 1, 461-465. U. H. F. Bunz and V. M. Rotello, Gold nanoparticle-fluorophore complexes: Sensitive and discerning 'noses' for biosystems sensing, Angew. Chemie - Int. Ed., 2010, 49, 3268-3279.

A. Bajaj, V. M. Rotello, I.-B. Kim, U. H. F. Bunz, O. R. Miranda, D. J. Jerry and R. L. Phillips, Detection and differentiation of normal, cancerous, and metastatic cells using nanoparticle-polymer sensor arrays, Proc. Natl. Acad. Sci., 2009, 106, 10912-10916.

Y. Kim, R. C. Johnson and J. T. Hupp, Gold Nanoparticle-Based Sensing of "Spectroscopically Silent" Heavy Metal Ions, Nano Lett., 2002, 1, 165-167.

G. S. Wilson and Y. Hu, Enzyme-based biosensors for in vivo measurements, Chem. Rev., 2000, 100, 2693-2704. S. Zhang, N. Wang, H. Yu, Y. Niu and C. Sun, Covalent attachment of glucose oxidase to an Au electrode modified with gold nanoparticles for use as glucose biosensor, Bioelectrochemistry, 2005, 67, 15-22.

B. K. Jena and C. R. Raj, Enzyme-free amperometric sensing of glucose by using gold nanoparticles, Chem. - A Eur. J., 2006, 12, 2702-2708.

B. Y. Wu, S. H. Hou, F. Yin, J. Li, Z. X. Zhao, J. D. Huang and Q. Chen, Amperometric glucose biosensor based on layer-by-layer assembly of multilayer films composed of chitosan, gold nanoparticles and glucose oxidase modified Pt electrode, Biosens. Bioelectron., 2007, 22, 838-844.

I. Pastoriza-Santos, C. Kinnear, J. Pérez-Juste, P. Mulvaney and L. M. Liz-Marzán, Plasmonic polymer nanocomposites, Nat. Rev. Mater., 2018, 3, 375-391.

R. Tanaka, T. Yuhi, N. Nagatani, T. Endo, K. Kerman, Y. Takamura and E. Tamiya, A novel enhancement assay for immunochromatographic test strips using gold nanoparticles, Anal. Bioanal. Chem., 2006, 385, 1414-1420. B. Y. Hsieh, Y. F. Chang, M. Y. Ng, W. C. Liu, C. H. Lin, H. T. Wu and C. Chou, Localized surface plasmon coupled fluorescence fiber-optic biosensor with gold nanoparticles, Anal. Chem., 2007, 79, 3487-3493.

L. R. Hirsch, J. B. Jackson, A. Lee, N. J. Halas and J. L. West, A whole blood immunoassay using gold nanoshells, Anal. Chem., 2003, 75, 2377-2381.

K. Sokolov, M. Follen, J. Aaron, I. Pavlova, A. Malpica, R. Lotan and R. Richards-Kortum, Real-Time Vital Optical Imaging of Precancer Using Anti-Epidermal Growth Factor Receptor Antibodies Conjugated to Gold Nanoparticles Advances in Brief Real-Time Vital Optical Imaging of Precancer Using Anti-Epidermal Growth Factor Receptor Antibodies Conj, Cancer Res., 2003, 63, 1999-2004.

E. Boisselier and D. Astruc, Gold nanoparticles in nanomedicine: Preparations, imaging, diagnostics, therapies and toxicity, Chem. Soc. Rev., 2009, 38, 1759-1782.

L. G. Carrascosa, M. Moreno, M. Álvarez and L. M. Lechuga, Nanomechanical biosensors: A new sensing tool, TrAC - Trends Anal. Chem., 2006, 25, 196-206.

M. Hakim, U. Tisch, G. Peng, N. Shehada, A. Kuten, H. Haick, R. Abdah-Bortnyak, Y. Y. Broza, O. Adams and S. Billan, Diagnosing lung cancer in exhaled breath using gold nanoparticles, Nat. Nanotechnol., 2009, 4, 669-673.

W. Gao, X. Cao, Y. Wang, L. Zhou and J. Tang, Visual DNA microarrays for simultaneous detection of human immunodeficiency virus type-1 and Treponema pallidum coupled with multiplex asymmetric polymerase chain reaction, Diagn. Microbiol. Infect. Dis., 2009, 65, 372-378. 
T. Vo-Dinh, H. N. Wang and J. Scaffidi, Plasmonic nanoprobes for SERS biosensing and bioimaging, J. Biophotonics, 2010, 3, 89-102.

K. C. Bantz, A. F. Meyer, N. J. Wittenberg, H. Im, Ö. Kurtuluş, S. H. Lee, N. C. Lindquist, S. H. Oh and C. L. Haynes, Recent progress in SERS biosensing, Phys. Chem. Chem. Phys., 2011, 13, 11551-11567. Semrock, Surface-Enhanced Raman Scattering (SERS).

A. M. Michaels, Jiang and L. Brus, Ag Nanocrystal Junctions as the Site for Surface-Enhanced Raman Scattering of Single Rhodamine 6G Molecules, J. Phys. Chem. B, 2002, 104, 11965-11971.

J. D. Driskell, K. M. Kwarta, R. J. Lipert, M. D. Porter, J. D. Neill and J. F. Ridpath, Low-Level Detection of Viral Pathogens by a Surface-Enhanced Raman Scattering Based Immunoassay, Anal. Chem., 2005, 77, 6147-6154. M. B. Wabuyele and T. Vo-Dinh, Detection of Human Immunodeficiency Virus Type 1 DNA Sequence Using Plasmonics Nanoprobes, Anal. Chem., 2005, 77, 7810-7815.

H. Su, R. Yuan, Y. Chai, L. Mao and Y. Zhuo, Ferrocenemonocarboxylic-HRP@Pt nanoparticles labeled RCA for multiple amplification of electro-immunosensing, Biosens. Bioelectron., 2011, 26, 4601-4604.

J. Zhou, M. Xu, D. Tang, Z. Gao, J. Tang and G. Chen, Nanogold-based bio-bar codes for label-free immunosensing of proteins coupling with an in situ DNA-based hybridization chain reaction, Chem. Commun., 2012, 48, 12207. Q. Guo, X. Li, C. Shen, S. Zhang, H. Qi, T. Li and M. Yang, Electrochemical immunoassay for the protein biomarker mucin 1 and for MCF-7 cancer cells based on signal enhancement by silver nanoclusters, Microchim. Acta, 2015, 182, 1483-1489.

Y. Zhao, Z. He and Z. Yan, Copper@carbon coaxial nanowires synthesized by hydrothermal carbonization process from electroplating wastewater and their use as an enzyme-free glucose sensor, Analyst, 2013, 138, 559-568. L.-M. Lu, L. Zhang, F.-L. Qu, H.-X. Lu, X.-B. Zhang, Z.-S. Wu, S.-Y. Huan, Q.-A. Wang, G.-L. Shen and R.-Q. Yu, A nano$\mathrm{Ni}$ based ultrasensitive nonenzymatic electrochemical sensor for glucose: Enhancing sensitivity through a nanowire array strategy, Biosens. Bioelectron., 2009, 25, 218-223.

J. Wang, S. V. Boriskina, H. Wang and B. M. Reinhard, Illuminating Epidermal Growth Factor Receptor Densities on Filopodia through Plasmon Coupling, ACS Nano, 2011, 5, 6619-6628.

J. Wang, Electrochemical biosensing based on noble metal nanoparticles, Microchim. Acta, 2012, 177, 245-270. A. Mohanty, N. Garg and R. Jin, A Universal Approach to the Synthesis of Noble Metal Nanodendrites and Their Catalytic Properties, Angew. Chemie, 2010, 122, 5082-5086.

K. Saha, S. S. Agasti, C. Kim, X. Li and V. M. Rotello, Gold Nanoparticles in Chemical and Biological Sensing, Chem. Rev., 2012, 112, 2739-2779.

R. Elshafey, A. C. Tavares, M. Siaj and M. Zourob, Electrochemical impedance immunosensor based on gold nanoparticles-protein $\mathrm{G}$ for the detection of cancer marker epidermal growth factor receptor in human plasma and brain tissue, Biosens. Bioelectron., 2013, 50, 143-149.

Q. Gao, J. Han and Z. Ma, Polyamidoamine dendrimers-capped carbon dots/Au nanocrystal nanocomposites and its application for electrochemical immunosensor, Biosens. Bioelectron., 2013, 49, 323-328.

Y. Ding, D. Li, B. Li, K. Zhao, W. Du, J. Zheng and M. Yang, A water-dispersible, ferrocene-tagged peptide nanowire for amplified electrochemical immunosensing, Biosens. Bioelectron., 2013, 48, 281-286.

J. Lin, H. Zhang and S. Niu, Simultaneous determination of carcinoembryonic antigen and $\alpha$-fetoprotein using an ITO immunoelectrode modified with gold nanoparticles and mesoporous silica, Microchim. Acta, 2015, 182, 719726.

J. Tang and D. Tang, Non-enzymatic electrochemical immunoassay using noble metal nanoparticles: a review, Microchim. Acta, 2015, 182, 2077-2089.

J. Zhou, L. Du, L. Zou, Y. Zou, N. Hu and P. Wang, An ultrasensitive electrochemical immunosensor for carcinoembryonic antigen detection based on staphylococcal protein A-Au nanoparticle modified gold electrode, Sensors Actuators B Chem., 2014, 197, 220-227.

L. Zhu, L. Xu, N. Jia, B. Huang, L. Tan, S. Yang and S. Yao, Electrochemical immunoassay for carcinoembryonic antigen using gold nanoparticle-graphene composite modified glassy carbon electrode, Talanta, 2013, 116, 809815.

N. Yan, When nanotechnology meets catalysis, Nanotechnol. Rev., 2013, 2, 485-486.

P. Bhawana and M. H. Fulekar, Nanotechnology: Remediation Technologies to clean up the Environmental pollutants, Res. J. Chem. Sci., 2012, 2, 90-96.

M. I. Setyawati, W. Fang, S. L. Chia and D. T. Leong, Nanotoxicology of common metal oxide based nanomaterials: their ROS-y and non-ROS-y consequences, Asia-Pacific J. Chem. Eng., 2013, 8, 205-217.

L. Zeng, E. W. Miller, A. Pralle, E. Y. Isacoff and C. J. Chang, A Selective Turn-On Fluorescent Sensor for Imaging Copper in Living Cells, J. Am. Chem. Soc., 2006, 128, 10-11.

S. Yoon, E. W. Miller, Q. He, P. H. Do and C. J. Chang, A Bright and Specific Fluorescent Sensor for Mercury in Water, Cells, and Tissue, Angew. Chemie, 2007, 119, 6778-6781.

L. Basabe-Desmonts, D. N. Reinhoudt and M. Crego-Calama, Design of fluorescent materials for chemical sensing, 
Chem. Soc. Rev., 2007, 36, 993.

410 P.-C. Chen, P. Roy, L.-Y. Chen, R. Ravindranath and H.-T. Chang, Gold and Silver Nanomaterial-Based Optical Sensing Systems, Part. Part. Syst. Charact., 2014, 31, 917-942.

411 Z. Luo, K. Zheng and J. Xie, Engineering ultrasmall water-soluble gold and silver nanoclusters for biomedical applications, Chem. Commun., 2014, 50, 5143-5155.

412 X. Yuan, Z. Luo, Y. Yu, Q. Yao and J. Xie, Luminescent Noble Metal Nanoclusters as an Emerging Optical Probe for Sensor Development, Chem. - An Asian J., 2013, 8, 858-871.

413 P. C. Ray, Size and Shape Dependent Second Order Nonlinear Optical Properties of Nanomaterials and Their Application in Biological and Chemical Sensing, Chem. Rev., 2010, 110, 5332-5365.

414 R. Wilson, The use of gold nanoparticles in diagnostics and detection, Chem. Soc. Rev., 2008, 37, 2028.

415 X. Liu, M. Atwater, J. Wang and Q. Huo, Extinction coefficient of gold nanoparticles with different sizes and different capping ligands, Colloids Surfaces B Biointerfaces, 2007, 58, 3-7.

416 F. Chai, C. Wang, T. Wang, L. Li and Z. Su, Colorimetric Detection of Pb 2+ Using Glutathione Functionalized Gold Nanoparticles, ACS Appl. Mater. Interfaces, 2010, 2, 1466-1470.

417 J. M. Slocik, J. S. Zabinski, D. M. Phillips and R. R. Naik, Colorimetric Response of Peptide-Functionalized Gold Nanoparticles to Metal lons, Small, 2008, 4, 548-551.

418 D. Liu, W. Qu, W. Chen, W. Zhang, Z. Wang and X. Jiang, Highly Sensitive, Colorimetric Detection of Mercury(II) in Aqueous Media by Quaternary Ammonium Group-Capped Gold Nanoparticles at Room Temperature, Anal. Chem., 2010, 82, 9606-9610.

419 K. P. Lisha, Anshup and T. Pradeep, Towards a practical solution for removing inorganic mercury from drinking water using gold nanoparticles, Gold Bull., 2009, 42, 144-152.

420 Y.-H. Lin and W.-L. Tseng, Ultrasensitive Sensing of $\mathrm{Hg} 2+$ and CH $3 \mathrm{Hg}+$ Based on the Fluorescence Quenching of Lysozyme Type VI-Stabilized Gold Nanoclusters, Anal. Chem., 2010, 82, 9194-9200.

421 H. Kawasaki, K. Hamaguchi, I. Osaka and R. Arakawa, ph-Dependent Synthesis of Pepsin-Mediated Gold Nanoclusters with Blue Green and Red Fluorescent Emission, Adv. Funct. Mater., 2011, 21, 3508-3515. G. Guan, S.-Y. Zhang, Y. Cai, S. Liu, M. S. Bharathi, M. Low, Y. Yu, J. Xie, Y. Zheng, Y.-W. Zhang and M.-Y. Han, Convenient purification of gold clusters by co-precipitation for improved sensing of hydrogen peroxide, mercury ions and pesticides, Chem. Commun., 2014, 50, 5703.

423 H. K. Sung, S. Y. Oh, C. Park and Y. Kim, Colorimetric Detection of Co 2+ Ion Using Silver Nanoparticles with Spherical, Plate, and Rod Shapes, Langmuir, 2013, 29, 8978-8982.

424 J. Yguerabide and E. E. Yguerabide, Light-Scattering Submicroscopic Particles as Highly Fluorescent Analogs and Their Use as Tracer Labels in Clinical and Biological Applications, Anal. Biochem., 1998, 262, 137-156.

Y. Wang, F. Yang and X. Yang, Colorimetric Detection of Mercury(II) Ion Using Unmodified Silver Nanoparticles and Mercury-Specific Oligonucleotides, ACS Appl. Mater. Interfaces, 2010, 2, 339-342.

426 X. Yuan, T. J. Yeow, Q. Zhang, J. Y. Lee and J. Xie, Highly luminescent Ag+ nanoclusters for Hg2+ ion detection, Nanoscale, 2012, 4, 1968.

427 L. Shang and S. Dong, Silver nanocluster-based fluorescent sensors for sensitive detection of Cu(ii), J. Mater. Chem., 2008, 18, 4636.

428 G.-W. Wu, S.-B. He, H.-P. Peng, H.-H. Deng, A.-L. Liu, X.-H. Lin, X.-H. Xia and W. Chen, Citrate-Capped Platinum Nanoparticle as a Smart Probe for Ultrasensitive Mercury Sensing, Anal. Chem., 2014, 86, 10955-10960. Y.-L. Hung, T.-M. Hsiung, Y.-Y. Chen, Y.-F. Huang and C.-C. Huang, Colorimetric Detection of Heavy Metal lons Using Label-Free Gold Nanoparticles and Alkanethiols, J. Phys. Chem. C, 2010, 114, 16329-16334.

430 G. Sener, L. Uzun and A. Denizli, Lysine-Promoted Colorimetric Response of Gold Nanoparticles: A Simple Assay for Ultrasensitive Mercury(II) Detection, Anal. Chem., 2014, 86, 514-520.

431 J. Zheng, P. R. Nicovich and R. M. Dickson, Highly Fluorescent Noble-Metal Quantum Dots, Annu. Rev. Phys. Chem., 2007, 58, 409-431.

432 S. Choi, R. M. Dickson and J. Yu, Developing luminescent silver nanodots for biological applications, Chem. Soc. Rev., 2012, 41, 1867-1891.

433 L. Zhang and E. Wang, Metal nanoclusters: New fluorescent probes for sensors and bioimaging, Nano Today, 2014, 9, 132-157.

434 Y. Yue, T.-Y. Liu, H.-W. Li, Z. Liu and Y. Wu, Microwave-assisted synthesis of BSA-protected small gold nanoclusters and their fluorescence-enhanced sensing of silver(i) ions, Nanoscale, 2012, 4, 2251.

$435 \mathrm{~J}$. Xie, Y. Zheng and J. Y. Ying, Highly selective and ultrasensitive detection ofHg2+ based on fluorescence quenching of Au nanoclusters by Hg2+-Au+ interactions, Chem. Commun., 2010, 46, 961-963.

436 A. Sreekumaran Nair, R. T. Tom and T. Pradeep, Detection and extraction of endosulfan by metal nanoparticles, J. Environ. Monit., 2003, 5, 363-365.

437 A. Agarwal, S. W. Huang, M. O'Donnell, K. C. Day, M. Day, N. Kotov and S. Ashkenazi, Targeted gold nanorod contrast agent for prostate cancer detection by photoacoustic imaging, J. Appl. Phys., 2007, 102, 064701. 

detection of sentinel lymph nodes with gold nanobeacons, Biomaterials, 2010, 31, 4088-4093. L. Bickford, J. Sun, K. Fu, N. Lewinski, V. Nammalvar, J. Chang and R. Drezek, Enhanced multi-spectral imaging of live breast cancer cells using immunotargeted gold nanoshells and two-photon excitation microscopy, Nanotechnology, 2008, 19, 315102.

440 X. He, J. Gao, S. S. Gambhir and Z. Cheng, Near-infrared fluorescent nanoprobes for cancer molecular imaging: status and challenges, Trends Mol. Med., 2010, 16, 574-583.

441 E. İ. Altınoğlu and J. H. Adair, Near infrared imaging with nanoparticles, Wiley Interdiscip. Rev. Nanomedicine Nanobiotechnology, 2010, 2, 461-477.

442 D. Kim, S. Park, J. H. Lee, Y. Y. Jeong and S. Jon, Antibiofouling Polymer-Coated Gold Nanoparticles as a Contrast Agent for in Vivo X-ray Computed Tomography Imaging, J. Am. Chem. Soc., 2007, 129, 7661-7665. X. Qian, X.-H. Peng, D. O. Ansari, Q. Yin-Goen, G. Z. Chen, D. M. Shin, L. Yang, A. N. Young, M. D. Wang and S. Nie, In vivo tumor targeting and spectroscopic detection with surface-enhanced Raman nanoparticle tags, Nat. Biotechnol., 2008, 26, 83-90.

444 A. M. Gobin, M. H. Lee, N. J. Halas, W. D. James, R. A. Drezek and J. L. West, Near-Infrared Resonant Nanoshells for Combined Optical Imaging and Photothermal Cancer Therapy, Nano Lett., 2007, 7, 1929-1934.

445 Y. Wang, X. Xie, X. Wang, G. Ku, K. L. Gill, D. P. O'Neal, G. Stoica and L. V. Wang, Photoacoustic Tomography of a Nanoshell Contrast Agent in the in Vivo Rat Brain, Nano Lett., 2004, 4, 1689-1692.

446 K. Ataka and J. Heberle, Biochemical applications of surface-enhanced infrared absorption spectroscopy, Anal. Bioanal. Chem., 2007, 388, 47-54.

447 X. He, K. Wang and Z. Cheng, In vivo near-infrared fluorescence imaging of cancer with nanoparticle-based probes, Wiley Interdiscip. Rev. Nanomedicine Nanobiotechnology, 2010, 2, 349-366.

448 B. D. Chithrani, Nanoparticles for Improved Therapeutics and Imaging in Cancer Therapy, Recent Pat. Nanotechnol., 2010, 4, 171-180.

449 E. C. Cho, C. Glaus, J. Chen, M. J. Welch and Y. Xia, Inorganic nanoparticle-based contrast agents for molecular imaging, Trends Mol. Med., 2010, 16, 561-573.

450 J. C. Y. Kah, M. Olivo, T. H. Chow, K. S. Song, K. Z. Y. Koh, S. Mhaisalkar and C. J. R. Sheppard, Control of optical contrast using gold nanoshells for optical coherence tomography imaging of mouse xenograft tumor model in vivo, J. Biomed. Opt., 2009, 14, 054015.

451 J. Kneipp, H. Kneipp, B. Wittig and K. Kneipp, Novel optical nanosensors for probing and imaging live cells, Nanomedicine Nanotechnology, Biol. Med., 2010, 6, 214-226.

452 A. L. Oldenburg, M. N. Hansen, T. S. Ralston, A. Wei and S. A. Boppart, Imaging gold nanorods in excised human breast carcinoma by spectroscopic optical coherence tomography, J. Mater. Chem., 2009, 19, 6407.

453 P. Vartholomeos, M. Fruchard, A. Ferreira and C. Mavroidis, MRI-Guided Nanorobotic Systems for Therapeutic and Diagnostic Applications, Annu. Rev. Biomed. Eng., 2011, 13, 157-184.

454 X. Yang, E. W. Stein, S. Ashkenazi and L. V. Wang, Nanoparticles for photoacoustic imaging, Wiley Interdiscip. Rev. Nanomedicine Nanobiotechnology, 2009, 1, 360-368.

455 E. V Zagaynova, M. V Shirmanova, M. Y. Kirillin, B. N. Khlebtsov, A. G. Orlova, I. V Balalaeva, M. A. Sirotkina, M. L. Bugrova, P. D. Agrba and V. A. Kamensky, Contrasting properties of gold nanoparticles for optical coherence tomography: phantom, in vivo studies and Monte Carlo simulation, Phys. Med. Biol., 2008, 53, 4995-5009. J. Zhang, Y. Fu, Y. Mei, F. Jiang and J. R. Lakowicz, Fluorescent Metal Nanoshell Probe to Detect Single miRNA in Lung Cancer Cell, Anal. Chem., 2010, 82, 4464-4471.

457 S. Lee, S. Kim, J. Choo, S. Y. Shin, Y. H. Lee, H. Y. Choi, S. Ha, K. Kang and C. H. Oh, Biological Imaging of HEK293 Cells Expressing PLC 1 Using Surface-Enhanced Raman Microscopy, Anal. Chem., 2007, 79, 916-922. J. Kneipp, H. Kneipp, M. McLaughlin, D. Brown and K. Kneipp, In Vivo Molecular Probing of Cellular Compartments with Gold Nanoparticles and Nanoaggregates, Nano Lett., 2006, 6, 2225-2231.

459 A. Matschulat, D. Drescher and J. Kneipp, Surface-Enhanced Raman Scattering Hybrid Nanoprobe Multiplexing and Imaging in Biological Systems, ACS Nano, 2010, 4, 3259-3269.

460 P. J. Vikesland, Nanosensors for water quality monitoring, Nat. Nanotechnol., 2018, 13, 651-660.

461 I. Gupta, N. Duran and M. Rai, in Nano-Antimicrobials, Springer Berlin Heidelberg, Berlin, Heidelberg, 2012, pp. 525-548.

462 S. Shinde, N. Grampurohit, D. Gaikwad, S. Jadhav, M. Gadhave and P. Shelke, Toxicity induced by nanoparticles, Asian Pacific J. Trop. Dis., 2012, 2, 331-334.

463 M. Yu and J. Zheng, Clearance Pathways and Tumor Targeting of Imaging Nanoparticles, ACS Nano, 2015, 9, 66556674.

464 S. Park, A. Aalipour, O. Vermesh, J. H. Yu and S. S. Gambhir, Towards clinically translatable in vivo nanodiagnostics, Nat. Rev. Mater., 2017, 2, 17014. 
imaging agents: considerations and caveats, Nanomedicine, 2008, 3, 703-717.

J. Liu, M. Yu, C. Zhou, S. Yang, X. Ning and J. Zheng, Passive Tumor Targeting of Renal-Clearable Luminescent Gold Nanoparticles: Long Tumor Retention and Fast Normal Tissue Clearance, J. Am. Chem. Soc., 2013, 135, 4978-4981. X.-D. Zhang, Z. Luo, J. Chen, S. Song, X. Yuan, X. Shen, H. Wang, Y. Sun, K. Gao, L. Zhang, S. Fan, D. T. Leong, M. Guo and J. Xie, Ultrasmall Glutathione-Protected Gold Nanoclusters as Next Generation Radiotherapy Sensitizers with High Tumor Uptake and High Renal Clearance, Sci. Rep., 2015, 5, 8669.

E. B. Ehlerding, F. Chen and W. Cai, Biodegradable and Renal Clearable Inorganic Nanoparticles, Adv. Sci., 2016, 3, 1500223.

469 D. Cassano, S. Pocoví-Martínez and V. Voliani, Ultrasmall-in-Nano Approach: Enabling the Translation of Metal Nanomaterials to Clinics, Bioconjug. Chem., 2018, 29, 4-16.

470 D. Cassano, M. Santi, F. D'Autilia, A. K. Mapanao, S. Luin and V. Voliani, Photothermal effect by NIR-responsive excretable ultrasmall-in-nano architectures, Mater. Horizons, 2019, 6, 531-537.

R. Coradeghini, S. Gioria, C. P. García, P. Nativo, F. Franchini, D. Gilliland, J. Ponti and F. Rossi, Size-dependent toxicity and cell interaction mechanisms of gold nanoparticles on mouse fibroblasts, Toxicol. Lett., 2013, 217, 205216.

472 Y. Pan, S. Neuss, A. Leifert, M. Fischler, F. Wen, U. Simon, G. Schmid, W. Brandau and W. Jahnen-Dechent, SizeDependent Cytotoxicity of Gold Nanoparticles, Small, 2007, 3, 1941-1949.

473 C. L. Villiers, H. Freitas, R. Couderc, M.-B. Villiers and P. N. Marche, Analysis of the toxicity of gold nano particles on the immune system: effect on dendritic cell functions, J. Nanoparticle Res., 2010, 12, 55-60.

474 Y. Pan, A. Leifert, D. Ruau, S. Neuss, J. Bornemann, G. Schmid, W. Brandau, U. Simon and W. Jahnen-Dechent, Gold Nanoparticles of Diameter $1.4 \mathrm{~nm}$ Trigger Necrosis by Oxidative Stress and Mitochondrial Damage, Small, 2009, 5, 2067-2076.

475 C.-T. Ng, S. T. Dheen, W.-C. G. Yip, C.-N. Ong, B.-H. Bay and L.-Y. Lanry Yung, The induction of epigenetic regulation of PROS1 gene in lung fibroblasts by gold nanoparticles and implications for potential lung injury, Biomaterials, 2011, 32, 7609-7615.

476 J. J. Li, D. Hartono, C.-N. Ong, B.-H. Bay and L.-Y. L. Yung, Autophagy and oxidative stress associated with gold nanoparticles, Biomaterials, 2010, 31, 5996-6003.

477 Q. Zhang, V. M. Hitchins, A. M. Schrand, S. M. Hussain and P. L. Goering, Uptake of gold nanoparticles in murine macrophage cells without cytotoxicity or production of pro-inflammatory mediators, Nanotoxicology, 2011, 5, 284-295.

478 N. M. Schaeublin, L. K. Braydich-Stolle, A. M. Schrand, J. M. Miller, J. Hutchison, J. J. Schlager and S. M. Hussain, Surface charge of gold nanoparticles mediates mechanism of toxicity, Nanoscale, 2011, 3, 410.

479 A. Chompoosor, K. Saha, P. S. Ghosh, D. J. Macarthy, O. R. Miranda, Z.-J. Zhu, K. F. Arcaro and V. M. Rotello, The Role of Surface Functionality on Acute Cytotoxicity, ROS Generation and DNA Damage by Cationic Gold Nanoparticles, Small, 2010, 6, 2246-2249.

480 H. K. Patra and A. K. Dasgupta, Cancer cell response to nanoparticles: Criticality and optimality, Nanomedicine Nanotechnology, Biol. Med., 2012, 8, 842-852.

481 W. H. De Jong, W. I. Hagens, P. Krystek, M. C. Burger, A. J. A. M. Sips and R. E. Geertsma, Particle size-dependent organ distribution of gold nanoparticles after intravenous administration, Biomaterials, 2008, 29, 1912-1919. M. A. K. Abdelhalim and B. M. Jarrar, The appearance of renal cells cytoplasmic degeneration and nuclear destruction might be an indication of GNPs toxicity, Lipids Health Dis., 2011, 10, 147.

483 X.-D. Zhang, Wu, Shen, Liu, Sun, Zhang and Fan, Size-dependent in vivo toxicity of PEG-coated gold nanoparticles, Int. J. Nanomedicine, 2011, 2071.

484 K.-T. Kim, T. Zaikova, J. E. Hutchison and R. L. Tanguay, Gold Nanoparticles Disrupt Zebrafish Eye Development and Pigmentation, Toxicol. Sci., 2013, 133, 275-288.

485 Zhang, Toxicologic effects of gold nanoparticles in vivo by different administration routes, Int. J. Nanomedicine, 2010, 5, 771.

486 K. K. Panda, V. M. M. Achary, R. Krishnaveni, B. K. Padhi, S. N. Sarangi, S. N. Sahu and B. B. Panda, In vitro biosynthesis and genotoxicity bioassay of silver nanoparticles using plants, Toxicol. Vitr., 2011, 25, 1097-1105.

487 E.-J. Park, E. Bae, J. Yi, Y. Kim, K. Choi, S. H. Lee, J. Yoon, B. C. Lee and K. Park, Repeated-dose toxicity and inflammatory responses in mice by oral administration of silver nanoparticles, Environ. Toxicol. Pharmacol., 2010, 30, 162-168.

488 Y. S. Kim, J. S. Kim, H. S. Cho, D. S. Rha, J. M. Kim, J. D. Park, B. S. Choi, R. Lim, H. K. Chang, Y. H. Chung, I. H. Kwon, J. Jeong, B. S. Han and I. J. Yu, Twenty-Eight-Day Oral Toxicity, Genotoxicity, and Gender-Related Tissue Distribution of Silver Nanoparticles in Sprague-Dawley Rats, Inhal. Toxicol., 2008, 20, 575-583.

489 K. M. Newton, H. L. Puppala, C. L. Kitchens, V. L. Colvin and S. J. Klaine, Silver nanoparticle toxicity to Daphnia magna is a function of dissolved silver concentration, Environ. Toxicol. Chem., 2013, 32, $2356-2364$. 
Human Embryonic Stem Cell-Derived Fibroblasts and an L-929 Cell Line, J. Nanomater., 2012, 2012, 1-9. cancer cell line, A549, Arch. Toxicol., 2011, 85, 743-750.

492 S. Kim, J. E. Choi, J. Choi, K.-H. Chung, K. Park, J. Yi and D.-Y. Ryu, Oxidative stress-dependent toxicity of silver nanoparticles in human hepatoma cells, Toxicol. Vitr., 2009, 23, 1076-1084.

493 E. Oberdörster, Manufactured Nanomaterials (Fullerenes, C 60 ) Induce Oxidative Stress in the Brain of Juvenile Largemouth Bass, Environ. Health Perspect., 2004, 112, 1058-1062.

494 X. Sun, Z. Wang, S. Zhai, Y. Cheng, J. Liu and B. Liu, In vitro cytotoxicity of silver nanoparticles in primary rat hepatic stellate cells, Mol. Med. Rep., 2013, 8, 1365-1372.

495 E.-J. Park, J. Yi, Y. Kim, K. Choi and K. Park, Silver nanoparticles induce cytotoxicity by a Trojan-horse type mechanism, Toxicol. Vitr., 2010, 24, 872-878.

496 S. M. Hussain, K. L. Hess, J. M. Gearhart, K. T. Geiss and J. J. Schlager, In vitro toxicity of nanoparticles in BRL 3A rat liver cells, Toxicol. Vitr., 2005, 19, 975-983.

497 M. J. Piao, K. A. Kang, I. K. Lee, H. S. Kim, S. Kim, J. Y. Choi, J. Choi and J. W. Hyun, Silver nanoparticles induce oxidative cell damage in human liver cells through inhibition of reduced glutathione and induction of mitochondria-involved apoptosis, Toxicol. Lett., 2011, 201, 92-100.

498 J. S. Teodoro, A. M. Simões, F. V. Duarte, A. P. Rolo, R. C. Murdoch, S. M. Hussain and C. M. Palmeira, Assessment of the toxicity of silver nanoparticles in vitro: A mitochondrial perspective, Toxicol. Vitr., 2011, 25, 664-670.

499 R. Zhang, M. J. Piao, K. C. Kim, A. D. Kim, J.-Y. Choi, J. Choi and J. W. Hyun, Endoplasmic reticulum stress signaling is involved in silver nanoparticles-induced apoptosis, Int. J. Biochem. Cell Biol., 2012, 44, 224-232.

500 H. Rosas-Hernández, S. Jiménez-Badillo, P. P. Martínez-Cuevas, E. Gracia-Espino, H. Terrones, M. Terrones, S. M. Hussain, S. F. Ali and C. González, Effects of 45-nm silver nanoparticles on coronary endothelial cells and isolated rat aortic rings, Toxicol. Lett., 2009, 191, 305-313.

501 A. Chrastina and J. E. Schnitzer, lodine-125 radiolabeling of silver nanoparticles for in vivo SPECT imaging, Int. J. Nanomedicine, 2010, 5, 653.

502 J. H. Sung, J. H. Ji, J. U. Yoon, D. S. Kim, M. Y. Song, J. Jeong, B. S. Han, J. H. Han, Y. H. Chung, J. Kim, T. S. Kim, H. K. Chang, E. J. Lee, J. H. Lee and I. J. Yu, Lung Function Changes in Sprague-Dawley Rats After Prolonged Inhalation Exposure to Silver Nanoparticles, Inhal. Toxicol., 2008, 20, 567-574.

503 D. P. K. Lankveld, A. G. Oomen, P. Krystek, A. Neigh, A. Troost - de Jong, C. W. Noorlander, J. C. H. Van Eijkeren, R. E. Geertsma and W. H. De Jong, The kinetics of the tissue distribution of silver nanoparticles of different sizes, Biomaterials, 2010, 31, 8350-8361.

504 M. Korani, M. Rezayat and K. Gilani, Acute and subchronic dermal toxicity of nanosilver in guinea pig, Int. J. Nanomedicine, 2011, 6, 855-862.

505 P. V. Asharani, Y. Lianwu, Z. Gong and S. Valiyaveettil, Comparison of the toxicity of silver, gold and platinum nanoparticles in developing zebrafish embryos, Nanotoxicology, 2011, 5, 43-54.

506 Y. Yamagishi, A. Watari, Y. Hayata, X. Li, M. Kondoh, Y. Tsutsumi and K. Yagi, Hepatotoxicity of sub-nanosized platinum particles in mice., Pharmazie, 2013, 68, 178-82.

507 Y. Yamagishi, A. Watari, Y. Hayata, X. Li, M. Kondoh, Y. Yoshioka, Y. Tsutsumi and K. Yagi, Acute and chronic nephrotoxicity of platinum nanoparticles in mice, Nanoscale Res. Lett., 2013, 8, 395.

508 J. Jura, P. Konieczny, G. Goralczyk, Anna, L. Skalniak, J. Koziel, L. Filon, Francesca, M. Crosera, A. Cierniak, ZubaSurma, J. Borowczyk, E. Laczna, J. Drukala, E. Pyza, D. Semik, O. Woznicka, A. Klein and R. Szmyd, Effects triggered by platinum nanoparticles on primary keratinocytes, Int. J. Nanomedicine, 2013, 8, 3963-3975.

509 Y. Cheng, L. Yin, S. Lin, M. Wiesner, E. Bernhardt and J. Liu, Toxicity Reduction of Polymer-Stabilized Silver Nanoparticles by Sunlight, J. Phys. Chem. C, 2011, 115, 4425-4432.

510 J. Lan Hou, G. Shuo and L. Grozova, Reduction Of Silver Nanoparticle Toxicity By Sulfide, Adv. Mater. Lett., 2013, 4, 131-133.

511 S. Dominguez-Medina, J. Blankenburg, J. Olson, C. F. Landes and S. Link, Adsorption of a Protein Monolayer via Hydrophobic Interactions Prevents Nanoparticle Aggregation under Harsh Environmental Conditions, ACS Sustain. Chem. Eng., 2013, 1, 833-842.

512 J. E. Newton, J. A. Preece and B. G. Pollet, Control of nanoparticle aggregation in PEMFCs using surfactants, Int. J. Low-Carbon Technol., 2012, 7, 38-43.

513 A. K. Gupta and M. Gupta, Synthesis and surface engineering of iron oxide nanoparticles for biomedical applications, Biomaterials, 2005, 26, 3995-4021.

514 Z. S. Pillai and P. V. Kamat, What Factors Control the Size and Shape of Silver Nanoparticles in the Citrate Ion Reduction Method?, J. Phys. Chem. B, 2004, 108, 945-951.

515 H. Hattori, M. Ishihara, T. Ono, Y. Miyahira, S. Nakamura, T. Matsui and V. Q. Nguyen, Interaction of Silver Nanoparticles and Chitin Powder with Different Sizes and Surface Structures: The Correlation with Antimicrobial Activities, J. Nanomater., 2013, 2013, 1-9. 

photochemically prepared seed particles, J. Nanoparticle Res., 2001, 3, 257-261.

517 C. J. Ackerson, P. D. Jadzinsky and R. D. Kornberg, Thiolate Ligands for Synthesis of Water-Soluble Gold Clusters, J. Am. Chem. Soc., 2005, 127, 6550-6551.

518 S. Roux, B. Garcia, J.-L. Bridot, M. Salomé, C. Marquette, L. Lemelle, P. Gillet, L. Blum, P. Perriat and O. Tillement, Synthesis, Characterization of Dihydrolipoic Acid Capped Gold Nanoparticles, and Functionalization by the Electroluminescent Luminol, Langmuir, 2005, 21, 2526-2536.

519 J. D. E. T. Wilton-Ely, The surface functionalisation of gold nanoparticles with metal complexes, Dalt. Trans., 2008, 0, 25-29. 
2019-05-21

\section{A repertoire of biomedical applications of noble metal nanoparticles}

Azharuddin, Mohammad

Royal Society of Chemistry

Azharuddin M, Zhu GH, Das D, et al., (2019) A repertoire of biomedical applications of noble

metal nanoparticles. Chemical Communications, Volume 55, Issue 49, June 2019, pp. 6964-6996

https://doi.org/10.1039/C9CC01741K

Downloaded from Cranfield Library Services E-Repository 